\title{
Übertragung von BSE auf nicht humane Primaten als Modell für die variante Creutzfeldt-Jakob Erkrankung (vCJD) im Menschen
}

\author{
Dissertation \\ zur Erlangung des Doktorgrades \\ der Mathematisch-Naturwissenschaftlichen Fakultäten \\ der Georg-August-Universität zu Göttingen
}

\author{
vorgelegt von \\ Judith Montag \\ aus \\ Geseke
}

Göttingen, den 20.03.2007 
D7

Referent:

Prof. Dr. H.-J. Fritz

Korreferent:

Prof. Dr. W. Liebl

Tag der mündlichen Prüfung: $\quad$ 04.05.2007 


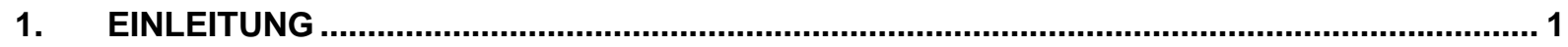

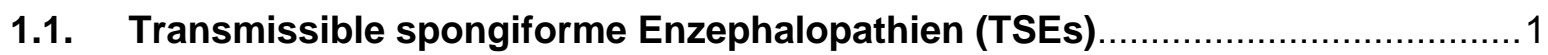

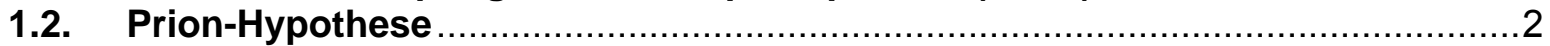

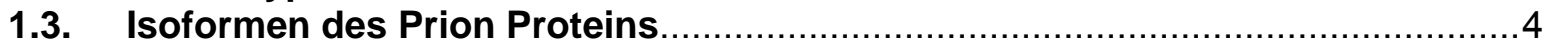

1.4. Potentielle Funktionen des zellulären Prion Proteins ..................................

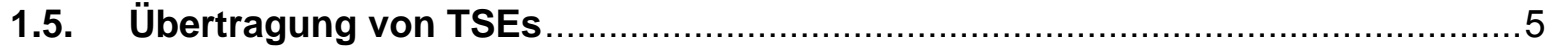

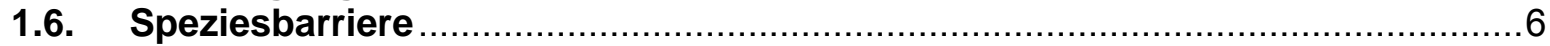

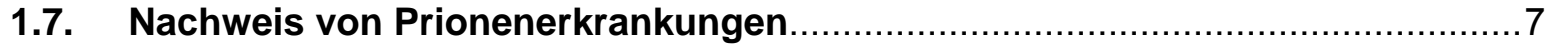

1.8. Subtypen von Prionenerkrankungen (Prionenstämme) ….......................... 8

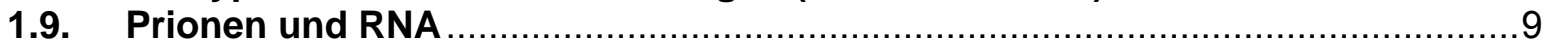

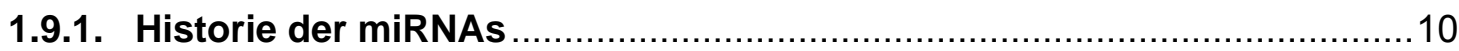

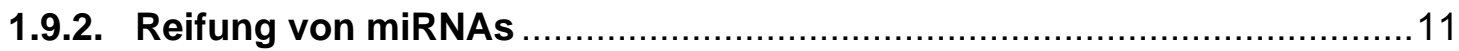

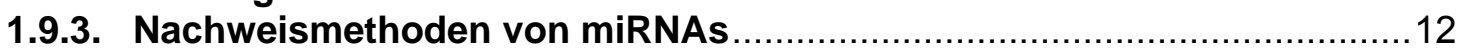

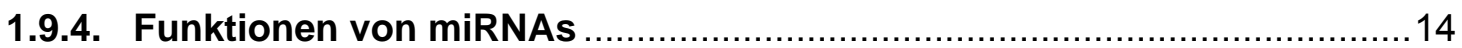

1.9.5. Einfluss von miRNAs auf Krebs und Viruserkrankungen........................ 14

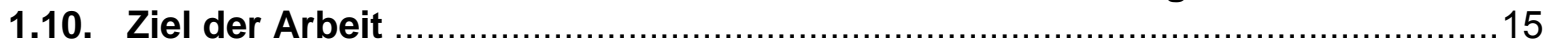

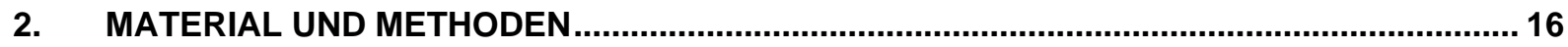

2.1. Materialien, Programme, Zelllinien und Versuchstiere ................................16

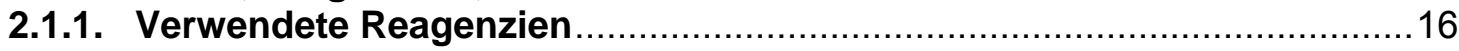

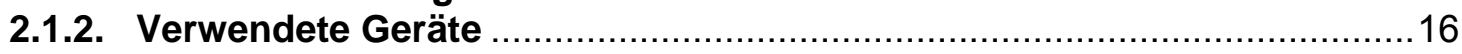

2.1.3. Verwendete Puffer und Lösungen.................................................... 17

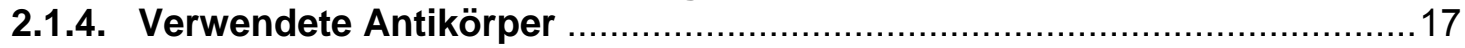

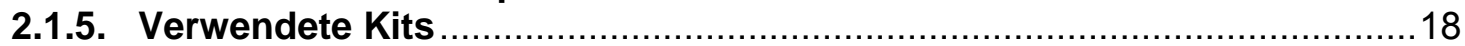

2.1.6. Verwendete Computerprogramme .................................................. 18

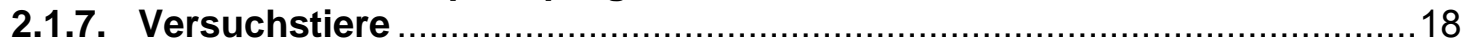

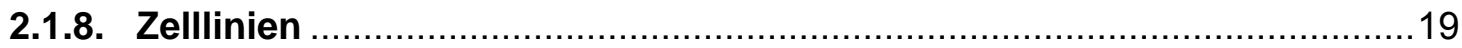

2.2. Aufarbeitung von Organen und Zellen ................................................... 19

2.2.1. Entnahme einzelner Hirnregionen aus gefrorenem Hirngewebe von Javaneraffen (Macaca fascicularis) …............................................... 19

2.2.2. Herstellung von Proteinextrakten aus Hirngewebe und Zellen................20

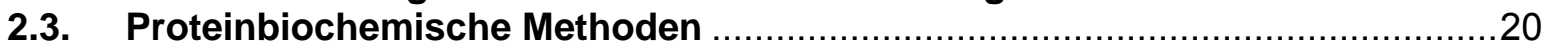

2.3.1. Proteinkonzentrationsbestimmung mit Bicinchoninischer Säure

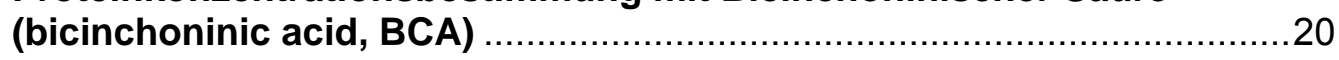

2.3.2. Markierung eines Antikörpers mit Biotin...........................................21

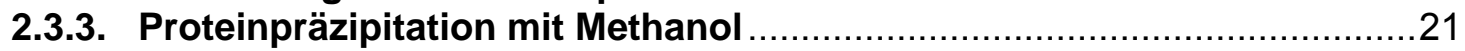

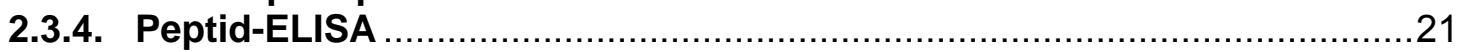

2.4. Nachweis und Charakterisierung der pathogenen Isoform des PrP ..............22

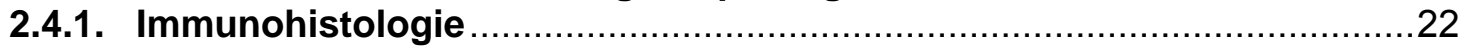

2.4.2. Proteinase K-Verdau von Proteinextrakten aus Hirngewebe .................. 22

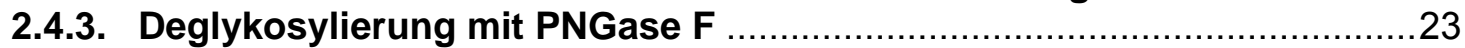

2.4.4. Lithiumdodecylsulfat Polyacrylamid Gelelektrophorese (LDS-PAGE)....23

2.4.5. Western Blot Analyse mit enhanced chemolumniscence Nachweis (ECLBlot).

2.4.6. Sandwich - Enzyme Linked Immunosorbent Assay (ELISA) ..................25

2.4.7. Denaturierung des Prion Proteins mit Guanidinium-Hydrochlorid

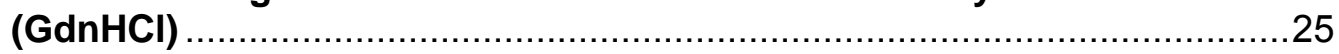

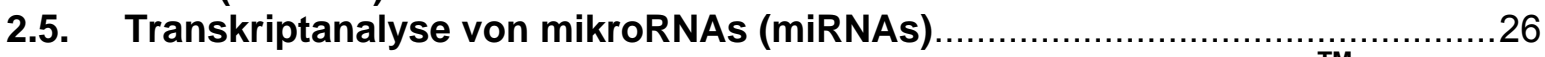

2.5.1. Isolierung von mikroRNA (miRNA) aus Hirngewebe (mirVana ${ }^{\mathrm{TM}} \mathrm{Kit}$, Ambion)

2.5.2. Konzentrationsbestimmung von Nukleinsäuren oder Fluoreszenzfarbstoffen 
2.5.3. miRNA-MicroArray.

2.5.4. Herstellung von cDNA aus mikroRNA (TaqMan ${ }^{\circledR}$ MicroRNA Assays, Applied Biosytems

2.5.5. Quantitative Real Time-Polymerase Kettenreaktion (TaqMan ${ }^{\circledR}$ MicroRNA

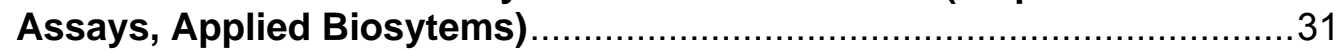

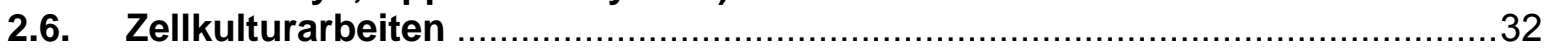

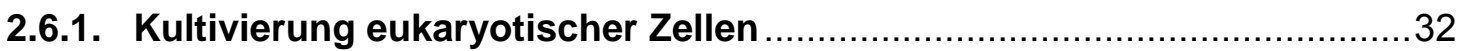

2.6.2. Infektion von neuronalen Zellen mit TSE ............................................ 33

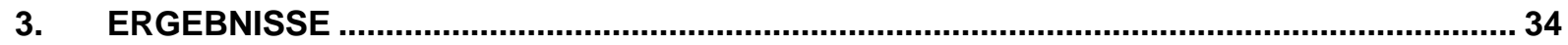

3.1. Übertragung von BSE auf Javaneraffen (Macaca fascicularis) .........................34

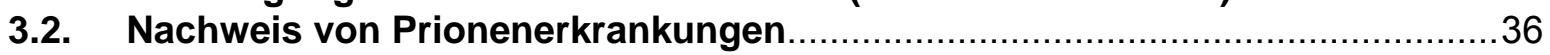

3.2.1. Charakterisierung monoklonaler anti-Prion Antikörper..........................36

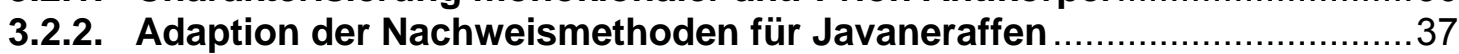

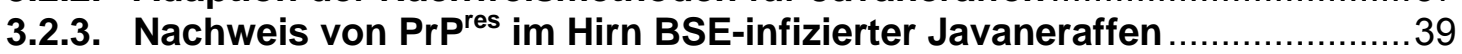

3.3. Charakterisierung der Prionenerkrankung in Javaneraffen ...........................43

3.3.1. Migrationsverhalten und Glykosylierungsmuster des simianen $\operatorname{PrP}^{\text {res }} \ldots 44$

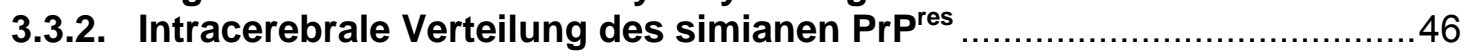

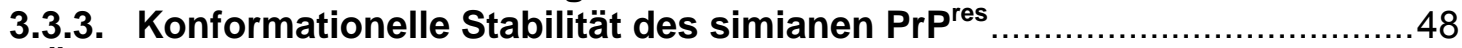

3.4. Übertragung von makakenadaptiertem BSE auf ein Zellkulturmodell ............51

3.5. Expression von mikro RNAs im Hirn BSE infizierter und nicht infizierter

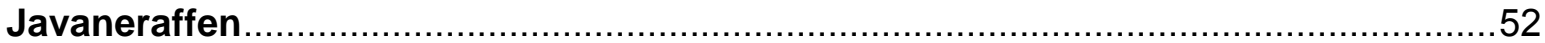

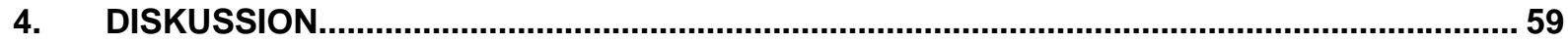

4.1. Prionenerkrankung in BSE-infizierten Primaten..........................................59

4.1.1. Nachweis von simianem vCJD in BSE-infizierten Javaneraffen .............59

4.1.2. Charakterisierung von $\operatorname{PrP}^{\text {res }}$ bei simianem vCJD .............................61

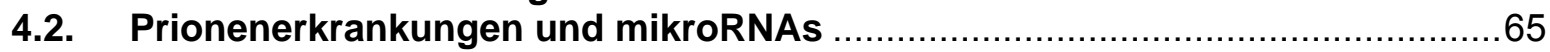

4.2.1. Expression von miRNAs in der basis pontis von Javaneraffen ..............65

4.2.2. Nachweis von differentiell exprimierten miRNAs bei simianem vCJD ...66

4.2.3. Charakterisierung differentiell exprimierter miRNAs bei simianem vCJD

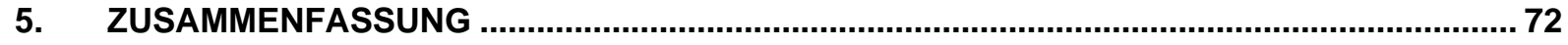

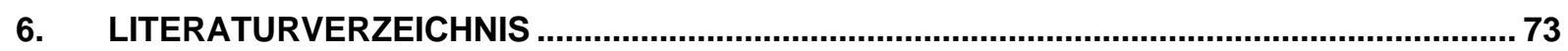

7. ANHANG 


\section{Abbildungsverzeichnis}

Abbildung 1.1

Abbildung 1.2

Abbildung 1.3

Abbildung 1.4

Abbildung 2.1

Abbildung 2.2

Abbildung 3.1

Abbildung 3.2

Abbildung 3.3

Abbildung 3.4

Abbildung 3.5

Abbildung 3.6

Abbildung 3.7

Abbildung 3.8

Abbildung 3.9

Abbildung 3.10

Abbildung 3.11

Abbildung 3.12

Abbildung 3.13

Abbildung 3.14

Abbildung 3.15

Abbildung 3.16

Abbildung 3.17

Abbildung 3.18
Prion Hypothese.

Nachweis von PrPres im Western Blot 8

MiR35-miR41-Cluster in C. elegans 10

Regulation der mRNA-Translation durch miRNA

Fluoreszenzmarkierung von miRNA

loop-primer der cDNA-Synthese des TaqMan® MicroRNA Assay.

Inkubationszeit der Prionenerkrankung bei BSE infizierten Javaneraffen..

Schematische Darstellung der Epitope von fünf monoklonalen anti-Prion Antikörpern

$\mathrm{PrP}^{\mathrm{res}}$ im EU-Referenzmaterial der Infektionsstudie.

37

Nachweis von simianem $\mathrm{PrP}^{\text {res }}$ in von Abhängigkeit von der PK........... 38

Nachweis von $\mathrm{PrP}^{\mathrm{res}}$ mit verschiedenen Primärantikörpern................ $\quad 39$

Deglykosylierung des PrP ${ }^{\text {res }}$ mit PNGase F............................ $\quad 40$

Nachweis von $\mathrm{PrP}^{\mathrm{res}}$ im Sandwich ELISA .............................. 41

Immunhistologie von Hirnschnitten BSE-infizierter Javaneraffen........... 43

Schematische Darstellung von Migrationsverhalten und Glykosylierungsmuster verschiedener CJD Typen.

Migrationsverhalten und Glykosylierungsmuster verschiedener CJD Typen dargestellt durch zwei verschiedene anti-PrP Antikörper.

Western Blots nach PK-Verdau verschiedener Hirnregionen BSE-infizierter Javaneraffen.

Die Signalstärke des PrP ${ }^{\text {res }}$ im Western Blot in Abhängigkeit von der Inkubationszeit.

Inter- und intraindividuelle Unterschieden in der relative Stabilität des $\operatorname{PrP}^{\text {res }}$ gegenüber Denaturierung mit $\mathrm{GdnHCl}$.

GdnHCl-abhängige PrP ${ }^{\text {res }}$ Konzentrationen im Sandwich-ELISA

Infektion von SN56 Zellen mit makakenadaptiertem BSE

50

Expression von miRNAs in der basis pontis von Javaneraffen.

Differentielle Expression von miRNAs in der basis pontis in Zusammenhang mit makakenadaptiertem BSE.

Untersuchung von miRNAs in der basis pontis BSE infizierter und nicht infizierter Javaneraffen mittels qRT-PCR.
Tabelle 2.1

Tabelle 2.2

Tabelle 3.1

Tabelle 3.2

Tabelle 4.1

Tabelle 4.2
Verwendete Zelllinien

Eingesetzte Proteinasen K

Übertragung von BSE auf nicht humane Primaten

In der basis pontis von Javaneraffen exprimierte miRNAs.

MiRNAs in der basis pontis von Javaneraffen.

67

Potentielle Zielgene der bei simianem vCJD disregulierten miRNAs 


\section{Abkürzungsverzeichnis}

\begin{tabular}{|c|c|}
\hline Abkürzung & Bedeutung \\
\hline A & Ampere \\
\hline Ac & Acetat \\
\hline AS & Aminosäure \\
\hline ATP & Adenosintriphosphat \\
\hline bp & Basenpaar \\
\hline BSA & Rinderserumalbumin (engl.: bovine serum albumine) \\
\hline BSE & Bovine spongiforme Enzephalopathie \\
\hline bzw. & beziehungsweise \\
\hline C- & zenti $\left(1 \times 10^{-2}\right)$ \\
\hline${ }^{\circ} \mathrm{C}$ & Grad Celsius \\
\hline CDI & engl.: conformation dependent immunoassay \\
\hline CJD & Creutzfeldt-Jakob-Krankheit (engl.: Creutzfeld-Jakob disease) \\
\hline C-Terminus & carboxyterminale Ende von Proteinen \\
\hline DMSO & Dimethylsulfoxid \\
\hline dNTP & Desoxynukleotidtriphosphat \\
\hline DNA & Desoxyribonukleinsäure (engl.: desoxyribonucleic acid) \\
\hline DPZ & Deutsches Primatenzentrum \\
\hline DSMZ & Deutsche Sammlung von Mikroorganismen und Zellkulturen GmbH \\
\hline ECL & engl.: enhanced chemiluminescence \\
\hline EDTA & Ethylendiamintetraessigsäure \\
\hline ELISA & enzymgekoppelter Immuntest (engl.: enzyme linked imminosorbent assay) \\
\hline et al. & et alteres \\
\hline FCS & Fötales Rinderserum (engl. fetal calv serum) \\
\hline g & Gramm \\
\hline $\mathrm{GdnHCl}$ & Guanidinium Hydrochlorid \\
\hline GPI & Glycosylphosphatidylinositol \\
\hline GSS & Gerstmann-Sträusler-Scheinker Krankheit \\
\hline $\mathrm{h}$ & Stunde \\
\hline $\mathrm{H}_{2} \mathrm{O}$ & Wasser \\
\hline HRP & Meerrettich Peroxidase (engl.: horseradish peroxidase) \\
\hline $\lg G$ & Immunglobulin G \\
\hline $\mathrm{k}$ & Kilo \\
\hline kb & Kilobasen \\
\hline kDa & Kilodalton \\
\hline l & Liter \\
\hline LDS & Lithiumdodecylsulfat \\
\hline M & molar $(=\mathrm{mol} / \mathrm{l})$ \\
\hline m & Meter \\
\hline m- & milli $\left(1 \times 10^{-3}\right)$ \\
\hline mAk & monoklonaler Antikörper \\
\hline miRNA & mikroRNA \\
\hline $\min$ & Minute \\
\hline$\mu-$ & mikro $\left(1 \times 10^{-6}\right)$ \\
\hline n- & nano $\left(1 \times 10^{-9}\right)$ \\
\hline NZM & Nitrozellulosemembran \\
\hline OD & optische Dichte \\
\hline PAGE & Polyacrylamid-Gelelektrophorese \\
\hline p- & piko $\left(1 \times 10^{-12}\right)$ \\
\hline PBS & phosphatgepufferte Kochsalzlösung (engl.: phosphate buffered saline) \\
\hline PCR & Polymerase Kettenreaktion (engl.: polymerase chain reaction) \\
\hline $\mathrm{pH}$ & negativer dekadischer Logarithmus der Protonenkonzentration \\
\hline PK & Proteinase K \\
\hline PMSF & Phenylmethylsulfonylfluorid \\
\hline POD & Peroxidase \\
\hline Prion & engl:: proteinaceous infetious particle \\
\hline
\end{tabular}




\begin{tabular}{ll} 
Prof. & Professor \\
PrP & Prion Protein \\
$\operatorname{PrP}^{\mathrm{C}}$ & zelluläres Prion Protein (engl.: c-cellular) \\
PrP $^{\text {res }}$ & PK resistenter Teil des PrP \\
PrP & pathogenes Prion Protein (engl.: Sc - Scrapie) \\
rhPrP & rekombinantes humanes Prion Protein \\
RISC & RNA induced silencing complex \\
RNA & Ribonukleinsäure (engl.: ribonucleic acid) \\
RNAse & RNA spaltendes Enzym \\
rpm & Rotation pro Minute \\
RT & Raumtemperatur \\
SD & Standardabweichung \\
SDS & Natriumdodecylsulfat (engl. : sodium dodecylsulfate) \\
sek & Sekunde \\
Tris & Tris-hydroxymethyl-aminomethan \\
TSE & Transmissible spongiforme Enzephalopahtie \\
Tween & Polyoxyethylensorbitanmonolaurat \\
u & Einheit (engl.: unit) \\
UTP & Uraciltriphosphat \\
UTR & nicht translatierte Region (engl.: untranslated region) \\
UV & Ultraviolett \\
V & Volt \\
v & Volumen \\
[v/v] & Volumen/Volumen \\
Vol & Volumen \\
$\times \mathrm{g}$ & fache Erdbeschleunigung (g = 9,80665 m/s ${ }^{2}$ ) \\
w & Gewicht (engl.: weight) \\
{$[\mathrm{w} / \mathrm{v}]$} & Gewicht/Volumen (engl.: weight/volume) \\
Z.B. & zum Beispiel \\
ZNS & Zentrales Nervensystem \\
\hline &
\end{tabular}




\section{Einleitung}

\subsection{Transmissible spongiforme Enzephalopathien (TSEs)}

Unter dem Begriff TSEs (transmissible spongiforme Enzephalopathien) oder auch Prionenerkrankungen werden verschiedene infektiöse, neurodegenerative Krankheiten zusammengefasst. Sie unterscheiden sich von anderen neurodegenerativen Krankheiten dadurch, dass sie sowohl innerhalb einer Spezies als auch auf andere Spezies übertragen werden können. Im Hirn der erkrankten Individuen können zu Fibrillen angeordnete Proteine (MERZ et al., 1981) und schwammartige Aussparungen mit amyloiden Ablagerungen nachgewiesen werden (PRUSINER et al., 1983; DEARMOND et al., 1985).

Humane TSEs können vererbt werden, spontan auftreten oder durch eine Infektion mit anderen TSEs hervorgerufen werden. Experimentell können aber auch diese TSEs auf andere Spezies übertragen werden. Das Gerstmann-Sträussler-Scheinker-Syndrom (GSS, GERSTMANN et al., 1939), die Fatale Familiäre Insomnie (FFI, LUGARESI et al., 1986) und die Creutzfeldt-Jakob Krankheit (CJD, CREUTZFELDT, 1920; JAKOB, 1921 a und b) werden durch genetische Dispositionen hervorgerufen. Zusätzlich kann CJD auch spontan auftreten (SCJD), ohne dass eine genetische Prädisposition besteht oder Kontakt zu TSE-infektiösen Agenzien nachgewiesen werden kann (WILL et al., 1993). Zu den erworbenen humanen TSEs zählen Kuru, eine durch rituellen Kannibalismus hervorgerufenene TSE (KLATZO et al., 1959, GAJDUSEK, 1967) und iatrogenes CJD (iCJD), das durch akzidentelle Übertragung von CJD bei ärztlicher Behandlung entstand (DUFFY et al., 1974; FRADKIN et al., 1991; WILL et al., 1993). Auch die neue Variante der Creutzfeldt-Jakob Krankheit (VCJD) ist eine erworbene TSE, die wahrscheinlich durch Aufnahme von BSE (bovine spongiforme Enzephalopathie)-kontaminierten Nahrungsmitteln auf den Menschen übertragen wurde (WILL et al., 1996). BSE trat in den letzten Jahrzehnten in Großbritannien aber auch auf dem europäischen Festland auf. Der Ursprung von BSE ist noch nicht geklärt. Es wird vermutet dass es entweder eine spontan aufgetretene TSE ist oder durch die Verfütterung von Tiermehl an Rinder entstand, das unter anderem aus den Tierkörpern Scrapie-erkrankter Schafen gewonnen wurde (ANDERSON et al., 1996). Scrapie ist eine weit verbreitete TSE bei Schafen und Ziegen und bereits seit über 200 Jahren bekannt. 


\subsection{Prion-Hypothese}

SIGURDSSON stellte 1957 die Theorie des slow virus als Erreger von Enzephalopathien mit ungewöhnlich langen Inkubationszeiten bei Schafen vor. Während der Versuche, den Erreger zu identifizieren, wurde entdeckt, dass die Infektiosität nach Behandlung mit ultravioletter und ionisierender Strahlung und weiteren Verfahren zur Inaktivierung von Nukleinsäuren, wie dem Autoklavieren, erhalten blieb (ALPER et al., 1967; GRIFFITH et al., 1967; GIBBS et al., 1978). Daraufhin stellte Griffith die Theorie auf, dass sich Scrapie unabhängig von Nukleinsäuren repliziert und verbreitet. 1982 formulierte Prusiner die protein-only hypothesis (Prion-Hypothese). Sie besagt, dass die Infektion der TSEs durch proteinaceous infectious particles (Prionen, engl. prions) hervorgerufen wird. Er beschrieb, dass die Infektiosität durch Prozesse, die zur Hydrolysierung oder Denaturierung von Proteinen führten reduziert werden konnte. Das aus den Fibrillen Scrapie-erkrankter Schafe isolierte Protein wurde Prion Protein ( $\operatorname{PrP})$ genannt und mit der Infektiosität in Verbindung gebracht (BOLTON et al., 1982). Später wurde entdeckt, dass die mRNA des PrP auch in nicht infizierten Säugerzellen nachgewiesen werden konnte (CHESEBRO et al., 1985). Es wurden zwei Isoformen des PrP postuliert, eine zelluläre, nicht pathogene $\left(\mathrm{PrP}^{\mathrm{C}}\right)$ und eine pathogene $\left(\mathrm{PrP}^{\mathrm{Sc}}\right)$. Der Hauptunterschied dieser Isoformen scheint in der Konformation zu liegen. Obwohl ihre Primärstruktur identisch ist (BASLER et al., 1986), besitzt das $\operatorname{PrP}^{S c}$ einen höheren Anteil an $\beta$ Faltblättern (PAN et al., 1993) und bildet Aggregate aus. Außerdem ist das PrPres partiell resistent gegen die Behandlung mit Proteinase K (PK) (BOLTON et al., 1982). Es wird angenommen, dass $\operatorname{PrP}^{\mathrm{C}}$ durch Interaktion mit $\operatorname{PrP}^{\mathrm{Sc}}$ ebenfalls $\mathrm{zu} \operatorname{PrP}^{\mathrm{Sc}}$ konvertiert (EIGEN, 1996; RIESNER, 1997). Die angereicherten $\operatorname{PrP}^{\mathrm{Sc}}$ Moleküle aggregieren und bilden Fibrillen, die zu einer Neurodegeneration führen (Abb. 1.1.).

Die Prion-Hypothese wird dadurch gestützt, dass PrP knock-out Mäuse nicht mehr mit TSEs infiziert werden können (BUELER et al., 1993). Außerdem wurden in vitro synthetisierte Fibrillen aus verkürztem rekombinanten PrP erfolgreich zur Infektion transgener Mäusen genutzt, die das verkürzte PrP überexprimieren (LEGNAME et al., 2004). Es kann aber nicht ausgeschlossen werden, dass diese transgenen Mäuse nicht spontan oder vererbt TSE entwickeln, wie es für andere PrP-transgene Mäuse beschrieben wurde (HSIAO et al., 1994; NAZOR et al., 2005). Außerdem konnten die synthetischen PrP Fibrillen bisher in Wildtypmäusen kein TSE hervorrufen.

Unanhängig von der Prion-Hypothese wird auch postuliert, das TSEs von einem Virus hervorgerufen werden. So wurden aus infiziertem Material RNA von 6 kb Größe (AKowitz et al., 1994) und RNA-Fragmente (KELLINGS et al., 1992 und 1994) gewonnen. Diese RNA könnten Teile eines viralen Genoms darstellen. Ferner entspricht das Inaktivierungsspektrum des Scrapie-infektiösen Agens dem des Tabak-Mosaik-Virus 
(CHESEBRO et al., 2003). Ein weiterer Hinweis darauf, dass Viren bei der Pathogenese von TSEs eine Rolle spielen, sind 20 bis $35 \mathrm{~nm}$ große virusartige Partikel (VLP, engl. virus-like particles). Diese konnten in verschiedenen TSEs nachgewiesen (DAVIDFERREIRA et al., 1968; BIGNAMI et al., 1971; LIBERSKI et al., 2004) und unabhängig von PrP aufgereinigt werden (SKLAVIADIS et al., 1992). In einem Zellkulturmodell konnten sie in CJD infizierten, nicht aber in nicht infizierten Zellen nachgewiesen werden (MANUELIDIS et al., 2007).

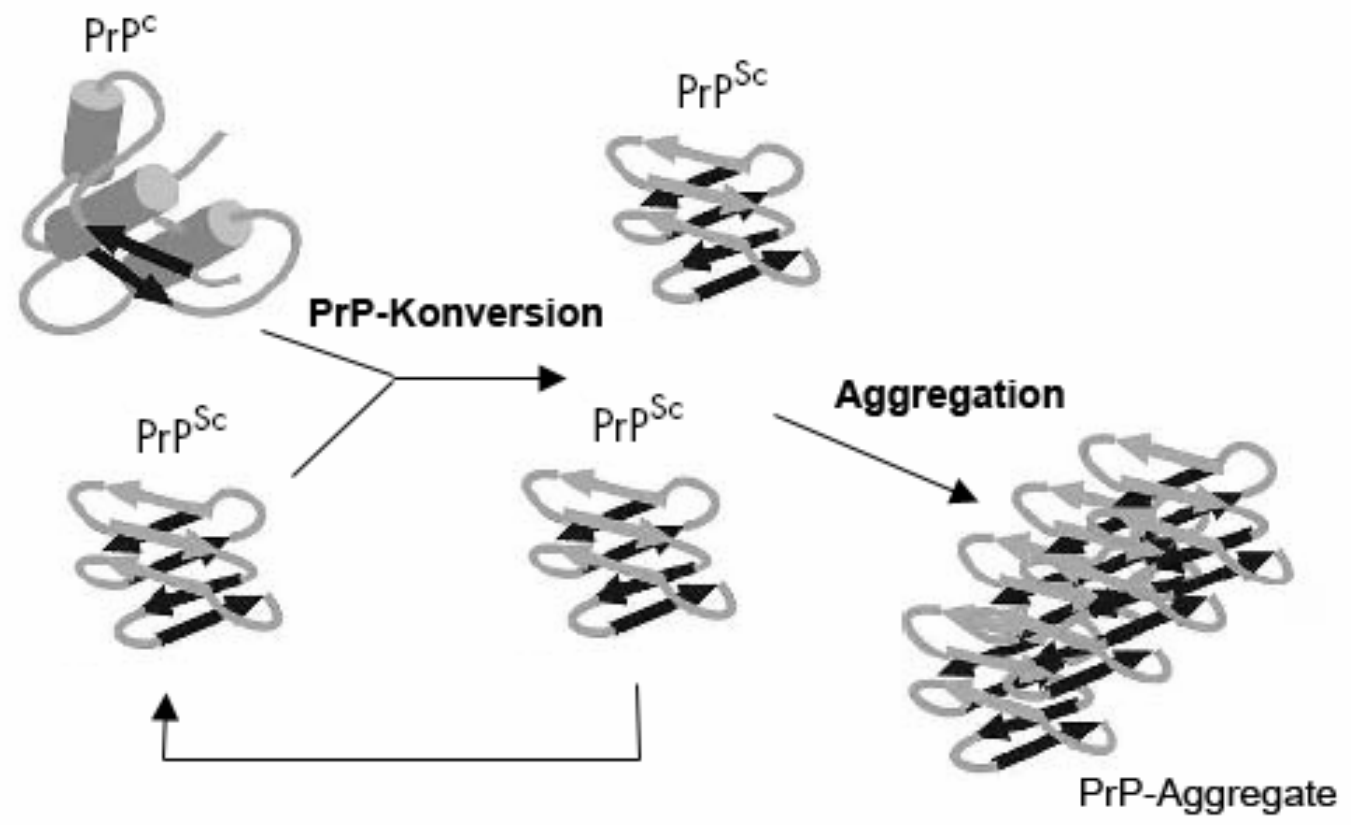

\section{Abbildung 1.1: Prion-Hypothese}

Die Prion-Hypothese ist hier schematisch dargestellt. Das $\operatorname{PrP}^{\mathrm{C}}$ nimmt durch den Kontakt mit PrP ${ }^{\mathrm{Sc}}$ dessen $\beta$-Faltblatt-reiche Struktur an. In einer Kettenreaktion können diese $\operatorname{PrP}^{\mathrm{Sc}}$-Moleküle wiederum zu einer weiteren $\mathrm{PrP}^{\mathrm{C}}-$ Konversion führen. Die $\mathrm{PrP}^{\mathrm{Sc}}-$ Moleküle aggregieren dann zu Fibrillen, die zur Neurodegeneration führen. 


\subsection{Isoformen des Prion Proteins}

Das zelluläre Prion Protein ist ein evolutionär hochkonserviertes Glykoprotein. Unter Säugetieren beträgt die Homologie der Aminosäuren 85\% bis 97\% (GABRIEL et al., 1992). Das PrP kommt in juvenilen Organismen in fast allen Geweben gleich konzentriert vor. In adulten Organismen ist es hauptsächlich in Neuronen lokalisiert, kann aber auch in geringeren Konzentrationen in anderen Geweben nachgewiesen werden (FOURNIER et al., 1998, LI et al., 2001; FORD et al., 2002; MIELE et al., 2003).

PrP wird im rauhen endoplasmatischen Retikulum (ER) synthetisiert. Danach wird im ER und im Golgiapparat das Signalpeptid abgespalten und die $23 \mathrm{C}$-terminalen Aminosäuren durch den Glykosidolphosphatidylinositol-Anker (GPI-Anker) ersetzt. Anschließend wird PrP an die Zelloberfläche transportiert und über den GPI-Anker mit der Außenmembran fixiert (STAHL et al., 1987). Das primäre Translationsprodukt des humanen PrP besitzt 253 Aminosäuren, das bovine 256 und das murine 254. Der N-Terminus (Aminosäuren 22 bis 125) des PrP ist durch eine hohe Variabilität in der Struktur charakterisiert (WÜTHRICH et al., 2001). In diesem Bereich befinden sich vier identische Sequenzabfolgen von je acht Aminosäuren, die Octarepeats. Der C-Terminus ist hochkonserviert und besteht aus zwei antiparallelen $\beta$-Faltblättern, drei $\alpha$-Helices und einer Disulfidbrücke (RIEK et al., 1996; ZAHN et al., 2000). Über die Seitenketten zweier Asparagine (AS 181 und AS 197) können durch N-Glykosylierung di- oder monoglykosylierte Formen des PrP entstehen (ENDO et al., 1989; HARAGUCH et al., 1989). Bis zu 50 verschiedene Oligosaccharide können an jede der Glykosylierungsstellen binden (RUDD et al. 1999).

$\operatorname{PrP}^{\mathrm{C}}$ und $\mathrm{PrP}^{\mathrm{Sc}}$ besitzen die gleiche Primärstruktur (BASLER et al., 1986), unterscheiden sich jedoch in der Sekundär-, Tertiär-, Quartärstruktur und ihrer biochemischen Eigenschaften stark voneinander. Diese Unterschiede werden der $\beta$-Faltblatt-reichen Struktur des $\operatorname{PrP}^{\mathrm{Sc}}$ zugeschrieben. Der Anteil an $\beta$-Faltblättern beträgt im $\operatorname{PrP}^{\mathrm{C}} 3 \%$ und im $\operatorname{PrP}^{S c} 43 \%$. Die $\alpha$-Helix Anteile betragen im $\operatorname{PrP}^{\mathrm{C}}$ 42\% und im $\operatorname{PrP}^{\mathrm{Sc}} 30 \%$ (PAN et al., 1993). Die genaue Struktur des $\operatorname{PrP}^{S c}$ konnte bisher nicht beschrieben werden, da aufgrund der Aggregatbildung eine Kristallisierung nicht möglich ist. Biochemisch unterschieden sich die Isoformen darin, dass das $\operatorname{PrP}^{\mathrm{Sc}}$ im Gegensatz zu dem $\operatorname{PrP}^{\mathrm{C}} \mathrm{zu}$ Fibrillen aggregiert (RUBENSTEIN et al., 1986), partiell PK resistent (BOLTON et al., 1982) und in nichtionischen Detergenzien unlöslich ist (BALDWIN et al., 1995). Außerdem konnte nur für das $\operatorname{PrP}^{C}$ die Bindung von Kupfer über die Histidine in der Octarepeat Region beschrieben werden (JACKSON et al., 2001; GARNETT et al., 2003). 


\subsection{Potentielle Funktionen des zellulären Prion Proteins}

Die Funktion des $\operatorname{PrP}^{C}$ ist nach wie vor ungeklärt. So konnte bei PrP knock-out Mäusen kein Phänotyp festgestellt werden, der Rückschlüsse auf die biologische Funktion zulässt (BUELER et al., 1993). Einige dieser Mäuse zeigen Schwankungen im Schlaf-WachRhythmus (TOBLER et al., 1996) oder leichte Ataxien (ROESLER et al., 1999). Daher werden verschiedene und auch widersprüchliche Funktionen des PrP diskutiert. Zum Beispiel wurde beschrieben, dass durch die Octarepeats des PrP eine Kupferbindung vermittelt wird (JACKSON et al., 2001; GARNETT et al., 2003). Diese soll zum Abbau des PrP in Endosomen führen (TAYLOR et al., 2005), den Kupferhaushalt in den Synapsen (BRown et al., 1997a) und die Reaktion auf oxidativen Stress (BRown et al., 1997b) regulieren. Des Weiteren wurde eine Kupfer/Zink-Superoxid-Dismutase-Aktivität für das PrP beschrieben (BROWN et al., 1999), die jedoch von einer anderen Arbeitsgruppen nicht bestätigt wurde (WAGGONER et al., 2000).

Es wird weiterhin vermutet, dass das PrP essentiell für die normale Funktion der Synapsen ist (COLLINGE et al., 1994; CARLETON et al., 2001), indem es über ein Interaktion mit der Tyrosinkinase fyn die Signaltransduktion in den Synapsen vermittelt (MOUILLET-RICHARD et al., 2000). Die Rolle des PrP während der Apoptose wird kontrovers diskutiert. Als PrP-Liganden oder Rezeptoren sind zum Beispiel das Hitzschockprotein Hsp60 (EDENHOFER et al., 1996) und der Lamininrezeptor-Vorläufer (RIEGER et al., 1997; HUNDT et al., 2001) beschrieben. Durch eine Interaktion des PrP mit dem Stress-induzierbaren Protein 1 (STI-1) (ZANATA et al., 2002) soll ein neuroprotektives Signal hervorgerufen werden. Die Theorie der antiapoptotischen Funktion des PrP wird auch durch die Entdeckung bestärkt, dass eine Überexpression von $\operatorname{PrP}^{\mathrm{C}}$ zu einem Stauroporin-induzierten Zelltod oder der Induktion der apoptotischen Kaskade durch Caspase 3 führen kann (PAITEL et al., 2002). Jedoch wurde auch eine Interaktion des PrP mit den antiapoptotischen Proteinen Bcl-2 (KURSCHNER et al., 1995) und Grb2 (SPIELHAUPTER et al., 2001) und damit eine proapoptotische Funktion des PrP beschrieben.

\section{5. Übertragung von TSES}

TSEs können sowohl innerhalb einer Spezies aber auch zwischen Spezies übertragen werden. Eine natürliche intra-Spezies-Übertragung findet z.B. bei Scrapie statt. Es wird vermutet, dass das infektiöse Agens über Körperflüssigkeiten erkrankter Tiere wie Speichel, Urin oder Blut in den Boden gelangt, dort konserviert und von gesunden Tieren aufgenommen wird (BROWN et al., 1991; CHESEBRO et al., 2003; JOHNSON et al., 2006). 
Eine experimentelle Übertragung von Scrapie auf andere Schafe wurde bereits 1899 beschrieben (BESNOIT, 1899) und 1936 bestätigt (CUILLE und CHELLE, 1936). Später wurde Scrapie auch auf Mäuse übertragen (CHANDLER et al., 1961). Dieses Tiermodell dient seitdem der Erforschung verschiedener TSEs.

Scrapie wurde in den 1970er Jahren wahrscheinlich auf Rinder übertragen. Es wird angenommen, dass Tiermehl aus Scrapie-erkrankten Schafen an Rinder und Kälber verfüttert wurde und diese Rinder später an BSE erkrankten (WELLS et al., 1987; BRADLEY et al., 1993). BSE wiederum wurde wahrscheinlich für den Menschen zu einem Gesundheitsrisiko. 1996 wurde eine neue Variante der Creutzfeldt-Jakob Krankheit (VCJD) beschrieben, an der hauptsächlich junge Menschen erkrankten (BRITTON et al., 1995; WILL et al., 1996). Es gibt mehrere unabhängige Evidenzen, die nahe legen, dass sie durch die Aufnahme von BSE-kontaminierten Nahrungsmitteln hervorgerufen wurde (WILL et al., 1996, Lasmézas et al., 2005). Nach dem derzeitigen Stand sind weltweit 188 Menschen an vCJD erkrankt (COLLEE et al., 2006). Wegen der langen Inkubationszeiten ist unklar, wie viele asymptomatische Träger der Krankheit es derzeit gibt. Es besteht das Risiko einer Übertragung von Mensch zu Mensch, z.B. über Bluttransfusionen (LLEWELYN et al., 2004) oder kontaminierte chirurgische Instrumente (DOERR et al., 2003). Zur Erforschung humaner TSEs wie vCJD werden häufig Primaten als Tiermodell eingesetzt (GADJUSEK et al., 1966 und 1971), da die Übertragung und der Krankheitsverlauf eher dem humanen CJD entsprechen.

\subsection{Speziesbarriere}

Im Allgemeinen können Prionenerkrankungen mit einer höheren Effizienz innerhalb einer Spezies oder auf nah verwandte Spezies übertragen werden (PATTISON et al., 1965). Die Übertragung auf weniger nah verwandte Spezies ist nur bedingt möglich und scheint eine progressive Anpassung während einer seriellen Übertragung in der neuen Wirtsspezies zu durchlaufen (CHESEBRO et al., 2003). Daher ist eine Übertragung in der zweiten Passage innerhalb einer Spezies sehr viel effizienter. Es wird vermutet, dass die Artenbarriere über die Homologie des PrP beeinflusst wird (CARLSON et al., 1986). Transgene Mäuse, die das PrP einer anderen Spezies exprimieren, zeigen eine erhöhte Suszeptibilität gegenüber deren TSEs (ScOTT et al., 1989; TELLING et al., 1994).

Ein Beispiel ist wahrscheinlich die Übertragung von BSE auf den Menschen. Auffälligerweise sind im Verhältnis zu den potentiellen Mengen an BSE-kontaminiertem Fleisch, das konsumiert wurde, nur sehr wenig Menschen an vCJD erkrankt. Es wird vermutet, dass die Übertragung von BSE auf den Menschen aufgrund der Artenbarriere 
ineffizient ist (ANDERSON et al., 1996). Eine Übertragung von Mensch zu Mensch wäre demnach aber sehr viel effizienter und stellt daher ein großes Risiko für den Menschen dar.

\subsection{Nachweis von Prionenerkrankungen}

Prionenerkrankungen werden immunhistologisch und biochemisch nachgewiesen. Immunhistologisch können im Hirn von Patienten mit Prionenerkrankungen so genannte amyloide Plaques gefunden werden, schwammartige Aussparungen im Bereich abgestorbener Neurone, in denen amyloiden Fibrillen abgelagert sind (BUDKA et al., 1995). Diese Fibrillen werden, im Gegensatz zu anderen neurodegenerativen Krankheiten, hauptsächlich aus PrP gebildet (BOLTON et al., 1982). Daher können Prionenerkrankung mit anti-PrP Antikörpern eindeutig nachgewiesen werden. Diese Methode gilt nach wie vor als der "gold-standard“ für den Nachweis von TSEs (WATTS et al., 2006).

Da es keinen Antikörper gibt, der die pathogene und die zelluläre Isoform des PrP unterscheidet, stützt sich der biochemische Nachweis auf die partielle PK-Resistenz des $\mathrm{PrP}^{\mathrm{Sc}}$. Während des PK-Verdaus wird das PrP vom N-Terminus ausgehend hydrolysiert. Dies führt beim $\operatorname{PrP}^{C}$ zu einem vollständigen Abbau des Proteins, während bei $\operatorname{PrP}^{S c}$ ein PK-resistenter Kern, das so genannte $\mathrm{PrP}^{\text {res }}$ bestehen bleibt (OESCH et al., 1985). Dieses wird im Western Blot oder im ELISA über anti-PrP Antikörper nachgewiesen. Im Western Blot können $\mathrm{PrP}^{\mathrm{C}}$ und $\mathrm{PrP}^{\text {res }}$ über ihr Molekulargewicht unterschieden werden, da beim $\mathrm{PrP}^{\text {res }}$ der N-Terminus abgespalten wurde. $\mathrm{PrP}^{\mathrm{C}}$ und $\operatorname{PrP}^{\text {res }}$ weisen im Western Blot drei Glykoformen auf, eine di-, eine mono- und eine unglykosylierte Form (Abb. 1.2) (HARAGUCH et al., 1989). Trennt man diese in einer 2D-Gelelektrophorese zusätzlich nach ihren isoelektrischen Punkten auf, können etwa 60 Isoformen identifiziert werden (CASTAGnA et al., 2002). 


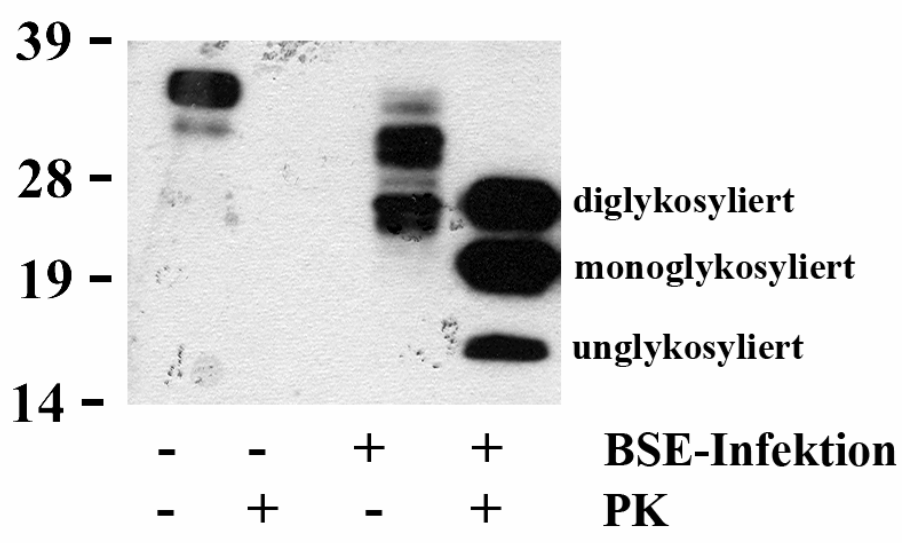

\section{Abbildung 1.2: Nachweis von $\operatorname{PrP}^{\text {res }}$ im Western Blot}

Proteinextrakte aus BSE-infiziertem (+)und nicht infiziertem (-) Hirn wurden mit PK behandelt (+) oder unbehandelt (-) im Western Blot dargestellt. Das PrP wird als drei unterschiedlich glykosylierte Isoformen dargestellt, di-, mono- und unglykosyliert. Diese Isoformen können nach PK-Verdau als PrP ${ }^{\text {res }}$ in TSE-infiziertem Gewebe nachgewiesen werden. Das Molekulargewicht von $\operatorname{PrP}^{\text {res }}$ ist geringer als das von $\operatorname{PrP}^{\mathrm{C}}$ (band shift).

\subsection{Subtypen von Prionenerkrankungen (Prionenstämme)}

Prionenstämme wurden ursprünglich anhand der Inkubationszeiten unterschieden (FRASER et al., 1968), die spezifisch für den Wirtsorganismus und für das infektiöse Agens sind (DICKINSON et al., 1968 und 1971). Auch die Verteilung der Spongiformität im Hirn der erkrankten Individuen (lesion profile) divergiert in Abhängigkeit vom Stamm (FRASER et al., 1968). Das lesion profile lässt sich auch über die Verteilung von $\mathrm{PrP}^{\text {res }} \mathrm{im}$ Hirn anhand von Histoblots (TARABOULOs et al., 1992; DEARMOND et al., 1997) oder Western Blots (PARCHI et al., 1999) darstellen. Neuere Studien unterscheiden Prionenstämme über die biochemischen Eigenschaften des $\mathrm{PrP}^{\text {res }}$. Einige Stämme weisen unterschiedliche PK-Spaltstellen auf (BESSEN und MARSH, 1992; MONARI et al., 1994; Parchi et al., 1999) und lassen sich im Western Blot über unterschiedliche Molekulargewichte differenzieren. Es wird auch vermutet, dass die Glykoformen des PrP bei den Stämmen in einem unterschiedlichen Verhältnis gebildet werden (COLLINGE et al., 1996). Außerdem wird angenommen, dass die Konformation des $\operatorname{PrP}^{\text {res }}$ spezifisch für die Prionenstämme sei. Dadurch sei das $\mathrm{PrP}^{\text {res }}$ unterschiedlich stabil gegenüber einer Denaturierung durch das chaotrope Salz Guanidinium Hydrochlorid (GdnHCl) (SAFAR et al., 1998). Die Stabilität kann über UV-Spektren (SAFAR et al., 1993) oder über die partielle PK-Resistenz (PERETZ et al., 2001) ermittelt werden.

Die Existenz von zahlreichen Subtypen der gleichen Prionenerkrankung (Prionenstämme) ist durch die Prion-Hypothese schwer zu erklären. Ein solches Phänomen ist für mikrobielle Infektionen bekannt und hier auf veränderte Genotypen der Erreger zurückzuführen. Da die Infektiosität der Prionenerkrankungen aber unabhängig 
von Nukleinsäuren replizieren soll, wird vermutet, dass die Stämme auf Unterschiede im PrP-Genotyp des Wirts zurückzuführen sind. Allerdings wurde festgestellt, dass sich aus dem gleichen TSE-infektiösen Agens auch bei gleichem PrP-Genotyp mehrere Stämme entwickeln können (BRUCE et al., 1991). Es wird daher angenommen, dass das PrP subtypspezifische Informationen in seiner Struktur kodiert und diese während der $\operatorname{PrP}^{\mathrm{Sc}}$ Replikation auf das Wirts-PrP ${ }^{C}$ übertragen werden (BESSEN et al., 1995; TELLING et al., 1996). Wird die Übertragung einer Prionenerkrankung durch die Speziesbarriere gehemmt, sind Prionenstämme zumeist nicht eindeutig zu unterscheiden. In weiteren Passagen ist diese Übertragung dann effektiver und eine Unterscheidung wird möglich (KIMBERLIN et al., 1987 und 1989, BRUCE et al., 2003).

\subsection{Prionen und RNA}

Auch unabhängig von der Diskussion, ob Prionenerkrankungen durch RNA-Viren hervorgerufen werden, wurden in der letzten Jahren Daten veröffentlicht, die eine Interaktion zwischen dem PrP und RNA beschreiben. Diese Interaktion scheint die Konversion von $\operatorname{PrP}^{C}$ zu $\operatorname{PrP}^{S c}$ zu beeinflussen, die als ein zentraler Aspekt der Pathogenese von Prionenerkrankungen angesehen wird. Die Konversion konnte in einem ex vivo-Konversionsassay nur in Anwesenheit von RNA stattfinden (DELEAULT et al., 2003). Die Interaktion von PrP mit RNA wurde mit Hilfe von RNA-Aptameren untersucht. Diese kurzen, synthetischen Oligonukleotide binden spezifisch an das $\operatorname{PrP}^{C}$ (WEISS et al., 1997), und in einem Zellkulturmodell konnte gezeigt werden, dass einige Aptamere die Konversion von $\operatorname{PrP}^{C}$ zu PrP ${ }^{S c}$ inhibieren können (PROsKE et al., 2002). Es sind Aptamer-Sequenzen beschrieben, die mit besonders hoher Affinität an das PrP binden (SEKIYA et al., 2005; MERCEY et al., 2006). Diese Aptamere bilden zumeist eine Haarnadelstruktur mit unvollkommenen Basenpaarungen aus. Eine derartige Struktur ist u.a. das Merkmal einer jüngst beschriebenen Klasse von nicht kodierenden RNAs, die so genannten mikroRNAs (miRNAs). MiRNAs sind endogene, nicht kodierende, etwa 22 Nukleotide lange RNA Moleküle, die über eine unvollständige komplementäre Basenpaarung die Translation von mRNAs regulieren und so eine zentrale Rolle im Stoffwechsel und auch der Regulation der Immunantwort spielen (AMBROS et al., 2003; LIM et al., 2003; BARTEL et al., 2004; PoY et al., 2004). Die Primärtranskripte der miRNAs bilden eine Haarnadelstruktur aus. Diese entsteht durch komplementäre Sequenzabschnitte, die eine Basenpaarung eingehen. Diese Basenpaarung ist aber unvollständig, da es in diesen kurzen Sequenzabschnitten auch Bereiche gibt, die nicht 
komplementär zueinander sind und so genannte Ausbuchtungen (bulges) bilden (AMBRos et al., 2003).

\subsubsection{Historie der miRNAs}

Die erste miRNA wurde 1993 für den Fadenwurm Caenorhabditis elegans beschrieben (LEE et al., 1993). Jedoch wurde erst mit der Entdeckung der hochkonservierten miRNA let-7 (REINHART et al., 2000) die Erforschung der Bedeutung der miRNAs weiter vorangetrieben. Etwa 800 miRNAs wurden bisher für Pflanzen, Würmer, Fliegen und Säugetiere experimentell nachgewiesen, häufig sind sie zwischen Vertebraten und Invertebraten konserviert (BARTEL, 2004). Viele miRNAs sind gewebespezifisch, andere werden ubiquitär exprimiert (BABAK et al., 2004; LIU et al., 2004; SEMPERE et al., 2004).

Auch Viren kodieren für miRNAs (PFEFFER et al., 2004, LeCELLIER et al., 2005). Diese regulieren die Virustranskription und interferieren mit der Immunantwort des Wirtsorganismus (CHAPMAN et al., 2004; CHEN et al., 2004).

Insgesamt werden für das humane Genom etwa 1000 miRNAs vorhergesagt. Etwa 300 davon sind bisher experimentell bestätigt. Die miRNA-Gene können sowohl in Introns und Exons kodierender Gene als auch in nicht kodierenden Regionen liegen. Häufig werden Cluster von miRNAs in einem kurzen Sequenzabschnitt beobachtet (Abb. 1.3) (LAU et al., 2001).

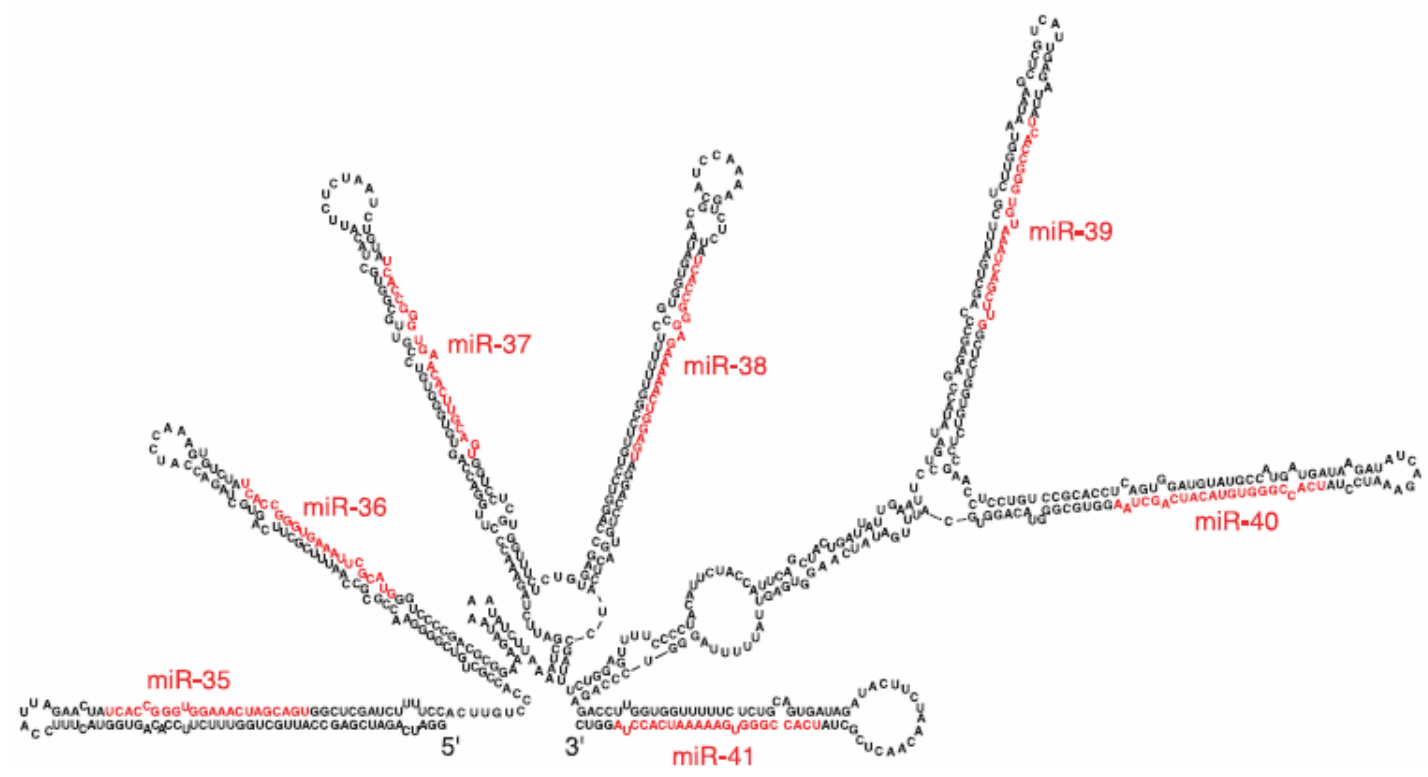

Abbildung 1.3: MiR35-miR41-Cluster in C. elegans (nach LAU et al., 2001)

Die Transkriptionsprodukte der miRNA-Gene bilden Haarnadelstrukturen aus. Diese zeichnen sich trotz einer unvollständigen Basenpaarung durch hohe thermodynamische Stabilität aus. Das miR35 bis miR41-Cluster ist ein Beispiel für miRNA-Cluster, miRNAs können aber auch einzeln im Genom liegen und transkribiert werden. Die später aktive miRNA ist rot gekennzeichnet. 


\subsubsection{Reifung von miRNAs}

MiRNAs können im Genom in nicht-kodierenden Regionen, innerhalb von ORFs und auch auf dem nicht kodierenden Strang lokalisiert sein. Die Reifung der miRNAs ist nach aktuellem Erkenntnisstand in Abbildung 1.4 schematisch dargestellt. Die miRNA-Gene werden im Zellkern als primäre miRNA (pri-miRNA) als Teil eines größeren Transkripts mit 5' 7-Methyl-Guanosin-Cap und 3'-Polyadenosin-Schwanz abgelesen (CAl et al., 2004). Aus dieser wird durch das RNAse III-Enzym Drosha die etwa 70 Nukleotide lange Vorläufer-miRNA (pre-miRNA, engl. precursor miRNA) prozessiert, die eine Haarnadel-Struktur ausbildet (LEE et al., 2003). Nach der Prozessierung werden die pre-miRNAs über eine Bindung an Exportin-5 ins Cytoplasma transportiert (YI et al., 2003). Durch das RNAse III-like Enzym Dicer wird die Schleife der Haarnadelstruktur abgetrennt. Es entstehen doppelsträngige, etwa 22 Nukleotide lange RNA-Moleküle mit einem Überhang von je 2 Nukleotiden am 3'Ende (HutVANGER et al., 2001). In den meisten Fällen wird der Strang mit der geringsten freien Enthalpie am 5'-Ende mit weiteren Enzymen zum RISC-Komplex (RNA induced silencing complex) zusammengesetzt (KHVOROVA et al., 2003; SCHWARZ et al., 2003). Der Strang der doppelsträngigen miRNA, der im RISC bindet, wird guide-strand genannt, der abgespaltene Strang passanger strand. In einigen miRNAs bilden beide Stränge aktive miRNAs (LAU et al., 2001). Der RISC-Komplex bindet über den miRNA-Kern (Nukleotidpositionen 2 bis 8 ) an die Ziel-mRNA, zumeist in der 3'-UTR (3'-untranslated region) (DOENCH and SHARP, 2004). Durch eine unvollkommene Basenpaarung mit der mRNA wird die Translation inhibiert, ist die Basenpaarung vollständig, wird die mRNA abgebaut (PILLAl et al., 2005). 


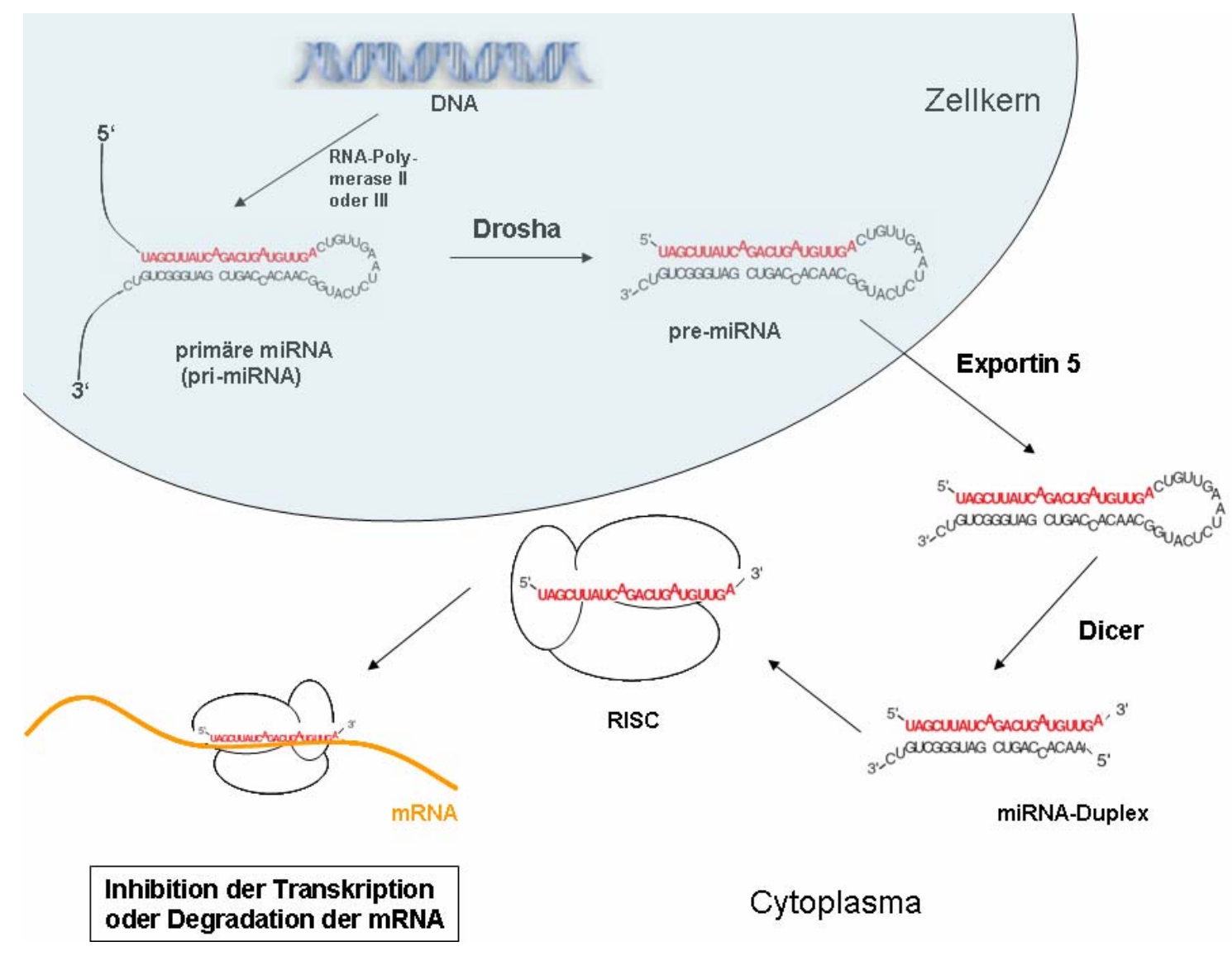

\section{Abbildung 1.4: Regulation der mRNA-Translation durch miRNA}

MiRNAs werden durch die RNA-Polymerasen des Typs II oder III von der DNA transkribiert. Die entstandene primäre miRNA (pri-miRNA) wird von dem Enzym Drosha zur precursor miRNA (pre-miRNA) prozessiert. Anschließend wird diese mit Hilfe des Enzyms Exportin 5 ins Cytoplasma transportiert und dort von dem Enzym Dicer weiter prozessiert. Der guide-strand der entstandenen miRNA-Duplex bildet mit weiteren Enzymen den RISC-Komplex. Dieser bindet über die miRNA die Ziel-mRNA und vermittelt dadurch die Inhibition der Translation bzw. die Spaltung der mRNA. Die Assemblierung der mRNA kann abhängig von deren Lokalisierung sowohl im Cytoplasma als auch im Zellkern stattfinden.

\subsubsection{Nachweismethoden von miRNAs}

Über experimentelle und bioinformatische Methoden wurden ca. 1000 miRNAs in Vertebraten und Invertebraten vorhergesagt (BENTWICH et al., 2005), deren Existenz über verschiedene Methoden nachgewiesen werden kann.

Um ein Expressionsprofil aller miRNAs zu erhalten, werden miRNA-MicroArrays eingesetzt. Hier sind Nukleotide mit komplementären Sequenzen der miRNAs auf geeignetes Trägermaterial gekoppelt. Eine miRNA-Präparation aus zu 
untersuchendem Gewebe wird mit Fluoreszenzfarbstoffen markiert und mit den komplementären Sequenzen hybridisiert. Anhand der Fluoreszenzsignale können anschließend Rückschlüsse auf die Expression der miRNAs gezogen werden (LIU et al., 2004). Da in einem miRNA-MicroArray die gesamte bekannte Population an miRNAs in einem Gewebe untersucht werden kann, können mit dieser Methode Expressionsprofile erstellt und miteinander verglichen werden. Betrachtet man die Veränderung der miRNA-Expression in Folge einer Krankheit, können die differentiell exprimierten miRNAs als diagnostischer Marker dienen oder auch Hinweise auf den Einfluss der miRNAs auf die Krankheit geben.

Soll die Expression oder die differentielle Expression einzelner miRNAs überprüft werden, werden häufig Northern Blots eingesetzt. Mit Hilfe dieser Methode wird die zu untersuchende miRNA-Fraktion elektrophoretisch aufgetrennt und die einzelnen miRNAs werden über spezifische DNA-Sonden nachgewiesen (LAGOS-QUINTANA et al., 2001; LAU et al., 2001). Der Vorteil dieser Methode ist, dass die Vorläuferstrukturen mit der gleichen Sonde detektiert werden und das Verhältnis von pre-miRNA zu prozessierter miRNA dargestellt werden kann (OBERNOSTERER et al., 2006). Für Northern Blots wird aber viel miRNA benötigt, und dies stellt für die meisten Analysen biologischer Proben einen limitierenden Faktor dar (LIU et al., 2004). Dieses Problem kann durch den Nachweis von miRNAs über quantitative reverse Transkriptase-PCR (qRT-PCR) umgegangen werden. Da die miRNAs durch ihre geringe Länge ein ungeeignetes Template für eine PCR darstellen, werden sie vor der cDNA-Synthese verlängert und dann als Matrize für die qRT-PCR eingesetzt. Es gibt verschiedene Möglichkeiten der miRNA-Verlängerung. An die gereifte Form der miRNA kann ein Oligonukleotid gekoppelt werden, das eine Haarnadelstruktur (loop-primer) ausbildet. Die Basen des 3'-Endes binden über komplementäre Basenpaarung an die miRNA. Dieses miRNA-loop primer Produkt kann über eine qRT-PCR mit einer spezifischen Sonde nachgewiesen werden (CHEN et al., 2005). Eine andere Möglichkeit stellt die Synthese eines Poly-A-Schwanzes am 3'-Ende der miRNA dar. Der cDNA-Primer besitzt ein Sequenzüberhang und wird so gewählt, dass der Übergang des Poly-A-Schwanzes und der miRNA als Matrize dienen. Die Primer der qRT-PCR binden einmal im Bereich der miRNA und einmal im Bereich des Sequenzüberhangs (FU et al., 2006). 


\subsubsection{Funktionen von miRNAs}

Da die miRNAs im Tierreich hochkonserviert sind, wird innen eine wichtige Rolle für die Entwicklung und den Stoffwechsel zugeschrieben. Für verschiedene Organismen wurde nachgewiesen, dass sie ohne das Enzym Dicer keine multipotenten Stammzellen entwickeln, die Ontogenese nicht durchlaufen und bereits im embryonalen Stadium absterben (KETTING et al., 2001; BERNSTEIN et al., 2003; WIENHOLDS et al., 2003). Einige Organismen können den Verlust von Dicer jedoch auch kompensieren (GIRALDEZ et al., 2005). Durch gezieltes Ausschalten von Dicer in bestimmten Geweben von Mäuseembryos oder in neugeborenen Mäusen konnte gezeigt werden, dass miRNAs für die Entwicklung der Haut (ANDL et al., 2006), des Lungenepithels (HARRIS et al., 2006) und der Extremitäten (HARFE et al., 2005) essentiell sind. Neben diesen Studien zur allgemeinen Funktion von miRNAs, wurden auch einzelne miRNAs gezielt untersucht. Da eine miRNA bis zu 200 Gene regulieren kann, ist die Beschreibung der Funktion einer miRNA sehr komplex. Über bioinformatische Vorhersagen potentieller Zielgene können mögliche Funktionen der miRNAs ermittelt werden. Anschließend können durch Ausschalten der miRNAs die Funktionen nachgewiesen werden. Mit Hilfe dieses Ansatzes wurde der Einfluss von miRNAs auf verschiedene Stoffwechselwege festgestellt. Es wurden miRNAs gefunden, die Einfluss auf den zeitlichen Ablauf der Entwicklung (PASQUINELLI et al., 2000; LIN et al., 2003; LI Et al., 2005) und die Signaltransduktionswege nehmen (BOEHM und SLACK, 2005; LAl et al., 2005). Mehrere miRNAs sind in unterschiedlichen Organismen und Geweben in die Regulation der Apoptose (CALIN et al., 2002; Xu et al., 2003; CHAN et al., 2005), des Fett-Metabolismus (TELEMAN et al., 2006) oder der Insulin-Sekretion (Poy et al., 2004) involviert.

\subsubsection{Einfluss von miRNAs auf Krebs und Viruserkrankungen}

miRNAs besitzen physiologische Funktionen. Sie regulieren unter anderem auch die Apoptose und Signaltransduktionswege (1.9.4), Stoffwechselwege, die in der Onkogenese disreguliert sind. Bei verschiedenen Krebserkrankungen konnten differentiell exprimierte miRNAs identifiziert werden, die potentiell Apoptosemechanismen und Signaltransduktionswege regulieren, deren Disregulation eine Onkogenese auslösen kann (CALIN et al., 2002; MICHAEL et al., 2003; METZLER et al., 2004; HE et al., 2005). Auch bei Virusinfektionen sind miRNAs differentiell exprimiert. Endogene miRNAs sind möglicherweise an der antiviralen Immunantwort beteiligt. Die humane miRNA hsa-miR32 z.B. inhibiert im Zellkulturmodell das 
Primaten foamy Virus Typ 1 (PFV-1) (LECELLIER et al., 2005). Außerdem wurden endogene miRNAs gefunden, die potentielle Zielgene im Genom von HIV besitzen (HARIHARAN et al., 2005). Schaltet man das miRNA-Gencluster hsa-miR17-92 aus, kann HIV-1 effizienter reproduzieren (TRIBOULET et al., 2007).

Im Genom verschiedener Viren wurden ebenfalls miRNAs identifiziert. Dies wurde zunächst für das Epstein-Barr-Virus (EBV) beschrieben (PFEFFER et al., 2004) aber auch für das human immunodeficiency virus (HIV) (BENNASSER et al., 2004) und für das Herpes simplex Virus (HSV) (CUl et al., 2006). Diese miRNAs greifen in den Metabolismus der Wirtszellen ein (CHAPMAN et al., 2004; CHEN et al., 2004). Z.B. inhibiert eine vom Herpes simplex Virus-1 (HSV-1) kodierte miRNA die Apoptose der Wirtszellen während der Latenzphase (GUPTA et al., 2006).

Viren können also direkt über miRNAs in den Stoffwechsel der Wirtszellen eingreifen. Auch die Immunantwort und physiologische Veränderungen des Körpers könnten durch die Expression der endogenen miRNAs widergespiegelt werden. Demnach können miRNAs potentielle diagnostische Marker oder sogar neue Ansatzpunkte für Therapien darstellen.

\subsection{Ziel der Arbeit}

Im Rahmen der EU-Studie QLK1-CT-2002-01096 soll das Risiko für den Menschen ermittelt werden, durch Aufnahme BSE-kontaminierter Nahrung an vCJD zu erkranken. Ziel der vorliegenden Arbeit war die Analyse der Prionenerkrankung in intracerebral mit BSE-infizierten Javaneraffen. Die Analyse sollte in zwei Schwerpunkten durchgeführt werden. Zunächst sollte die Krankheit der Javaneraffen als Prionenerkrankung bestätigt und charakterisiert werden. Dazu wurden die Standard-Nachweismethoden für Prionenerkrankungen, Immunhistologie, Western Blot- und ELISA-Analysen an den Nachweis simianer Prionenerkrankungen angepasst. Die Charakteristika der simianen Prionenerkrankungen der Tiere sollte miteinander und anschließend mit humanem vCJD verglichen werden. In einem zweiten Teil der Arbeit sollten neue intra vitam Marker für Prionenerkrankungen identifiziert werden. Dazu sollten mikroRNAs identifiziert werden, die in Prionenerkrankungen differentiell exprimiert sind. Diese sollten über einen miRNAMicroArray nachgewiesen und über quantitative RT-PCR bestätigt werden. 


\section{Material und Methoden}

\subsection{Materialien, Programme, Zelllinien und Versuchstiere}

\subsubsection{Verwendete Reagenzien}

Falls nicht anders angegeben, wurden die Reagenzien von der Firma Carl Roth $\mathrm{GmbH}$ in der höchsten Qualität bezogen.

\subsubsection{Verwendete Geräte}

\begin{tabular}{|c|c|}
\hline Gerät & Hersteller \\
\hline Brutschrank Heraeus $\left(37^{\circ} \mathrm{C}\right)$ & Kendro Laboratory Products \\
\hline ELISA-Reader MR5000 & Dynatech \\
\hline Feinwaage supermicro & Satorius \\
\hline Fotofilm Entwickler „Elite Chrome 400“ & Kodak \\
\hline Kühlschrank $\left(4^{\circ} \mathrm{C}\right)$ & Privileg \\
\hline Laborschüttler & Heidolph \\
\hline Laborwaage LC2200 & Satorius \\
\hline Magnetrührer MR 2002 & Heidolph \\
\hline Neubauer-Zählkammer & Carl Roth $\mathrm{GmbH}$ \\
\hline pH-Meter & Hannah \\
\hline Pipetten & Eppendorf \\
\hline Pipettierhilfe, elektrisch & Brand \\
\hline Sterilwerkbank Gelaire & BioFlow Technik \\
\hline Stickstofftank & Chronos Messer \\
\hline Real Time Cycler „TaqMan ${ }^{\circledR} 7500 “$ & Applied Biosystems \\
\hline Thermocycler „my cycler“ & BioRad \\
\hline Tiefkühlschrank $\left(-20^{\circ} \mathrm{C}\right)$ & Privileg \\
\hline Tiefkühlschrank $\left(-80^{\circ} \mathrm{C}\right)$ & New Brunswick Scientific \\
\hline Tischzentrifuge $5417 \mathrm{R}$ & Eppendorf \\
\hline Tischzentrifuge „Biofuge A“ & Heraeus Christ \\
\hline Spektralphotometer „NanoDrop“ & PeqLab \\
\hline Untertischzentrifuge Multifuge 1 & Heraeus Sorvall \\
\hline Vortexer & Ernst Schütt \\
\hline Wasserbad GFL (beheizbar) & Gebr. Rettberg Labor und Glasgeräte \\
\hline
\end{tabular}




\subsubsection{Verwendete Puffer und Lösungen}

\begin{tabular}{|c|c|}
\hline Puffer & Zusammensetzung \\
\hline $\mathrm{H}_{2} \mathrm{O}_{\text {DEPC }}$ & $\begin{array}{l}0,1 \% \text { [v/v] Diethylpyrocarbonat (DEPC) in } \mathrm{H}_{2} \mathrm{O}, 24 \\
\text { Stunden (h) bei RT rühren, autoklavieren }\end{array}$ \\
\hline Laufpuffer & $\begin{array}{l}50 \mathrm{mM} \text { MOPS, } 50 \mathrm{mM} \text { Tris, 0,1\% [w/v] SDS, } 1 \mathrm{mM} \\
\text { EDTA, pH 7,6 }\end{array}$ \\
\hline MPBST & $\begin{array}{l}5 \%[\mathrm{w} / \mathrm{v}] \text { fettfreies Milchpulver, } 0,1 \%[\mathrm{v} / \mathrm{v}] \text { Tween } 20 \text { in } \\
\text { PBS }\end{array}$ \\
\hline Natriumphosphatpuffer (10x) & $1 \mathrm{M} \mathrm{Na}_{3} \mathrm{PO}_{4} \times 12 \mathrm{H}_{2} \mathrm{O}$ in $\mathrm{H}_{2} \mathrm{O}$, pH 8,0 \\
\hline PBS & $\begin{array}{l}120 \mathrm{mM} \mathrm{NaCl}, 17 \mathrm{mM} \mathrm{Na} \mathrm{HPO}_{4}, 3 \mathrm{mM} \mathrm{KH} \mathrm{PO}_{4}, \mathrm{pH} \\
7,2\end{array}$ \\
\hline PBST & $0,1 \%[v / v]$ Tween 20 in PBS \\
\hline Tris-Lysispuffer & $\begin{array}{l}10 \mathrm{mM} \text { Tris/HCl }(\mathrm{pH} 7,5), 100 \mathrm{mM} \mathrm{NaCl}, 10 \mathrm{mM} \\
\text { EDTA, 0,5\% [w/v] Triton X-100, 0,5\% [w/v] DOC }\end{array}$ \\
\hline
\end{tabular}

2.1.4. Verwendete Antikörper

\begin{tabular}{|c|c|c|c|c|c|}
\hline Antikörper & Spezifität & Spezies & Produktion & Form & $\begin{array}{l}\text { eingestellte } \\
\text { Konzentration } \\
\text { bzw. } \\
\text { Verdünnung }\end{array}$ \\
\hline 3B5 & PrP & Maus-IgG & * & Ascitis & $1: 7000$ \\
\hline $3 F 4$ & $\operatorname{PrP}$ & Maus-IgG & $* *$ & & $1: 1000$ \\
\hline 4F2 & PrP & Maus-IgG & * & Ascitis & 1:1000 \\
\hline $8 G 8$ & PrP & Maus-IgG & * & Ascitis & 1:1000 \\
\hline $11 \mathrm{C} 6$ & PrP & Maus-IgG & $\begin{array}{l}\text { Sifin } \mathrm{GmbH} \text {, } \\
\text { Deutschland }\end{array}$ & $\begin{array}{l}\text { Affinitäts- } \\
\text { gereinigt }\end{array}$ & $\begin{array}{l}1 \mathrm{ng} / \mathrm{ml} \\
\text { (Western Blot) } \\
200 \mathrm{ng} / \text { Well } \\
\text { (ELISA) }\end{array}$ \\
\hline $12 \mathrm{~F} 10$ & PrP & Maus-IgG & $\begin{array}{l}\text { Sifin } \mathrm{GmbH} \text {, } \\
\text { Deutschland }\end{array}$ & $\begin{array}{l}\text { Affinitäts- } \\
\text { gereinigt }\end{array}$ & $\begin{array}{l}500 \mathrm{ng} / \text { Well } \\
\text { (ELISA) }\end{array}$ \\
\hline $12 \mathrm{~F} 10$ & PrP & Maus-IgG & * & Ascitis & $\begin{array}{l}\text { 1:1000 } \\
\text { (Western Blot) }\end{array}$ \\
\hline $\begin{array}{l}\text { anti-Maus- } \\
\text { IgG-POD }\end{array}$ & Maus-IgG & Ziege-IgG & $\begin{array}{l}\text { Jackson } \\
\text { Immuno } \\
\text { Research }\end{array}$ & $\begin{array}{l}\text { Affinitäts- } \\
\text { gereinigt }\end{array}$ & $67 \mathrm{ng} / \mathrm{ml}$ \\
\hline
\end{tabular}


2.1.5. Verwendete Kits

\begin{tabular}{lll}
\hline Kit & Firma & Verwendungszweck \\
\hline mirVana $^{\text {TM }}$ & Ambion & $\begin{array}{l}\text { Isolierung von mikroRNA aus } \\
\text { Gewebe }\end{array}$ \\
BCA-Assay & Sigma Aldrich & $\begin{array}{l}\text { Proteinkonzentrationsbestimmung } \\
\text { TaqMan MicroRNA }\end{array}$ \\
$\begin{array}{l}\text { Applied } \\
\text { Assays }\end{array}$ & Expressionsanalyse von mikroRNAs \\
\hline
\end{tabular}

\subsubsection{Verwendete Computerprogramme}

Zum Durchsuchen von öffentlichen Datenbanken wurde der NCBI-Server, der miRBase Server (GRIFFITH-JONES et al., 2006) und der BLAST-Algorithmus (Basic Local Alignment Search Tool; ALTSCHUL et al., 1997) verwendet. Daten von mindestens zwei unabhängigen Experimenten mit mindestens 2 Replika wurden statistisch mit Microsoft ${ }^{\circledR}$-Excel 2003 SP2 oder dem Programm GraphPad Prism (Version 3.0 for Windows; GraphPad Prism Software Inc.) ausgewertet. Statistische Signifikanzen wurden durch einen student t-test mit Welch's Korrektur erhoben. Als Kriterium für Signifikanz wurde $p<0.05$ gesetzt. Für densitometrische Analysen wurde das Programm ImageJ (Version 1.37v for Windows) genutzt. Die Western Blots wurden eingescannt (HP Scanjet 4890) und mit dem Programm Adobe Photoshop 8.0.1 for Windows dargestellt. Zur Erstellung der Dissertation diente Microsoft ${ }^{\circledR}$ Word.

\subsubsection{Versuchstiere}

Als Versuchstiere dienten Javaneraffen (Macaca fascicularis). Sie wurden im Deutschen Primatenzentrum gehalten und tierärztlich betreut. Die Haltung erfolgte gemäß der Richtlinien des Instituts und gemäß des Deutschen Tierschutzgesetzes vom 25. Mai 1998 in der derzeit geltenden Fassung. Die Tiere stammten aus Mauritius.

Die Javaneraffen wurden im Rahmen der EU-Studie QLK1-CT-2002-01096 mit Hirnhomogenat BSE infizierter Rinder intercerebral infiziert (i.c.) und in sozialen Gruppen zu je 6 Weibchen gehalten. 


\subsubsection{Zelllinien}

Eine in vitro Infektion neuronaler Zellen mit unterschiedlichen TSE-infektiösen Agenzien wurde an einer murinen und einer humanen Zelllinie durchgeführt. Im Folgenden sind die Zelllinien und ihre Kulturbedingungen spezifiziert. Die murine neuronale Zelllinie SN56 wurde freundlicherweise von Prof. Bruce Wainer (Emory University Atlanta, USA) zur Verfügung gestellt.

Tabelle 2.1: Verwendete Zelllinien

\begin{tabular}{|c|c|c|c|}
\hline Zelllinie & Zelltyp & Medium (Fa. Gibco) & Herkunft/ Referenz \\
\hline SMB.s15 & $\begin{array}{l}\text { murine } \\
\text { mesodermale } \\
\text { Zelllinie } \\
\text { (Subklon s15) }\end{array}$ & DMEM, 10\% FCS (v/v) & $\begin{array}{l}\text { Etabliert aus Hirnzellen Scrapie } \\
\text { (Chandler) infizierter Mäuse, } \\
\text { chronisch Scrapie infiziert. } \\
\text { CLARKE und HAIG, } 1970\end{array}$ \\
\hline SMB.PS & $\begin{array}{l}\text { murine } \\
\text { mesodermale } \\
\text { Zelllinie }\end{array}$ & DMEM, 10\% FCS (v/v) & $\begin{array}{l}\text { Etabliert aus SMB Zellen, durch } \\
\text { Behandlung mit Pentosan- } \\
\text { Polysulfat, kein PrP } \\
\text { nachweisbar. } \\
\text { BIRKETT et al., } 2001\end{array}$ \\
\hline SN56 & $\begin{array}{l}\text { murine septal- } \\
\text { neuronale } \\
\text { Zelllinie }\end{array}$ & DMEM, 10\% FCS (v/v) & $\begin{array}{lrr}\text { Etabliert } & \text { aus } & \text { murinen } \\
\text { embryonalen } & \text { Septalzellen, die } \\
\text { mit } & \text { murinen } \\
\text { Neuroblastomazellen } & \text { fusioniert } \\
\text { wurden. } & \\
\text { HAMMOND et al., } 1989 & \end{array}$ \\
\hline $\begin{array}{l}\text { SH-SY5Y } \\
\text { (DSMZ Nr.: } \\
\text { ACC209) }\end{array}$ & $\begin{array}{l}\text { humane } \\
\text { Neuroblastoma } \\
\text { Zelllinie }\end{array}$ & $\begin{array}{l}\text { DMEM / Nut Mix F-12 } \\
\text { (1:1), } 2 \text { mM L-Glutamin, } \\
\text { 15\% FCS (v/v) }\end{array}$ & $\begin{array}{l}\text { Subklon der Neuroblastoma- } \\
\text { Zellinie SK-N-SH (ATCC-Nr.: } \\
\text { HTB-11), die } 1970 \text { aus einem } \\
\text { metastatischen Knochenmarks- } \\
\text { Tumor einer } 4 \text { Jahre alten } \\
\text { Patientin resektomiert wurde. } \\
\text { Ross et al., } 1983\end{array}$ \\
\hline
\end{tabular}

\subsection{Aufarbeitung von Organen und Zellen}

\subsubsection{Entnahme einzelner Hirnregionen aus gefrorenem Hirngewebe von Javaneraffen (Macaca fascicularis)}

In dorso-ventral angefertigten Schnitten schockgefrorenen Hirngewebes von Javaneraffen wurden 7 Hirnregionen (gyrus frontalis, gyrus cinguli, gyrus parietalis, gyrus occipitalis, nucleus caudatus, vermis cerebelli, basis pontis) makroskopisch identifiziert. Zusätzlich wurde Hirngewebe aus der Stammhirnregion entnommen. Die Schnitte wurden auf Trockeneis bereitgelegt. Mit einer in einen Akkuschrauber (Fa. Schwarzberg) befestigten Biopsiestanze (Durchmesser $5 \mathrm{~mm}$, Fa. Stiefel Laboratorium $\mathrm{GmbH}$ ) wurden Areale aus den Hirnregionen in gefrorenem Zustand 
entnommen. Das Gewebe wurde in Eppendorfgefäße überführt und ausgewogen und entweder sofort weiterverarbeitet oder bei $-80^{\circ} \mathrm{C}$ gelagert.

\subsubsection{Herstellung von Proteinextrakten aus Hirngewebe und Zellen}

Zum Nachweis des Prion Proteins in Hirngewebe wurde ein $17 \%$ iges Homogenat hergestellt. Dazu wurden 6 Volumen (w/v) Tris-Lysispuffer auf das Gewebe gegeben. Durch vortexen und mörsern mit einem Mini-Pistill (Fa. Eppendorf) wurde eine Suspension hergestellt. Diese wurde bei 8000 x g für 5 Minuten (min) zentrifugiert, um die Proteine im Überstand anzureichern. Der Proteinextrakt wurde bei $-80^{\circ} \mathrm{C}$ gelagert oder durch eine Präzipitation mit Methanol angereichert und anschließend im Ausgangsvolumen Kulturmedium aufgenommen.

Aus Zelllysat der SMB.s15 Zellen wurde Proteinextrakt gewonnen. Je $4 \times 10^{6}$ Zellen wurden in $500 \mu \mathrm{l}$ Kulturmedium aufgenommen, durch vortexen lysiert und bei 10.000 x g für 5 min zentrifugiert. Der Überstand wurde direkt weiterverarbeitet.

\subsection{Proteinbiochemische Methoden}

\subsubsection{Proteinkonzentrationsbestimmung mit Bicinchoninischer Säure (bicinchoninic acid, BCA)}

Da die pathogene Isoform des PrP nur in Detergenzien löslich ist, wurden die Proteinextrakte mit detergenzhaltigen Puffern hergestellt. In diesen Puffern war jedoch keine Proteinkonzentrationsbestimmung nach BRADFORD (1976) möglich. Daher wurde der Bicinchonic Acid (BCA) Kit (Fa. Sigma-Aldrich) eingesetzt. Dieser besteht aus einer BCA-Lösung und einer Kupfersulfatlösung (4\% [w/v]). Die Proteinkonzentration wird über die Bildung eines Protein-Kupfer-Komplexes und der daraus resultierenden Reduktion von $\mathrm{Cu}^{2+} \mathrm{zu} \mathrm{Cu}^{+}$bestimmt. In Folge entsteht ein chromogener $\mathrm{Cu}^{+}-\mathrm{BCA}-K o m p l e x$. Die Konzentration des Komplexes korreliert mit der Proteinkonzentration (SMITH et al., 1985).

Die Kupfersulfat- und die BCA-Lösung wurden im Verhältnis 1:50 eingesetzt. Eine Standardreihe mit BSA (Fraktion V) wurde durch serielle Verdünnung in Wasser hergestellt. Die Hirnhomogenate wurden jeweils 1:5 in Tris-Lysispuffer verdünnt und unverdünnt eingesetzt. Je $5 \mu \mathrm{l}$ der Standardreihe oder der Probe wurden mit $350 \mu \mathrm{l}$ des BCA-Kupfersulfatgemischs für $1 \mathrm{~h}$ bei $37^{\circ} \mathrm{C}$ inkubiert. Anschließend wurde die Absorption bei $595 \mathrm{~nm}$ (ELISA-Reader MR5000, Fa. Dynatech) in Triplikaten von je

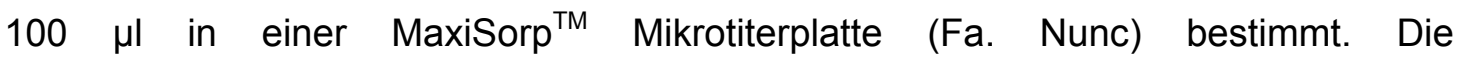


Konzentrationsbestimmung erfolgte durch lineare Regression des linearen Bereichs der Standardreihe.

\subsubsection{Markierung eines Antikörpers mit Biotin}

Der monoklonale anti-Prion Antikörper 11C6 wurde mit Biotin markiert (ProtON-Kit, Fa. VectorLab). Es wurden $900 \mu \mathrm{g}$ des monoklonalen anti-Prion Antikörpers 11C6 in einem Volumen von $100 \mu \mathrm{l}$ 1x Natriumphosphatpuffer (Endkonzentration) aufgenommen. Die Reaktion wurde nach Zugabe von 1/40 Volumen des BiotinReagenzes (50 mg/ $\mu \mathrm{l}$ in DMSO) gestartet und nach $30 \mathrm{~min}\left(37^{\circ} \mathrm{C}\right)$ durch Zugabe von $1 / 50$ Volumen Ethanolamin ( 5 min, RT) abstoppt. Der Antikörper wurde in Aliquots zu $2 \mu \mathrm{l}$ bei $-20^{\circ} \mathrm{C}$ gelagert.

\subsubsection{Proteinpräzipitation mit Methanol}

Ein Proteingemisch wurde mit 5x Volumen eiskalten Methanols versetzt und für mindestens $2 \mathrm{~h}$ bei $-20^{\circ} \mathrm{C}$ inkubiert. Die Proteine wurden durch Zentrifugation bei $15.000 \times \mathrm{g}$ und $4^{\circ} \mathrm{C}$ für 20 min pelletiert. Das Pellet wurde getrocknet und in TrisLysispuffer oder Zellkulturmedium aufgenommen.

\subsubsection{Peptid-ELISA}

Zur Charakterisierung der Epitope der monoklonalen anti-Prion Antikörper wurden Peptide von je 13 Aminosäuren eingesetzt, die das humane PrP um je zwei Aminosäuren versetzt abdecken.

Die einzelnen Inkubationsschritte des ELISA wurden für $1 \mathrm{~h}$ bei $37^{\circ} \mathrm{C}$ in einem Volumen von $100 \mu \mathrm{l}$ durchgeführt. Nach jedem Schritt wurden ungebundene

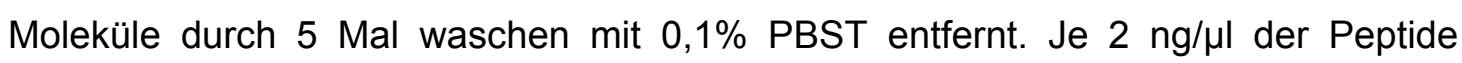
wurden pro Well an eine MaxiSorp ${ }^{\mathrm{TM}}$ (Fa. Nunc) Mikrotiterplatte gekoppelt. Die freien Bindungsstellen wurden mit 1,5\% [w/v] BSA abgesättigt. Anschließend wurden die Antikörper wie in 2.1.4 angegeben eingesetzt. Als Sekundärantikörper diente der Peroxidase gekoppelten anti-Maus-IgG Antikörper (s. 2.1.4). Gebundene Moleküle wurden über das Substrat TMB und Zugabe von Wasserstoffperoxid nachgewiesen. $\mathrm{H}_{2} \mathrm{O}_{2}$ wird durch die Peroxidase umgesetzt und führt zu einer chromogenen Reaktion des Substrats. Diese wurde durch Zugabe von $100 \mu \mathrm{l} \mathrm{M} \mathrm{H}_{2} \mathrm{SO}_{4}$ gestoppt. Die 
Absorption wurde bei $450 \mathrm{~nm}$ (630 nm Referenzwellenlänge) als $O_{450 \mathrm{~nm}}$ bestimmt (ELISA-Reader MR5000, Fa. Dynatech).

\subsection{Nachweis und Charakterisierung der pathogenen Isoform des PrP}

\subsubsection{Immunohistologie}

Die immunhistologischen Untersuchungen zum Nachweis von schwammartigen Veränderungen und PrP Ablagerungen im Hirn der BSE infizierten Javaneraffen wurden von Dr. Walther Schulz-Schäffer im Rahmen der EU-Studie QLK1-CT-200201096 durchgeführt.

\subsubsection{Proteinase K-Verdau von Proteinextrakten aus Hirngewebe}

Als Marker für die pathogene Isoform des Prion Proteins gilt die partielle Resistenz gegen eine Proteinase K (PK) Behandlung. Die Proteinase K spaltet Aminosäuren vom N-Terminus des PrP ab. Die zelluläre Isoform des PrP wird auf diese Weise vollständig abgebaut, während bei der pathogenen Isoform $\left(\mathrm{PrP}^{\mathrm{res}}\right)$ ein Proteinkern von 27 bis $30 \mathrm{kDa}$ Größe erhalten bleibt. Diese Eigenschaft des PrP ${ }^{\text {res }}$ wird zum Nachweis der Infektiosität von Prionen herangezogen (BOLTON et al., 1982).

Zum Nachweis des PrP ${ }^{\text {res }}$ wurden die Proteinextrakte (2.2.2) mit PK behandelt. Je $180 \mu \mathrm{g}$ Gesamtprotein der Hirnhomogenate wurden mit Tris-Lysispuffer auf ein Volumen von $25 \mu \mathrm{l}$ aufgefüllt und mit $50 \mu \mathrm{g} / \mathrm{ml} \mathrm{PK}(625 \mu \mathrm{g} / \mathrm{ml}$ Stock-Lösung in Wasser) für $1 \mathrm{~h}$ bei $37^{\circ} \mathrm{C}$ inkubiert. Es wurden Proteinasen verschiedener Anbieter verglichen (Tab. 2.2). Die Reaktion wurde durch Zugabe von $4 \mathrm{mM}$ PMSF abgestoppt. Für einen PK-Verdau von bovinem Hirnhomogenat wurde eine Konzentration von $6 \mu \mathrm{g} / \mathrm{ml}$ PK eingesetzt.

Tabelle 2.2: Eingesetzte Proteinasen K

\begin{tabular}{ll}
\hline \multicolumn{1}{c}{ Firma } & Produktnummer \\
\hline Sigma-Aldrich & P8044 \\
Serva & 33752 \\
Boehringer Mannheim & 1092766 \\
Merck & 1.24568 .0100 \\
\hline
\end{tabular}




\subsubsection{Deglykosylierung mit PNGase F}

Die Glykosylketten, die durch N-Glykosylierung der Asparagine an Position 180 und 191 (humanes PrP) an das PrP gebunden sind, können durch die Deglykosylase PNGase $F$ abgespalten werden. Hierzu wurde das PNGase Kit der Firma NEB genutzt. Mit Tris-Lysispuffer wurde PK behandeltes Proteinextrakt (2.3.4) auf eine Äquivalentkonzentration von je 4,1 $\mu \mathrm{g} / \mu \mathrm{l}$ Gesamtprotein vor PK Behandlung eingestellt. Es wurden $9 \mu \mathrm{l}$ mit $1 \mu \mathrm{l}$ Denaturierungspuffer (10x) versetzt und für $10 \mathrm{~min}$ bei $95^{\circ} \mathrm{C}$ denaturiert. Anschließend wurden je $1 \%[\mathrm{v} / \mathrm{v}]$ (Endkonzentration) NP-40 (10\% [w/v]) und G7-Puffer (10\% [v/v]) zugesetzt. Die Deglykosylierung wurde nach Zugabe von 100 u PNGase F für $1 \mathrm{~h}$ bei $37^{\circ} \mathrm{C}$ durchgeführt. Das deglykosylierte Proteinextrakt wurde entweder bei $-80^{\circ} \mathrm{C}$ gelagert oder sofort weiterverarbeitet.

\subsubsection{Lithiumdodecylsulfat Polyacrylamid Gelelektrophorese (LDS-PAGE)}

Die Proteinextrakte wurden nach Größe getrennt. Dazu wurde eine abgewandelte Form der SDS-PAGE (LAEMMLI, 1970) angewandt. Die Hirnhomogenate wurden in einem Lithiumdodecylsulfat-haltigen (LDS) Puffer aufgenommen. Das LDS denaturiert die Proteine über Bindung an Aminosäurereste. Dadurch entstehen LDSProtein-Komplexe, deren Nettoladung nur von den anionischen LDS-Molekülen bestimmt wird. Somit kann eine Trennung der Proteine im elektrischen Feld nach Größe, unabhängig von der Eigenladung der Proteine erreicht werden.

Für die LDS-PAGE wurde, falls nicht anders angegeben, das NuPAGE ${ }^{\circledR}$ System der Firma Invitrogen genutzt. Die Proteingemische der Hirnhomogenate wurden mit $1 \mathrm{x}$ NuPAGE $®$ LDS Sample Buffer (Endkonzentration) versetzt und für $10 \mathrm{~min}$ bei $70^{\circ} \mathrm{C}$ denaturiert. Je 12 bis $30 \mu \mathrm{l}$ entsprechend 45 bis $60 \mu \mathrm{g}$ Äquivalentmenge des Gesamtproteins wurden auf ein $12 \%$ iges Bis-Tris Gel $\left(\right.$ NuPAGE$\left.^{\circledR}\right)$ geladen. Der Laufpuffer wurde auf der Anodenseite mit 1/400 Volumen NuPAGE $®$ Antioxidant versetzt. Die Proteingemische und ein gefärbter Molekulargewichtsmarker (See Blue Plus $2^{\mathrm{TM}}$ ) wurden bei konstanter Spannung von $200 \mathrm{~V}$ für etwa $1 \mathrm{~h}$ im Gel getrennt, bis das im NuPAGE $®$ LDS Sample Buffer enthaltene ServaBlue ${ }^{\mathrm{TM}}$ den unteren Rand des Gels erreicht hatte. 


\subsubsection{Western Blot Analyse mit enhanced chemolumniscence Nachweis (ECL-} Blot)

Um die elektrophoretisch getrennten Proteine nachzuweisen, wurden sie auf eine Nitrozellulosemembran (NZM) transferiert und auf dieser über spezifische Antikörper dargestellt (Western Blot, TowBIN et al., 1979). Die Bindung der Proteine an die NZM erfolgt über die hydrophoben Aminosäurereste der Proteine.

Für den Transfer der Proteine wurde das X-Cell II $^{\mathrm{TM}}$ System der Firma Invitrogen genutzt. Eine NZM (Protan BA Nitrozellulose, 0,2 $\mu \mathrm{m}$, Fa. Schleicher und Schüll) wurde in NuPAGE ${ }^{\circledR}$ Transfer Buffer (20x Stock, verdünnt mit 20\% Methanol, 0,1\% NuPAGE $®$ Antioxidant) für $10 \mathrm{~min}$ aktiviert. Der Transfer wurde bei konstanter Spannung von $30 \mathrm{~V}$ für $2 \mathrm{~h}$ durchgeführt. Das Gel wurde verworfen. Die freien Proteinbindungsstellen der NZM wurden durch Inkubation für $1 \mathrm{~h}$ mit $0,1 \%$ MPBST bei $37^{\circ} \mathrm{C}$ abgesättigt.

Die Membran wurde über Nacht bei $4^{\circ} \mathrm{C}$ mit monoklonalen anti-Prion Antikörpern (Verdünnungen in $10 \mathrm{ml}$ MPBST, 2.1.4) inkubiert. Anschließend wurde die Membran für 5 min mit PBST gewaschen und dann mit einem Peroxidase gekoppelten antiMaus IgG (2.1.4) in $30 \mathrm{ml}$ MPBST für $1 \mathrm{~h}$ bei $37^{\circ} \mathrm{C}$ inkubiert. Die Membran wurde $5 \mathrm{x}$ mit PBST und 2x mit PBS für je 5 min gewaschen.

Der Nachweis des PrP erfolgte indirekt über die Reaktion der Peroxidase des Sekundärantikörpers mit einen Luminol-Wasserstoffperoxid-Substrat (SuperSignal West Pico, Fa. Pierce; Immobilon Western Chemiluminescent HRP Substrate, Fa. Millipore). Bei dieser Reaktion wird Licht der Wellenlänge $422 \mathrm{~nm}$ emittiert, das auf einen Fotofilm (Fa. Amersham) sichtbar gemacht wurde. Hierzu wurde in einer Dunkelkammer die Membran in eine Klarsichthülle gelegt und mit $1 \mathrm{ml}$ des Substrats (nach Anleitung des Herstellers) für 3 min inkubiert. Anschließend wurde das Substrat entfernt und ein Fotofilm wurde dem emittierten Licht der Membran exponiert. Dieser wurde nach $1 \mathrm{~min}, 5 \mathrm{~min}$ und Exposition über Nacht automatisch entwickelt (Elite Chrome 400, Fa. Kodak).

Die relativen Molekulargewichte der Proteine wurden über lineare Regression des Molekulargewichtsmarkers SeeBlue Plus2 (Fa. Invitrogen) ermittelt. 


\subsubsection{Sandwich - Enzyme Linked Immunosorbent Assay (ELISA)}

Zum Nachweis von PrP in Proteinextrakten aus Hirngewebe wurde ein SandwichELISA verwendet. Der monoklonale anti-Prion Antikörper 12F10 (KRASEMANN et al., 1996) wurde an eine Polystyren-Oberfläche gebunden (Fänger-Antikörper). Hierzu wurden $100 \mu \mathrm{l}$ des Antikörpers (5 ng/ $\mu \mathrm{l}$ in PBS) für $2 \mathrm{~h}$ bei $37^{\circ} \mathrm{C}$ in einer Mikrotiterplatte (MaxiSorp ${ }^{\mathrm{TM}}$, Fa. Nunc) inkubiert. Die weiteren Inkubationsschritte wurden jeweils in einem Volumen von $100 \mu$ für $1 \mathrm{~h}$ bei $37^{\circ} \mathrm{C}$ durchgeführt, und ungebundene Moleküle wurden anschließend durch 5 Mal waschen mit 0,1\% PBST entfernt. Die freien Bindungsstellen der Mikrotiterplatte wurden mit 1,5\% BSA [w/v] in PBS abgesättigt. Die Proteinextrakte wurden mit Tris-Lysispuffer auf eine Konzentration von $1,0 \mu \mathrm{g} / \mu \mathrm{l}$ Gesamtprotein bzw. eine Äquivalentkonzentration von 4,5 $\mu \mathrm{g} / \mu \mathrm{l}$ Gesamtprotein vor PK-Verdau eingestellt (Endvolumen $20 \mu \mathrm{l}$ ), bei $95^{\circ} \mathrm{C}$ für $10 \mathrm{~min}$ denaturiert, in $200 \mu \mathrm{l}$ Tris-Lysispuffer aufgenommen und anschließend auf der Mikrotiterplatte inkubiert (10 $\mu \mathrm{g}$ bzw. $45 \mu \mathrm{g}$ pro Well). Das PrP wurde über den Biotingekoppelten anti-Prion Antikörper 11C6 (Krasemann et al., 1996) nachgewiesen (2 $\mathrm{ng} / \mu \mathrm{l}$ in PBS). Der Nachweis erfolgte indirekt über einen Peroxidase gekoppeltes Streptavidin (1:1000) und Tetramethyl-benzidin (TMB) als Substrat (s. 2.3.4).

\subsubsection{Denaturierung des Prion Proteins mit Guanidinium-Hydrochlorid (GdnHCl)}

Zur Bestimmung eines Prionenstämme wird die relative Stabilität des PrP res gegenüber $\mathrm{GdnHCl}$ herangezogen. Dazu werden Proteingemische mit einer Verdünnungsreihe $\mathrm{GdnHCl}$ inkubiert und anschließend mit Proteinase $\mathrm{K}$ behandelt. Die GdnHCl-Konzentration, bei der die Hälfte des PrP sensitiv gegenüber der PK ist $\left(\mathrm{GdnHCl}_{1 / 2}\right)$, wird als Maß für die relative Stabilität des Prion-Stamms angenommen (PERETZ et al., 2001).

Es wurden 90, 120 oder $180 \mu \mathrm{g}$ Gesamtprotein in einer Verdünnungsreihe von 0-6 M $\mathrm{GdnHCl}$ in Tris-Lysispuffer aufgenommen und für $1 \mathrm{~h}$ bei Raumtemperatur inkubiert. Anschließend wurde das Protein präzipitiert (2.3.3). Das Pellet wurde in $25 \mu \mathrm{l}$ TrisLysispuffer aufgenommen und mit PK behandelt (2.3.4). Die PK-Sensitivität wurde im ECL-Blot (2.3.7) und im Sandwich-ELISA (2.3.8) untersucht. Der $\mathrm{GdnHCl}_{1 / 2}$-Wert wurde mit dem Programm GraphPad Prism 3.0 ermittelt. 


\subsection{Transkriptanalyse von mikroRNAs (miRNAs)}

Um das Risiko einer Hydrolyse der RNA Moleküle durch RNasen zu minimieren, wurden die Arbeiten mit RNA unter möglichst RNAse freien Bedingungen durchgeführt. Daher wurden Arbeitsflächen und Pipetten mit RNase AWAY (Fa. Molecular Bio Products) dekontaminiert und sterile, gestopfte Pipettenspitzen (Fa. Sarstedt) und Rnase freie Reaktionsgefäße (Fa. Sarstedt) genutzt. Die RNA wurde in $\mathrm{H}_{2} \mathrm{O}_{\text {DEPC }}$ aufgenommen. Puffer und Lösungen wurden mit $\mathrm{H}_{2} \mathrm{O}_{\text {DEPC }}$ angesetzt. Die RNA wurde bei $-80^{\circ} \mathrm{C}$ gelagert.

\subsubsection{Isolierung von mikroRNA (miRNA) aus Hirngewebe (mirVana ${ }^{\mathrm{TM}} \mathrm{Kit}$, Ambion)}

Aus gefrorenem Hirngewebe von Javaneraffen wurde RNA isoliert. Diese wurde über unterschiedliche Ethanolkonzentrationen in Fraktionen von mehr als 200 Basen (makroRNA) bzw. weniger als 200 Basen (mikroRNA) aufgeteilt. Bei einer Ethanolkonzentration von $30 \%-40 \%$ werden makroRNAs, bei $70 \%$ Ethanol mikroRNAs an einen Glasfieber-Filter gebunden.

Aus gefrorenem Hirn BSE-infizierter und nicht infizierter Javaneraffen wurden wie unter 2.2.1 beschrieben aus den Arealen von vermis cerebelli und basis pontis Gewebe entnommen. Diese wurden ausgewogen und unter flüssigem Stickstoff mit Mörser und Pistill zu einem gleichmäßigen Pulver zerrieben. Dieses Pulver wurde in ein 1,5 ml Reaktionsgefäß (Fa. Sarstedt) überführt. Die Isolierung der miRNA wurde mit dem mirVANA ${ }^{\mathrm{TM}}$-Kit (Fa. Ambion) nach Angaben des Herstellers durchgeführt. Die Elution der miRNA erfolgte abweichend von diesen $2 \mathrm{x}$ mit $25 \mu \mathrm{l} 95^{\circ} \mathrm{C}$ heißem $\mathrm{H}_{2} \mathrm{O}_{\text {DEPC. }}$. Um das Eluat von überschüssigen Salzen $z u$ reinigen, wurde eine Natriumacetat-Ethanol-Fällung (NaAc/EtOH-Fällung) durchgeführt. Die gelösten Nukleinsäuren wurden mit 1/10 Volumen $3 \mathrm{M} \mathrm{NaAc}(\mathrm{pH} 5,5)$ und 2 1/2 Volumen 96\% Ethanol (RNAse frei, Fa. Sigma-Aldrich) versetzt, gemischt und für mindestens $2 \mathrm{~h}$ bei $-20^{\circ} \mathrm{C}$ inkubiert. Anschließend wurden die Ansätze nochmals gemischt und bei $14.000 \mathrm{rpm}$ (Biofuge $\mathrm{A}$ ) und $4^{\circ} \mathrm{C}$ für 30 min zentrifugiert. Die Pellets wurden 2 Mal mit $70 \%$ eiskalten Ethanol gewaschen, bei $37^{\circ} \mathrm{C}$ getrocknet und in Puffer oder Wasser aufgenommen. 


\subsubsection{Konzentrationsbestimmung von Nukleinsäuren oder Fluoreszenzfarb- stoffen}

Die Bestimmung der Konzentration isolierter oder markierter Nukleinsäuren erfolgte photometrisch mit dem NanoDrop (Fa. Peqlab). Es wurde ein Spektrum der Absorption von 220 bis $750 \mathrm{~nm}$ aufgenommen und die Konzentration wurde über die Lambert-Beer'sche Gleichung berechnet:

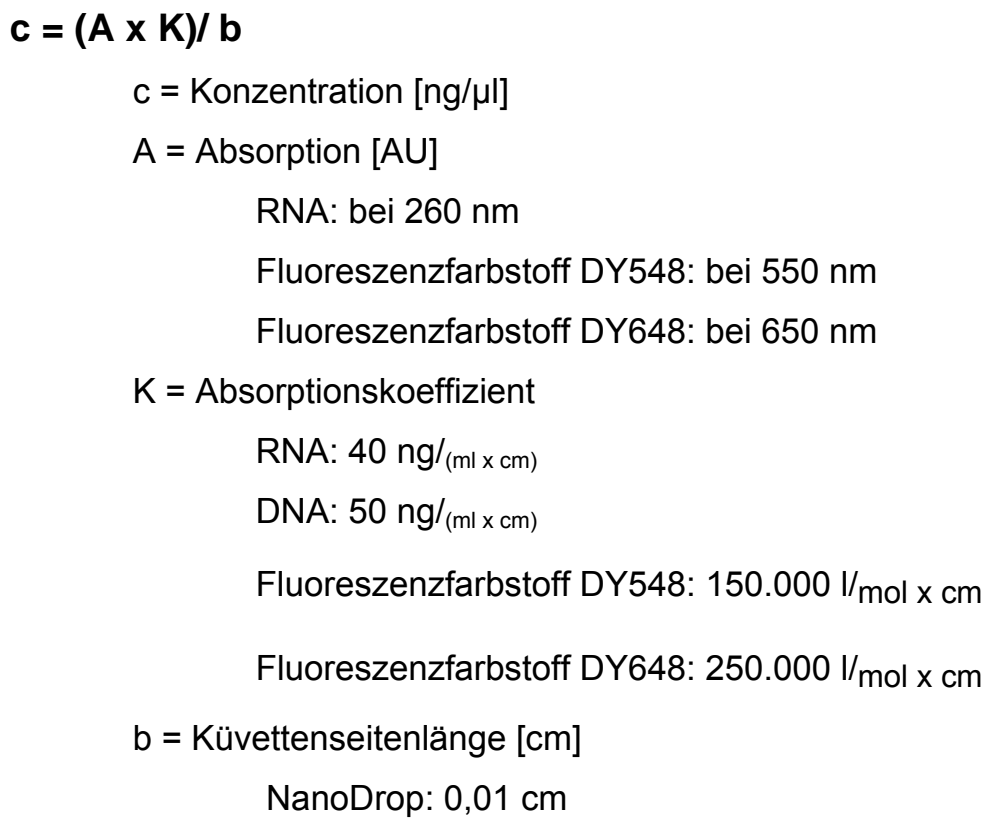

\subsection{3. miRNA-MicroArray}

Mithilfe eines MicroArrays wurden miRNAs identifiziert, die im Hirn von Javaneraffen exprimiert sind und deren Expression durch eine BSE-Infektion reguliert wird. Bei einem MicroArray werden immobilisierte Nukleinsäuren mit fluoreszenzmarkierten komplementären Nukleinsäuren hybridisiert. Über die Hybridisierung können Aussagen über die relative Menge der Nukleinsäuren im untersuchten Gewebe und damit über die Expression getroffen werden.

Die Fluoreszenzmarkierung der mikroRNAs wurde in zwei Schritten durchgeführt (Abb. 2.1). Zunächst wurde die miRNA am 3'-Ende mit Uracil und Amino-Allyl-Uracil verlängert (Poly-Udenylierung). Das Enzym Poly A-Polymerase nutzt ATP als Substrat, um Adenosinmonophosphat an das 3' Ende von RNA Molekülen zu koppeln (GETHING et al., 1980). Durch Zugabe von $\mathrm{MnCl}_{2}$ kann die Substratspezifität des Enzyms herabgesetzt werden. Unter diesen Bedingungen wird auch UTP und AminoAllyl-UTP als Substrat genutzt und eine Polyudenylierung wird ermöglicht. An die Amino-Allyl-Gruppen des Poly-U-Schwanzes wurden dann durch eine Esterbindung NHS-Fluoreszenzfarbstoffe kovalent gebunden (Fluoreszenzmarkierung). 

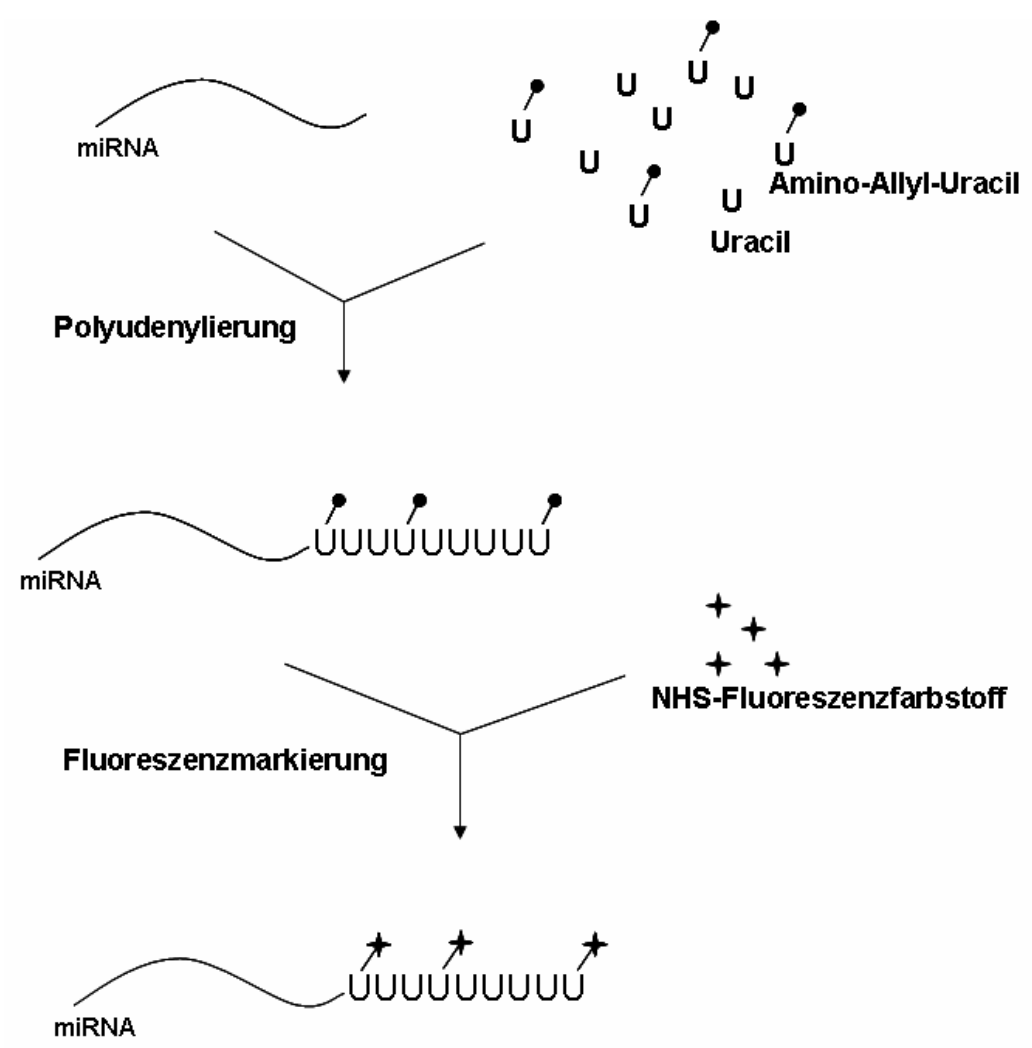

\section{Abbildung 2.1: Fluoreszenzmarkierung von miRNA}

Die miRNA wird zunächst mit Uracil und Amino-Allyl-Uracil verlängert (Polyudenylierung). An die Amino-Allyl Gruppe wird dann im nächsten Schritt durch Esterbindung ein Fluoreszenzfarbstoff gebunden.

Für eine Poly-Udenylierung wurden $200 \mathrm{ng}$ bis $2 \mu \mathrm{g}$ miRNA aus Hirngewebe oder synthetische miRNA eingesetzt. Diese wurden in $20 \mu$ leiner Udenylierungslösung (10 mM UTP (Fa. Biozym Epicentre), 10 mM AA-UTP (Fa. Biozym Epicentre), 1x Puffer B (5x, 5 mM DTT, 0,25 mM EDTA, 25\% [w/v] Glycerin, 250 mM KCl, 250 mM Tris-HCl, pH 8,5), 100 mM MnCl 2,40 u RNase Inhibitor (Fa. Fermentas), 4 u Poly APolymerase (Fa. Biozym Epicentre) aufgenommen und für $1 \frac{1}{2} \mathrm{~h}$ bei $37^{\circ} \mathrm{C}$ inkubiert. Anschließend wurde die RNA wie unter 2.4.1 beschrieben gefällt.

Zur Markierung der RNA wurden die Fluoreszenzfarbstoffe DY548 und DY648 (Fa. MoBiTech) eingesetzt. Je $1 \mathrm{mg}$ der Farbstoffe wurde in $40 \mu \mathrm{l}$ DMSO gelöst und in Aliquots zu 25 oder $50 \mu \mathrm{g}$ aufgeteilt. Die Pellets wurden unter Vakuum getrocknet und bei $-20^{\circ} \mathrm{C}$ gelagert. Um die RNA über die Amino-Allyl-Gruppen mit einem Fluoreszenzfarbstoff zu markieren, wurde die gefällte RNA in $5 \mu \mathrm{NaCO}_{3}(200 \mathrm{mM}$, $\mathrm{pH} 9$,5) aufgenommen. Die Farbstoffe wurden mit $\mathrm{H}_{2} \mathrm{O}_{\text {DEPC }}$ auf eine Konzentration von 2,3 $\mu \mathrm{g} / \mu \mathrm{l}$ eingestellt und der RNA in gleichem Volumen zugesetzt. Nach $2 \mathrm{~h}$ Inkubation bei Raumtemperatur im Dunkeln wurde die markierte RNA wie unter 2.4.1 beschrieben gefällt. Das Pellet wurde in $10 \mu \mathrm{H}_{2} \mathrm{O}_{\text {DEPC }}$ aufgenommen. Die RNA- und 
die Farbstoffkonzentration wurde bestimmt (vgl. 2.3.4) und daraus die Markierungseffizienz ermittelt. Diese errechnet sich aus der Anzahl der Farbstoffmoleküle pro Nanogramm RNA:

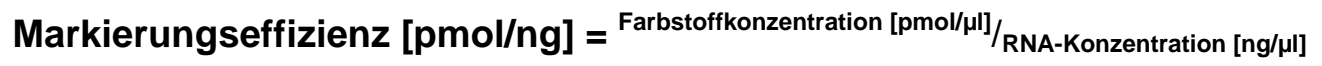

Der Nachweis der exprimierten miRNAs mittels miRNA-MicroArray fand in Zusammenarbeit mit dem Transkriptomanalyselabor der Universität Göttingen unter der Leitung von Dr. Reiner Hitt statt. Es wurde die miRNA-MicroArray Plattform mirVana miRNA Probe Set Version 1 der Firma Ambion verwendet. Diese enthält die komplementären DNAs aller beschriebenen miRNAs. Diese wurden auf Amersham Codelink Objektträger gekoppelt (LANDGREBE et al., 2002).

Für den Array wurden gleiche Mengen der zu vergleichenden miRNA eingesetzt. Die Konzentration wurde nach der Fluoreszenzmarkierung (2.4.4) bestimmt und aneinander angeglichen. Für die Triplika der Arrays wurden 600 oder 1500 ng markierte miRNA in RNase freiem Wasser $(20 \mu \mathrm{l})$ aufgenommen, für $3 \mathrm{~min}$ bei $70^{\circ} \mathrm{C}$ denaturiert und sofort mit $600 \mu \mathrm{l}$ Hybridisierungspuffer (1x Hybridisierungspuffer (Fa. Agilent), 0,2 $\mathrm{mg} / \mathrm{ml}$ Yeast- t-RNA, 0,01 $\mathrm{mg} / \mathrm{ml}$ Lachsspermien-DNA) versetzt. Diese wurden gleichmäßig auf drei Arrays aufgeteilt. Die Arrays wurden über Nacht bei $58^{\circ} \mathrm{C}$ hybridisiert und anschließend gescannt (Genetic Microsystems GMS 418 Array Scanner, Fa. Affimetrix). Die Bedingungen wurden so gewählt, dass die Stärke aller Signale unterhalb des Sättingungslimts des Scanners lagen (unter 65536 units).

\subsubsection{Herstellung von cDNA aus mikroRNA (TaqMan ${ }^{\circledR}$ MicroRNA Assays, Applied Biosytems}

In einer PCR Reaktion kann nur DNA amplifiziert werden. Um RNA quantitativ mittels PCR zu analysieren, wird diese durch das Enzym Reverse Transkriptase in komplementäre DNA (engl.: complementary DNA, cDNA) transkribiert. Die cDNASynthese erfolgt in einem Zyklus (Denaturierung der RNA, Anlagerung des Primers, Transkription). Somit entspricht die Menge an synthetisierter cDNA näherungsweise der Menge an eingesetzter RNA.

Da miRNAs etwa 22 bp lang sind, kann keine herkömmliche reverse Transkripition durchführt werden. Dazu müsste der Primer fast die gesamte miRNA abdecken, um ein Nukleotid zu bilden, das lang genug ist, um eine Reaktion mit der Reversen Transkriptase zu ermöglichen. Damit kann aber keine Elongation mehr stattfinden und in einer folgenden PCR Reaktion wird die Menge an eingesetztem Primer 
nachgewiesen. Daher nutzt der eingesetzte Assay Primer, die eine HaarnadelStruktur ausbilden (loop-primer) und am 3'-Ende etwa 6 Basen spezifisch mit dem 3'Ende der miRNA hybridisieren (Abb. 2.2). Dadurch entsteht eine RNA, die ein Reaktion mit der Reverse Transkriptase ermöglicht. Zusätzlich verhindert die Struktur des loop-primers, dass längere RNAs wie z.B. nicht prozessierte miRNAs revers transkribiert werden (CHEN et al., 2005).

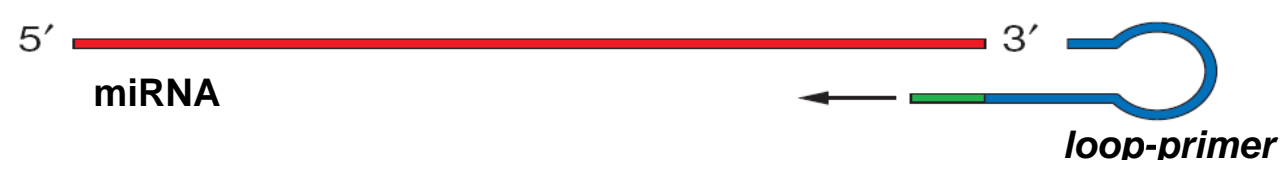

Abbildung 2.2: loop-primer der cDNA-Synthese des TaqMan ${ }^{\circledR}$ MicroRNA Assay (nach CHEN et al., 2005)

Für die reverse Transkription von miRNAs werden Primer eingesetzt, die eine Haarnadelstruktur ausbilden und deren 3'-Ende revers komplementär zum 3' Ende der miRNA ist. Dadurch hybridisieren miRNA und Primer und eine spezifische reverse Transkription wird ermöglicht.

Die cDNA-Synthese wurde mit TaqMan $^{\circledR}$ MicroRNA Assays nach Angaben des Herstellers (Fa. Applied Biosystems) in einem Volumen von $15 \mu \mathrm{l}$ durchgeführt.

Master Mix für die cDNA-Synthese:

$$
\begin{array}{rll}
15 & \text { nmol } & \text { dNTPs } \\
1 & x & \text { RT-Puffer } \\
4 & \mathrm{u} & \text { RNase Inhibitor } \\
4 & \mathrm{u} & \text { MulitScribe }{ }^{\mathrm{TM}} \mathrm{RT} \\
100 & \mathrm{nmol} & \text { miRNA spezifischer loop-primer } \\
1 & \mathrm{ng} & \text { miRNA } \\
& & \mathrm{H}_{2} \mathrm{O}_{\text {DEPC }}
\end{array}
$$

Die Synthese erfolgte nach folgendem Temperaturprofil:

$$
\begin{array}{rrrl}
30 & \min & 16^{\circ} \mathrm{C} & \text { Hybridisierung } \\
30 & \min & 42^{\circ} \mathrm{C} & \text { Elongation } \\
5 & \min & 85^{\circ} \mathrm{C} & \text { Abstoppen der Reaktion }
\end{array}
$$

Die cDNA wurde bei $-20^{\circ} \mathrm{C}$ gelagert. 


\subsubsection{Quantitative Real Time-Polymerase Kettenreaktion (TaqMan ${ }^{\circledR}$ MicroRNA} Assays, Applied Biosytems)

Die Expression der miRNAs, die im miRNA-MicroArray bei BSE-infizierten und nicht infizierten Javaneraffen in unterschiedlichen Mengen nachgewiesen worden waren, wurde mit einer quantitativen Real Time PCR untersucht. Diese ist eine Erweiterung der Polymerase Kettenreaktion (polymerase chain reaction (PCR), (SAIKI et al., 1985), bei der die Synthese neuer DNA-Doppelstränge nach jedem Zyklus nachgewiesen wird. Dies kann in Form von minor grove binder (MGB) Molekülen geschehen, die durch Bindung an DNA Doppelstränge fluoreszieren. Die Fluoreszenzintensität korreliert in diesem Fall mit der Menge an DNA-Doppelsträngen, also mit der Menge an generierter DNA. Ein Nachteil der MGB ist, dass auch Primer-Dimere gebunden werden und ein unspezifisches Signal entstehen kann. Der Nachweis von neu synthetisierter DNA kann auch über spezifische DNA-Sonden geführt werden. Diese sind am 5'-Ende an einen Fluoreszenzfarbstoff und am 3'-Ende an einen Quencher gekoppelt. Ein Quencher nimmt die Anregungsenergie des Fluoreszenzfarbstoffs auf und verhindert somit die Emission von Licht (Fluoreszenz-Resonanz-EnergieTransfer, FRET). Der Energiezustand des Quenchers wird dadurch angehoben. Dieser kehrt entweder durch Emission von Licht einer anderen Wellenlänge als der des Fluoreszenzfarbstoffs oder Schwingungsenergie in den Grundzustand zurück. Die DNA Sonde hybridisiert über komplementäre Basenpaarung mit der Ziel-DNA. Während der quantitativen Real Time-PCR wird die Sonde durch die Exonukleaseaktivität der Taq Polymerase hydrolysiert (HOLLAND et al., 1991). Dadurch werden Fluoreszenzfarbstoff und Quencher räumlich voneinander getrennt und die Anregungsenergie des Fluoreszenzfarbstoffs wird nicht mehr auf den Quencher transferiert. Dadurch emittiert der Fluoreszenzfarbstoff Licht. Die Menge an emittiertem Licht ist proportional zur Menge an neu generierter DNA. Für den Nachweis der PCR Reaktion über die Fluoreszenzänderung wurde der $\operatorname{TaqMan}^{\circledR}$ 7500 (Fa. Applied Biosystems) eingesetzt. Für die Anregung benutzt das Gerät einen Argon-Laser (488 nm). Die Emissionsdaten von 500-660 nm werden von einer CCDKamera jeweils nach der Elongation gesammelt.

Die Expression der miRNAs von BSE-infizierten und nicht infizierten Javaneraffen wurde untersucht. Dazu wurden $\operatorname{TaqMan}^{\circledR}$ MicroRNA Assays (Fa. Applied Biosystems) genutzt. In diesen Assays ist die Sonde am 5'-Ende mit dem Fluoreszenzfarbstoff $\mathrm{FAM}^{\mathrm{TM}}$ modifiziert. Der Quencher ist nicht fluoreszent (nonfluorescent quencher, NFQ), dass heißt die Desaktivierung des Quenchers erfolgt über Schwingungsenergien. Die qRT-PCR wurde nach den Angaben des Herstellers durchgeführt. Die cDNA für die Reaktion wurde mit der miRNA als Template gebildet 
(2.4.4.2). Pro Reaktionsansatz wurden folgende Reagenzien pipettiert (Endvolumen $20 \mu \mathrm{l})$ :

$10 \mu \mathrm{l} \quad \operatorname{TaqMan}^{\circledR} 2 \mathrm{x}$ Universal PCR Master Mix

$0,5 \mu \mathrm{l} \operatorname{ROX}(10 \mathrm{x})$

$1 \mu \mathrm{l} \quad \operatorname{TaqMan}^{\circledR}$ MicroRNA Assay (20x)

$2 \mu \mathrm{l} \quad$ cDNA (Template)

$6,5 \mu \mathrm{l} \quad \mathrm{H}_{2} \mathrm{O}_{\text {DPEC }}$

Die Reaktion fand nach folgendem Temperaturprofil statt:

10 min $95^{\circ} \mathrm{C} \quad$ AmpliTaq Gold ${ }^{\circledR}$ Enzymaktivierung

$15 \mathrm{sec} 95^{\circ} \mathrm{C}$ Denaturierung

$45 \mathrm{sec} 60^{\circ} \mathrm{C}$ Hybridisierung und Elongation 40 Zyklen

\subsection{Zellkulturarbeiten}

\subsubsection{Kultivierung eukaryotischer Zellen}

Die verwendeten Zelllinien wurden bei $37^{\circ} \mathrm{C}$ in wasserdampfgesättigter $\mathrm{CO}_{2}(5 \%)$ Atmosphäre in Zellkulturflaschen mit einer Oberfläche von $75 \mathrm{~cm}^{2}$ (Fa. Sarstedt) oder in 96 well Zellkulturplatten (Fa. Sarstedt) kultiviert (Medien: Tab. 2.1). Bei 70\% bis 90\% Konfluenz wurden die Zellen mit $37^{\circ} \mathrm{C}$ warmen PBS (Fa. Gibco) gewaschen und anschließend mit 1x Trypsin/ETDA (Fa. PAN Biotech $\mathrm{GmbH}$ ) bei $37^{\circ} \mathrm{C}$ von der Kultivierungsoberfläche gelöst. Das Trypsin wurde durch Zugabe von $5 x$ Volumen Kulturmedium mit $10 \%$ bis $15 \%$ fötalen Kälberserum (fetal calv serum, FCS, Fa. PAN Biotech $\mathrm{GmbH}$ ) inaktiviert. Die Zellen wurden bei $700 \mathrm{rpm}$ (Multifuge 1) für $7 \mathrm{~min}$ zentrifugiert, in frischem Medium $\left(37^{\circ} \mathrm{C}\right)$ resuspendiert und auf eine Konfluenz von $25 \%$ bis $30 \%$ eingestellt.

Zur dauerhaften Lagerung wurden die Zelllinien in flüssigem Stickstoff eingefroren. Dazu wurden die Zellen nach der Zentrifugation auf eine Konzentration von $4 \times 10^{6}$ Zellen in Einfriermedium (70\% Kulturmedium, 20\% FCS, 10\% DMSO) eingestellt und in Kryogefäße (Fa. Sarstedt) überführt. Um die Bildung zellstrukturschädigender Kristalle während des Einfrierens zu verhindern, wurden die Zellen in Isopropanol für je $1^{\circ} \mathrm{C} / \mathrm{min}$ (Cryo-Einfiergerät, Fa. Nalgene) bis auf $-80^{\circ} \mathrm{C}$ abgekühlt. Dann wurden die Kryogefäße in flüssigen Stickstoff überführt. 
Zur Analyse der Zellen auf PrP ${ }^{\text {res }}$ wurden die Zellen in PBS gewaschen und in Pellets zu je 4 bis 8 Millionen Zellen bei $-80^{\circ} \mathrm{C}$ gelagert.

\subsubsection{Infektion von neuronalen Zellen mit TSE}

Die Infektion der Zelllinien mit TSE-infektiösen Agenzien wurde im 96 well Zellkulturplatten (Fa. Sarstedt) durchgeführt. Die Zellen wurden auf eine Konzentration von 7000 SN56-Zellen bzw. 40.000 SH-SY5Y-Zellen pro well in einem Volumen von $100 \mu \mathrm{l}$ eingestellt und für 24 Stunden kultiviert. Dann wurde das Medium durch je $75 \mu \mathrm{l}$ der Infektionsagenzien in Kulturmedium (+1\% Gentamycin) ersetzt und nach $4 \mathrm{~h}$ Inkubation mit 1x Volumen Kulturmedium versetzt. Nach $16 \mathrm{~h}$ wurden die Zellen mit PBS gewaschen und wie unter 2.6.1 beschrieben kultiviert. Nach 7, 21 und 35 Tagen wurden je 2/3 der Zellen auf eine 24 well Zellkulturplatte (Fa. Sarstedt) überführt und kultiviert. Bei Erreichen von 90\% Konfluenz wurden die Zellen auf eine 6 well Zellkulturplatte (Fa. Sarstedt) und von dieser auf eine Zellkulturflasche (Fa. Sarstedt) überführt und kultiviert. Bei $90 \%$ Konfluenz wurden die Zellen trypsiniert, mit PBS gewaschen und als Pellets bei $-80^{\circ} \mathrm{C}$ gelagert.

Nach 49 Tagen wurden die Zellen ebenfalls auf Zellkulturflaschen expandiert. Bei 90\% Konfluenz wurden anschließend nach jeder Passage 2/3 der Zellen als Zellpellet bei $-80^{\circ} \mathrm{C}$ gelagert und $1 / 3$ der Zellen wurden kultiviert. Zehn Wochen nach Infektion wurden je 3 Mal $4 \times 10^{6}$ Zellen in flüssigem Stickstoff eingefroren. 


\section{Ergebnisse}

\section{1. Übertragung von BSE auf Javaneraffen (Macaca fascicularis)}

Im Rahmen der EU-Studie QLK1-CT-2002-01096 soll das Risiko ermittelt werden, durch Aufnahme von BSE-kontaminierter Nahrungsmitteln an der varianten Creutzfeldt-JakobKrankheit (vCJD) zu erkranken. Als Tiermodel für den Menschen wurden Javaneraffen (Macaca fascicularis) ausgewählt. Diese gelten als das nicht humane Tiermodel, das dem Menschen in Stoffwechsel (LASMÉZAS et al., 1996) und genetischem Hintergrund (SCHÄTZL et al., 1995) am ähnlichsten ist und dessen Einsatz ethisch vertretbar ist. Die Übertragung von Scrapie und BSE auf Javaneraffen ist bereits erfolgreich durchgeführt worden (GIBBS et al., 1972, LASMÉZAs et al., 1996).

Für die Übertragungsstudie wurden soziale Gruppen von je sechs Tieren mit einem Gemisch aus Hirnhomogenaten 11 BSE-erkrankter Rinder infiziert. Die Infektion erfolgte mit absteigenden Konzentrationen des BSE-Materials, um die minimale infektiöse Dosis zu ermitteln. Als Negativkontrolle wurde Hirnhomogenat von nicht infizierten Rindern eingesetzt. Die Tiere wurden oral infiziert, um die Infektionsroute von vCJD darzustellen. Um das Krankheitsbild des makakenadaptiertem BSE zunächst zu definieren, wurde je sechs Gruppen mit absteigenden Konzentrationen an Hirnhomogenat in den Cortex der rechten Hirnhälfte injiziert (intracerebrale (i.c.) Infektion) (Tab. 3.1). Die Studie begann im Jahr 2001 mit der Injektion des Hirnhomogenats.

Tabelle 3.1: Übertragung von BSE auf nicht humane Primaten (EU-Studie QLK1-CT-2002-01096)

\begin{tabular}{ccc}
\hline Gruppe & Infektionsweg & Dosis \\
\hline A & i.c. & $50 \mathrm{mg}$ \\
B & i.c. & $5 \mathrm{mg}$ \\
C & i.c. & $0,5 \mathrm{mg}$ \\
D & i.c. & $0,05 \mathrm{mg}$ \\
E & i.c. & $0,005 \mathrm{mg}$ \\
F & i.c. & mock \\
\hline G & oral & $16 \mathrm{~g}$ \\
H & oral & $5 \mathrm{~g}$ \\
I & oral & $0,5 \mathrm{~g}$ \\
J & oral & $0,05 \mathrm{~g}$ \\
K & oral & $0,005 \mathrm{~g}$ \\
L & oral & mock \\
\hline
\end{tabular}


Die vorliegende Arbeit befasst sich mit der Analyse der Prionenerkrankung in i.c. infizierten, nicht humanen Primaten und wurde an den Tieren der Gruppe A durchgeführt. Das für das PrP kodierende Gen prnp dieser Tiere wurde sequenziert. Alle Tiere wiesen eine identische Sequenz auf (Datenbank: gi|52782268|dbj|AB125193.1|[52782268]) und waren homozygot für Methionin an der Aminosäureposition 129 (129MM).

931 bis 1340 Tage (Mittelwert \pm SD: $1198 \pm 213$ ) nach Infektion zeigten die Tiere erste Symptome einer Prionenerkrankung (Abb. 3.1). Es wurden Ataxien der Gliedmaßen und des Körpers, erhöhte Schreckhaftigkeit und eine fortschreitende Demenz beobachtet. Nach weiteren 17 bis 143 (Mittelwert: $92 \pm 41$ ) Tagen war die Krankheit so weit fortgeschritten, dass die Tiere euthanasiert wurden. Sowohl die Inkubationszeit als auch die Dauer der klinischen Phase der Tiere waren stark unterschiedlich. Auffälligerweise erkrankten vier Tiere (A1, A3, A4 und A6) innerhalb von 94 Tagen, die zwei weiteren Tiere (A2 und A5) jedoch erst 315 bzw. 373 Tage später. Anhand der Inkubationszeiten können die Tiere in eine Gruppe mit kurzer Inkubationszeit von $962( \pm 43)$ Tage und eine Gruppe mit langer Inkubationszeit von $1369( \pm 41)$ Tage eingeteilt werden.

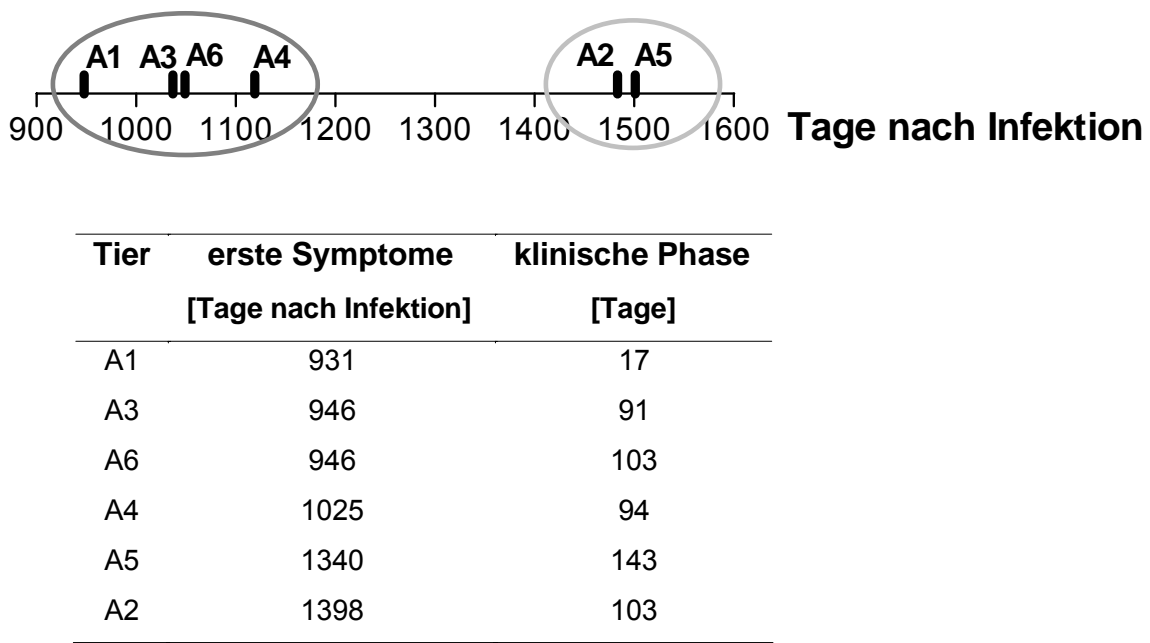

Abbildung 3.1: Inkubationszeit der Prionenerkrankung bei BSE infizierten Javaneraffen

Der Zeitpunkt der ersten Symptome einer Prionenerkrankung wurde für jedes Tier auf einer Zeitlinie dargestellt. Die Tiere wurden anhand der Inkubationszeit in zwei Gruppen eingeteilt, eine mit einer gemittelten Inkubationszeit von $962( \pm 43)$ Tagen und eine mit $1369( \pm 41)$ Tagen. 


\subsection{Nachweis von Prionenerkrankungen}

Der biochemische Nachweis von Prionenerkrankungen ist an das $\mathrm{PrP}^{\text {res }}$ als Markermolekül gebunden, da dieses konstant in Verbindung mit der Infektiosität der Prionenerkrankungen steht. Diese gehen mit einer Konformationsänderung eines wirtskodierten Proteins, des zellulären $\operatorname{PrP}\left(\operatorname{PrP}^{C}\right)$ einher, bei der das $\operatorname{PrP}^{C}$ einen $\mathrm{PK}$ resistenten Kern ausbildet (PrP ${ }^{\text {res }}$ ) (CAUGHEY et al., 1991, PAN et al., 1993). Nach einer PK-Behandlung wird in infiziertem Gewebe das $\mathrm{PrP}^{\text {res }}$, in nicht infiziertem Gewebe hingegen kein PrP detektiert (BOLTON et al., 1982). PK-behandelte Proteinextrakte werden im Western Blot oder im ELISA eingesetzt und auf ihren $\mathrm{PrP}^{\text {res }}$-Gehalt überprüft, um eine Prionenerkrankung nachzuweisen. Diese Methoden wurden in der vorliegenden Arbeit etabliert bzw. für den Nachweis des simianen $\mathrm{PrP}^{\text {res }}$ adaptiert.

\subsubsection{Charakterisierung monoklonaler anti-Prion Antikörper}

Um die monoklonalen anti-Prion Antikörper 3B5, 4F2, 8G8, $11 \mathrm{C6}$ und 12F10 (KRASEMANN et al., 1996) näher zu charakterisieren, wurde ein Epitopmapping in Form eines Peptid-ELISA durchgeführt. Als Antigen dienten 13 Aminosäuren lange Peptide, die das humane PrP um 11 Aminosäuren überlappend abdecken. Die Signale im ELISA wurden den Peptidsequenzen zugeordnet und mit der Sequenz des humanen PrP verglichen. Abbildung 3.2 zeigt eine schematische Darstellung des humanen PrP und die Position der Epitope.

Die Antikörper 3B5 und 4F2 zeigten Signale auf den Peptiden, die das Octarepeat des PrP abdecken (Aminosäuren 54 bis 86 des humanen PrP). Zusätzlich wies der 4F2 Antikörper auch ein Peptid mit der Sequenz des murinen Octarepeats nach. Der 8G8 Antikörper erzeugte sowohl ein Signal auf den Peptiden des Octarepeats als auch ein schwaches Signal auf einem Peptid, das die Aminosäuren 98 bis 111 abdeckt. Der 12F10 Antikörper erzeugte ein Signal auf Peptiden, die den Aminosäuren 141 bis 154 des humanen PrP entsprechen. Der 11C6 Antikörper wies keines der Peptide, jedoch humanes und murines rekombinantes PrP nach. 


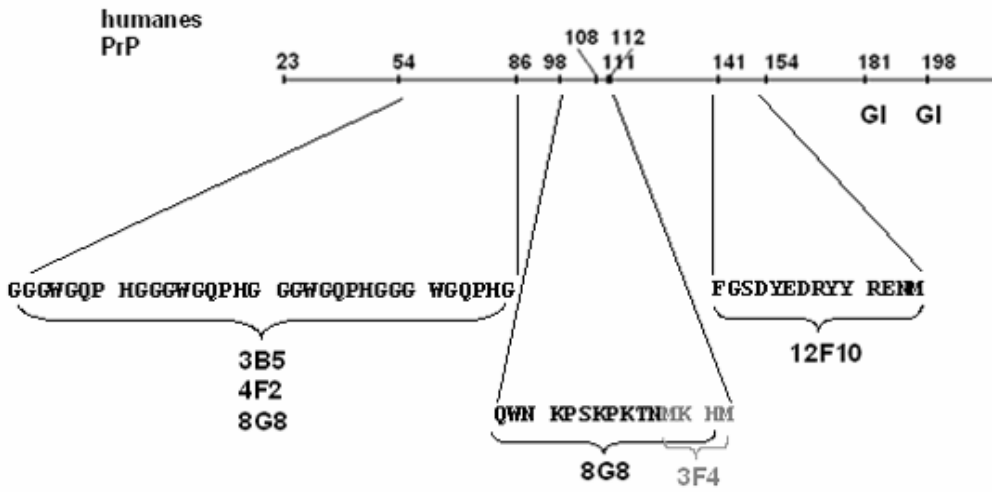

Abbildung 3.2: Schematische Darstellung der Epitope von fünf monoklonalen anti-Prion Antikörpern

Die Epitope der monoklonalen anti-Prion Antikörper wurden in einem Peptid-ELISA bestimmt. Es wurden Peptide von 13 Aminosäuren Länge eingesetzt, die das gesamte PrP abdecken und um je 11 Aminosäuren überlappen. Dargestellt sind die Sequenzabschnitte des PrP, auf deren korrespondierenden Peptiden die jeweiligen Antikörper im ELISA ein Signal erzeugten. Das Epitop des Antikörpers 3F4 wurde von BOLTON et al. (1991) beschrieben.

\subsubsection{Adaption der Nachweismethoden für Javaneraffen}

Zunächst wurde das PrP $^{\text {res }}$ des Inokulums im Western Blot dargestellt. Das 20\%ige Homogenat aus dem Hirn von 11 BSE-erkrankten Rindern wurde mit PK behandelt (2.4.2), elektrophoretisch getrennt (2.4.4) und geblottet (2.4.5). In kommerziellen BSE-Tests werden Antikörpergemische zum Nachweis von BSE genutzt (BioRad). Daher wurde hier für den Nachweis ein Gemisch der monoklonalen anti-Prion Antikörper 11C6 und 12F10 (KRASEMANN et al., 1996, Tab. 2.1) eingesetzt (Abb. 3.3). In der unbehandelten Probe wurden 3 Banden mit einem korrespondierenden Molekulargewicht von $28 \mathrm{kDa}$ bis $38 \mathrm{kDa}$ nachgewiesen. Nach PK-Behandlung wurden Banden von geringerem Molekulargewicht (16 kDa bis 26 kDa) dargestellt. Somit wurde im Inokulum der Infektionsversuche $\operatorname{PrP}^{\text {res }}$ als Markermolekül für die BSE-Infektiosität erfolgreich nachgewiesen.

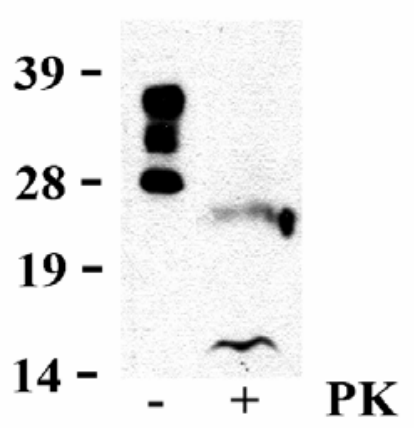

Abbildung 3.3: PrP $^{\text {res }}$ im EU-Referenzmaterial der Infektionsstudie

Hirnhomogenat (20\% in Saccharose) von 11 BSE infizierten Rinder wurde PK behandelt $(+)$ und unbehandelt (-) im Western Blot eingesetzt. Pro Spur wurden $60 \mu \mathrm{g}$ Gesamtprotein bzw. $240 \mu \mathrm{g}$ Gesamtprotein äquivalent vor PK-Behandlung eingesetzt. PrP bzw. PrP ${ }^{\text {res }}$ wurde mit einem Gemisch der monoklonalen anti-Prion Antikörper $11 \mathrm{C} 6$ und $12 \mathrm{~F} 10$ nachgewiesen. 
Die Protokolle für den Nachweis von $\mathrm{PrP}^{\text {res }}$ können nur bedingt auf andere Spezies übertragen werden (W. Schulz-Schäffer, persönliche Mitteilung). Daher wurde das bestehende Nachweisprotokoll für bovines $\mathrm{PrP}^{\text {res }}$ an den Nachweis von simianem $\mathrm{PrP}^{\text {res }}$ angepasst. Zunächst wurde die PK-Behandlung des simianen PrP eingestellt. Dazu wurde die Protein- und PK-Konzentration entsprechend eines publizierten Protokolls zum Nachweis humaner Prionenerkrankungen ausgewählt (COLLINGE et al., 1996). Es wurden $15 \mu \mathrm{g} / \mu \mathrm{l}$ Gesamtprotein eines Proteinextraktes mit $50 \mu \mathrm{g} / \mathrm{ml} \mathrm{PK}$ (Fa. Sigma-Aldrich) behandelt und im Western Blot eingesetzt. Das PrP wurde mit einem Gemisch der Antikörper 12F10 und 3B5 detektiert. Nur im Proteinextrakt des BSE-infizierten Tieres konnte ein Signal nachgewiesen werden. Die Banden entsprachen im Molekulargewicht denen des $\operatorname{PrP}^{\mathrm{C}}$ (Abb. 3.4 A), für $\operatorname{PrP}^{\text {res }}$ ist aber ein geringeres Molekulargewicht beschrieben (BOLTON et al., 1982). Daher wurde das gleiche Protokoll mit PKs verschiedener Anbieter (Tab. 2.2) durchgeführt. Im Western Blot wurden nach Behandlung mit PKs der Firmen Boehringer Mannheim, Merck und Serva die erwarteten PrP $^{\text {res }}$ Banden nachgewiesen (Abb. 3.4 B). Diese wurden am deutlichsten nach Behandlung mit der Proteinase $\mathrm{K}$ von Boehringer Mannheim dargstellt. Daher wurde diese PK in allen weiteren Experimenten eingesetzt.

A

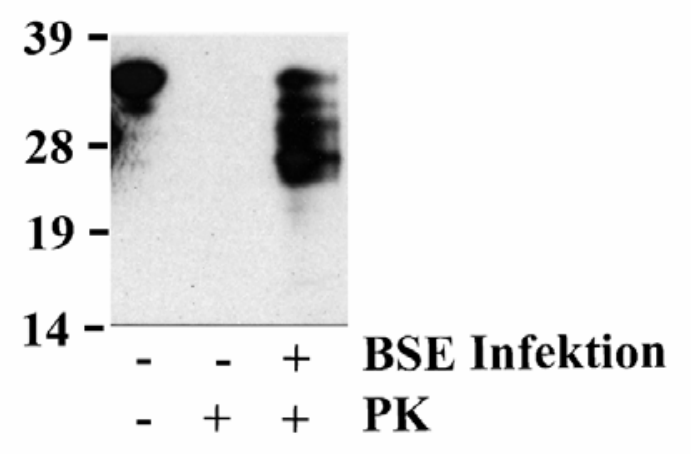

B

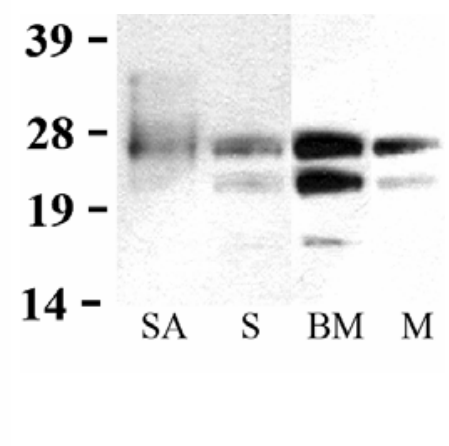

\section{Abbildung 3.4: Nachweis von simianem PrP $^{\text {res }}$ in von Abhängigkeit von der PK}

Proteinextrakte von BSE-infizierten Javaneraffen wurden elektrophoretisch getrennt, geblottet und mit einem Gemisch der monoklonalen anti-Prion Antikörper $12 \mathrm{~F} 10$ und 3B5 nachgewiesen. A: Proteinextrakte eines BSE infizierten und eines nicht infizierten Javaneraffen wurden mit PK behandelt und im Western Blot eingesetzt (45 $\mu \mathrm{g}$ Gesamtprotein äquivalent vor PK-Verdau pro Spur). Als Kontrolle diente nicht PK-behandeltes Proteinextrakt (20 $\mu \mathrm{g}$ pro Spur). B: Proteinextrakt aus Hirngewebe eines BSE infizierten Javaneraffen wurde mit PK verschiedener Anbieter (Sigma-Aldrich (SA), Serva (S), Boehringer Mannheim (BM) und Merck (M)) behandelt. Je $45 \mu \mathrm{g}$ Gesamtprotein (Äquivalentmenge vor PK-Verdau) wurden pro Spur für den Western Blot eingesetzt. 
Nachdem das simiane $\mathrm{PrP}^{\text {res }}$ mit einem Antikörpergemisch nachgewiesen werden konnte (Abb. 3.4), wurde die Sensitivität der zur Verfügung stehenden Antikörper zum Nachweis von simianem PrP $^{\text {res }}$ untersucht. Dazu wurde PK-behandeltes Proteinextrakt eines BSE-infizierten Javaneraffen auf einem präparativen LDS-Gel getrennt und anschließend geblottet. Dieses wurde in Streifen geschnitten und mit den Antikörpern 3B5, 4F2, 8G8, $11 \mathrm{C} 6$ und 12F10 (Ascitis ${ }^{1}$, Tab. 2.1) inkubiert. Der 11C6 Antikörper wies drei Banden von 16 bis 27 kDa und der 12F10 Antikörper eine schwachen Bande von 27 kDa nach (Abb. 3.5). Die Antikörper 3B5, 4F2 und 8G8 konnten kein $\mathrm{PrP}^{\text {res }}$ detektieren. Dies korrespondiert mit den Ergebnissen des Epitopmappings, da diese Antikörper im Octarepeat des PrP binden und dieses durch den PK-Verdau abgespalten wird. Für die weiteren Untersuchungen wurde, falls nicht anders angegeben, der Antikörper 11C6 eingesetzt.

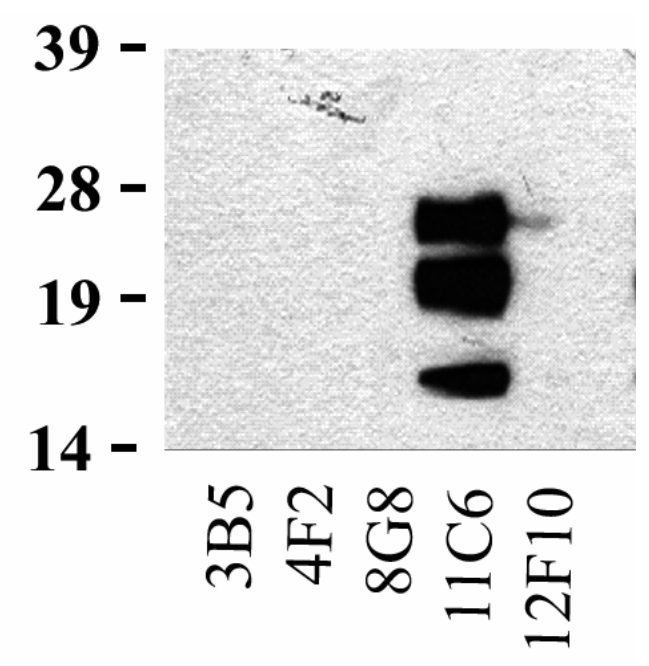

\section{Abbildung 3.5: Nachweis von PrP ${ }^{\text {res }}$ mit verschiedenen Primärantikörpern}

Proteinextrakt aus Hirnhomogenat $(540 \mu \mathrm{g})$ eines BSE infizierten Javaneraffen (Tier A2) wurde mit PK behandelt, elektrophoretisch getrennt, geblottet und mit verschiedenen anti-PrP Antikörpern inkubiert. Der Nachweis des PrP ${ }^{\text {res }}$ erfolgte jeweils pro Streifen mit den monoklonalen anti-Prion Antikörpern 3B5, 4F2, 8G8, $11 \mathrm{C} 6$ und $12 \mathrm{~F} 10$.

\subsubsection{Nachweis von PrP $^{\text {res }}$ im Hirn BSE-infizierter Javaneraffen}

Unter denaturierenden Bedingungen im SDS-PAGE wird das PrP in Form von drei Banden dargestellt (BOLTON et al., 1982). Diese Banden wurden als di-, mono- und unglykosylierte Formen des PrP beschrieben, da nach einer Deglykosylierung der Proteinextrakte im Western Blot nur eine Bande nachgewiesen werden kann. Deren Molekulargewicht korreliert mit dem der unglykosylierten Form des PrP (HARAGUCHI

\footnotetext{
${ }^{1}$ freundlicherweise zur Verfügung gestellt von J. Grassi, CEA
} 
et al., 1989). Diese Methode wird daher eingesetzt, um den Nachweis von $\operatorname{PrP}^{\text {res }}$ im Western Blot zu verifzieren. Daher sollten die beobachteten Banden als Glykoformen des $\operatorname{PrP}^{\text {res }}$ bestätigen werden. Dazu wurde Proteinextrakt aus dem Hirn eines infizierten Javaneraffen nach PK-Behandlung (2.4.2) zusätzlich mit PNGase F deglykosyliert (2.4.3) und vergleichend im Western Blot untersucht (2.4.4 und 2.4.5). In unbehandeltem Proteinextrakt wurden drei Banden korrespondierend mit $26 \mathrm{kDa}$, $33 \mathrm{kDa}$ und $36 \mathrm{kDa}$ Molekulargewicht detektiert. In PK-behandeltem Extrakt wurden drei Banden von geringerem Molekulargewicht (16 kDa, 24 kDa und $27 \mathrm{kDa}$ ) dargestellt. Nach Deglykosylierung mit PNGase F wurde nur eine Bande von 16 kDa Größe nachgewiesen (Abb. 3.6). Somit wurde mit Hilfe eines anti-Prion Antikörpers ein Protein mit drei Glykoformen nachgewiesen. Dies entsprach dem in der Literatur (BOLTON et al., 1982; HARAGUCHI et al., 1989) beschriebenen Nachweis von PrPres und zeigte, dass im Hirn der BSE-infizierten Javaneraffen $\operatorname{PrP}^{\text {res }}$ gebildet wurde.

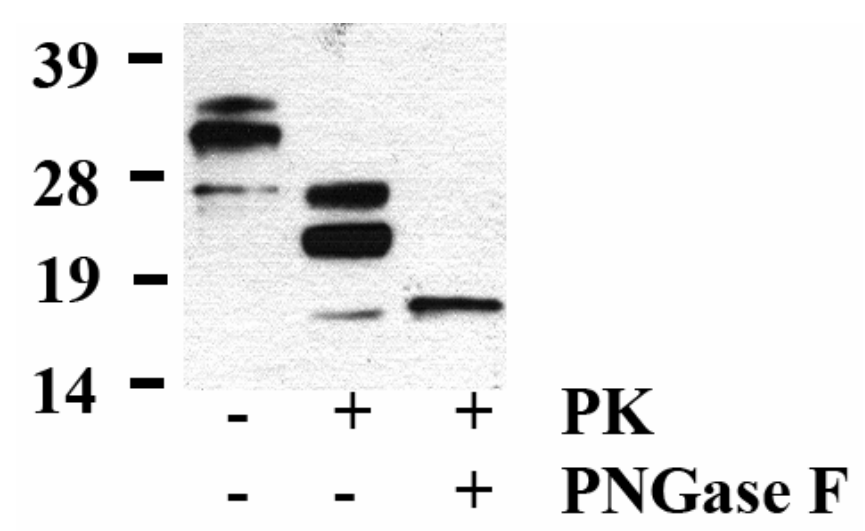

\section{Abbildung 3.6: Deglykosylierung des PrP $^{\text {res }}$ mit PNGase F}

Proteinextrakt eines BSE-infizierten Javaneraffen wurde nach einer PK-Behandlung $(+)$ mit PNGase $F$ deglykosyliert $(+)(37 \mu \mathrm{g}$ pro spur) und unbehandelt $(-)(45 \mu \mathrm{g}$ pro Spur) im Western Blot eingesetzt. Als Kontrolle wurden $20 \mu \mathrm{g}$ nicht PK und nicht PNGase F behandeltes Proteinextrakt aufgetragen. Das PrP wurde mit dem 11C6 Antikörper nachgewiesen.

Um die Ergebnisse des Western Blots mit einer alternativen Nachweismethode verifizieren zu können, wurde ein Sandwich enzyme linked immunosorbent assay (Sandwich-ELISA) etabliert. Dieser unterscheidet sich von einem ELISA durch einen Fänger-Antikörper, der spezifisch das Antigen bindet. Dieses wird dann über einen zweiten Antikörper nachgewiesen (KATO et al., 1977). Da das Antigen in einem Sandwich-ELISA über zwei Antikörper nachgewiesen wird, ist der Nachweis spezifischer als in einem ELISA. Eine erhöhte Sensitivität kann erreicht werden, 
indem der Nachweis-Antikörper mit Biotin markiert wird. Da pro Antikörper mehrere Biotin-Moleküle gebunden werden, wird das Signal des Sekundärantikörpers multipliziert.

Proteinextrakte eines mit BSE infizierten und eines nicht infizierten Javaneraffen wurden mit PK behandelt (2.4.2) und im Sandwich-ELISA eingesetzt (2.4.6). Als Fänger-Antikörper diente der 12F10 Antikörper, als Nachweis-Antikörper der Biotingekoppelte 11C6 Antikörper (2.3.2). Der Sandwich-ELISA wurde exemplarisch mit Proteinextrakten von drei infizierten Tieren und einem nicht infizierten Tier durchgeführt. Um die Signale aus PK-behandelten Proteinextrakten infizierter und nicht infizierter Tieren zu unterscheiden, wurde ein Schwellenwert definiert. In Proben, deren OD oberhalb dieses Schwellenwertes lag, war $\operatorname{PrP}^{\text {res }}$ enthalten. Der Schwellenwert wurde aus dem Mittelwert der OD des nicht infizierten Tieres zuzüglich der Standardabweichung ermittelt. OD-Werte, die unterhalb dieses Schwellenwertes lagen, wurden durch unspezifische Reaktionen hervorgerufen, da in dem Proteinextrakt des nicht infizierten Tiers kein $\mathrm{PrP}^{\text {res }}$ enthalten war. Dieses wies eine OD von 0,274 \pm 0,177 auf, der daraus resultierende Schwellenwert lag bei einer OD von 0,45. Die Proteinextrakte der BSE-infizierten Javaneraffen wiesen OD-Mittelwerte von 0,8 bis 1,0 auf. Somit wurde auch im Sandwich-ELISA PrPres in Proteinextrakten der infizierten Tiere nachgewiesen.

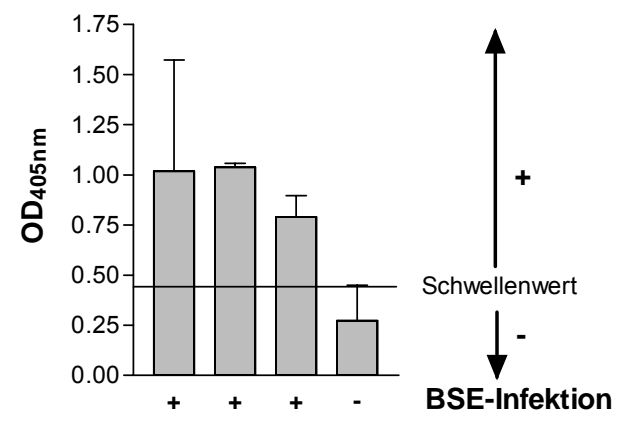

\section{Abbildung 3.7: Nachweis von PrP ${ }^{\text {res }}$ im Sandwich ELISA}

Proteinextrakte aus Hirnhomogenat eines BSE infizierten und eines nicht infizierten Javaneraffen wurde mit PK-behandelt und im Sandwich ELISA eingesetzt (180 $\mu \mathrm{g}$ Gesamtproteinmenge äquivalent vor PKVerdau).

Um die Erkrankung der Javaneraffen eindeutig als Prionenerkrankung zu bestätigen, wurden Hirnschnitte der BSE-infizierten Javaneraffen immunhistologisch untersucht. Der immunhistologische Nachweis von schwammartigen Strukturen und PrPAblagerungen im Hirn infizierter Individuen gilt nach wie vor als der standardisierte Nachweis von Prionenerkrankungen (WATTS et al., 2006). Die Ergebnisse der 
immunhistologischen Untersuchungen wurden freundlicherweise von W. SchulzSchäffer (Universitätsklinik Göttingen) zur Verfügung gestellt.

Dorso-ventrale Schnitte ( 5 bis $7 \mu \mathrm{m}$ ) der linken Hemisphäre der BSE infizierten Primaten wurden mit Haematoxylin/Eosin (H/E) angefärbt. Dadurch wurden Aussparungen im Hirngewebe sichtbar gemacht. Durch Färbung des folgenden dorsalen Schnittes mit dem 12F10 Antikörper konnten PrP Ablagerungen nachgewiesen werden. In den Hirnschnitten aller sechs Tiere wurden schwammartige Aussparungen (Spongiformität), $\operatorname{PrP}$ Ablagerungen und ein Nervenzellverlust nachgewiesen. Der Nervenzellverlust wurde durch eine intraneuronale Vakuolisierung hervorgerufen (Abb. 3.8 A, Pfeil). In diesen Bereichen wurde ein übermäßiges Wachstum der Gliazellen (Gliose) festgestellt. Es wurden zwei verschiedene Profile der PrP-Ablagerungen beobachtet. Bei den Tieren A2 und A5 waren komplexe granuläre PrP-Ablagerungen im Bereich untergehender Neuronen prominent ausgeprägt. Diese waren von Spongiformität umgeben (Abb. 3.8 B, Pfeil). Die Tiere $A 1, A 3, A 4$ und $A 6$ zeigten hauptsächlich fein-granuläre Ablagerungen, lediglich im Cingulum überwog die komplex-granuläre Form. Anhand dieser unterschiedlichen Profile konnten die Tiere in zwei Gruppen eingeteilt werden, die mit der Inkubationszeit korrelieren (3.1).

Um PrPres in den Hirnschnitten nachzuweisen, wurde die PET-Blot Methode angewandt (SCHULZ-SCHÄFFER et al., 2000). Ein zentral gelegender Hirnschnitt (Tier A3) der linken Hemisphäre (dorso-ventral geschnitten) wurde auf einer Nitrozellulosemembran fixiert und auf dieser mit Proteinase $\mathrm{K}$ behandelt. Das $\operatorname{PrP}^{\text {res }}$ wurde mit dem 12F10 Antikörper nachgewiesen (Abb. 3.8 C). Die weiße Materie des Hirns wies eine schwache granuläre, die tieferen Gewebeschichten des Cortexes dagegen eine starke perikuläre Färbung auf. Die Färbung war am Ammonshorn und im Cingulum am stärksten ausgeprägt.

Die immunhistologischen und neuropathologischen Untersuchungen bestätigen den biochemischen Nachweis von PrP ${ }^{\text {res }}$ im Hirn der BSE-infzierten Javaneraffen. Die Tiere haben demnach aufgrund der BSE-Infektion eine Prionenerkrankung ausgebildet. Allerdings wurden zwei verschiedene Ausprägungen dieser Erkrankung beobachtet. Die erste korreliert mit einer kurzen Inkubationszeit und fein granulären PrP-Ablagerungen im Hirn. Die zweite korreliert mit langen Inkubationszeiten und komplexen PrP-Ablagerungen. Diese Ausprägungen stellen zwei unterschiedliche Typen der simianen Prionenerkrankung dar. 

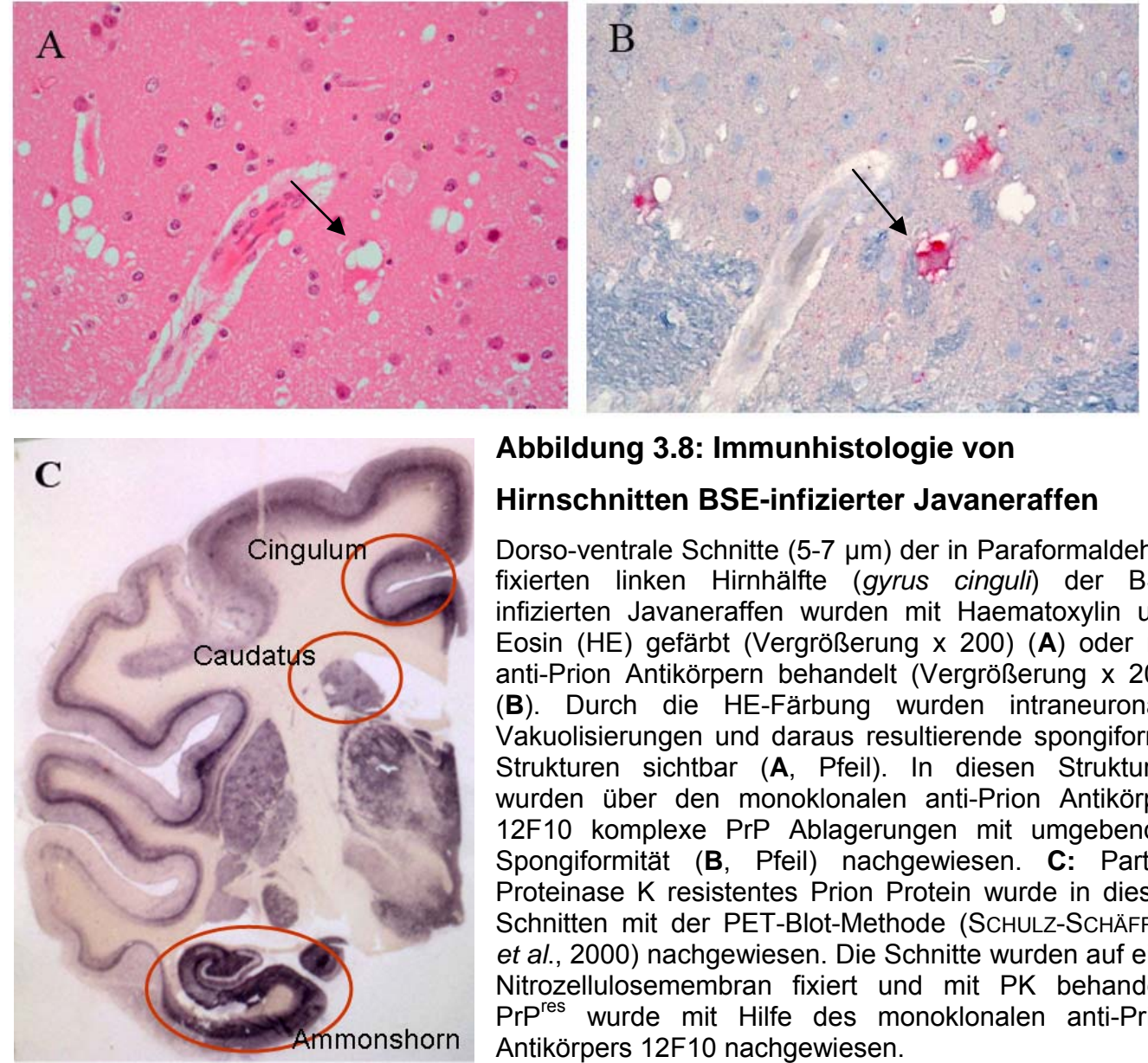

Abbildung 3.8: Immunhistologie von

Hirnschnitten BSE-infizierter Javaneraffen

Dorso-ventrale Schnitte (5-7 $\mu \mathrm{m})$ der in Paraformaldehyd fixierten linken Hirnhälfte (gyrus cinguli) der BSE infizierten Javaneraffen wurden mit Haematoxylin und Eosin (HE) gefärbt (Vergrößerung x 200) (A) oder mit anti-Prion Antikörpern behandelt (Vergrößerung x 200) (B). Durch die HE-Färbung wurden intraneuronale Vakuolisierungen und daraus resultierende spongiforme Strukturen sichtbar (A, Pfeil). In diesen Strukturen wurden über den monoklonalen anti-Prion Antikörper 12F10 komplexe PrP Ablagerungen mit umgebender Spongiformität (B, Pfeil) nachgewiesen. C: Partiell Proteinase $\mathrm{K}$ resistentes Prion Protein wurde in diesen Schnitten mit der PET-Blot-Methode (SCHULZ-SCHÄFFER et al., 2000) nachgewiesen. Die Schnitte wurden auf eine Nitrozellulosemembran fixiert und mit PK behandelt. $\mathrm{PrP}^{\mathrm{res}}$ wurde mit Hilfe des monoklonalen anti-Prion Antikörpers $12 \mathrm{~F} 10$ nachgewiesen.

\subsection{Charakterisierung der Prionenerkrankung in Javaneraffen}

Im Menschen treten verschiedene Typen der Creutzfeldt-Jakob Krankheit (CJD) auf. Diese unterscheiden sich in der Inkubationszeit, dem Alter der Patienten und dem Infektionsweg. Die Krankheit kann spontan auftreten (sporadic CJD, sCJD), durch ärztliche Behandlung ausgelöst (iatrogenic CJD, iCJD) oder über Nahrungsaufnahme von BSE infiziertem Material (new variant CJD, vCJD) übertragen werden. Die Unterscheidung der Typen wird biochemisch über verschiedene Marker geführt.

Über das Migrationsverhalten in der PAGE werden zwei Typen von CJD unterschieden. Sie unterscheiden sich in der Größe des PK-resistenten Kerns des PrP res, da während der PK-Behandlung die N-terminalen 81 oder 96 Aminosäuren abgespalten werden. Im Western Blot weist der SCJD Typ1 (PrPres: Aminosäuren 82 bis 231) ein um 2 kDa größeres Molekulargewicht als der sCJD Typ2 (PrPres: Aminosäuren 97 bis 231) auf (PARCHI et al., 1996, PARCHI et al., 2000). Während sCJD Patienten entweder ein Typ1 
oder ein Typ2 Migrationsverhalten aufweisen, wird in vCJD und iCJD immer ein Migrationsverhalten des Typ2 nachgewiesen (COLLINGE et al., 1996).

Um sCJD Typ2, vCJD und iCJD im Western Blot zu unterscheiden, werden die relativen Signalstärken der di-, mono- und unglykosylierten Banden untereinander verglichen (Glykosylierungsmuster). Die diglykosylierte Bande ist im Verhältnis zu den anderen Glykoformen bei vCJD über- und bei sCJD und iCJD unterrepräsentiert. Bei iCJD ist die monoglykosylierte Bande am stärksten ausgeprägt (COLLINGE et al., 1996). Das Migrationsverhalten und die Glykosylierungsmuster sind schematisch in Abbildung 3.9 dargestellt.

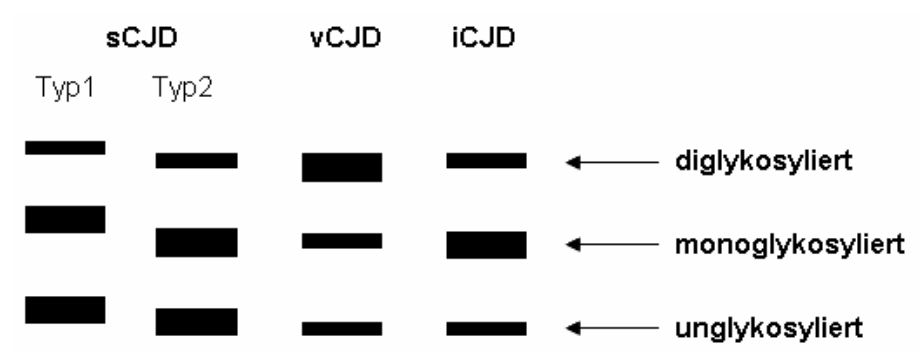

Abbildung 3.9: Schematische Darstellung von Migrationsverhalten und Glykosylierungsmuster verschiedener CJD Typen (nach PARCHI et al., 1996 und 2000b)

Dargestellt sind die drei Glykoformen des $\operatorname{PrP}^{\text {res }}$ (di-, mono- und unglykosyliert) wie sie sich in einem Western Blot darstellen. Anhand des Migrationsverhaltens werden zwei Typen für SCJD unterschieden. Die Prionenerkrankungen vCJD und iCJD werden von SCJD Typ2 über eine unterschiedlich starke Darstellung der einzelnen Glykoformen unterschieden. Die Glykosylierungsmuster wurden mit dem 3F4 Antikörper dargestellt

\subsubsection{Migrationsverhalten und Glykosylierungsmuster des simianen $\operatorname{PrP}^{\text {res }}$}

Die simiane Prionenerkrankung sollte zunächst allgemein klassifiziert werden. Dazu wurde untersucht, ob sie einem der bekannten humanen CJD-Typen entspricht. Dazu wurde das simiane $\mathrm{PrP}^{\text {res }}$ aller Tiere mit dem $\mathrm{PrP}^{\text {res }}$ verschiedener CJD-Typen (vCJD, sCJD Typ 1 und Typ 2) ${ }^{2}$ verglichen. Für den Nachweis wurden die monoklonalen anti-Prion Antikörper 11C6 und der 3F4 im Vergleich eingesetzt. In der Literatur wurde der 3F4 Antikörper genutzt, um sCJD Typ1 und Typ2 anhand ihres Migrationsverhaltens bzw. sCJD und vCJD anhand ihres Glykosylierungsmusters zu unterscheiden (COLLINGE et al. 1996; PARCHI et al. 1996).

\footnotetext{
2 Das Referenzmaterial wurde immunhistochemisch klassifiziert und freundlicherweise zur Verfügung gestellt (sCJD: W. Schulz-Schäffer, Universitätsklinik Göttingen; vCJD: H.A. Kretschmar, Zentrum für Neuropathologie und Prionforschung, München).
} 
Das $\mathrm{PrP}^{\text {res }}$ der CJD-Typen wurden mit dem 3F4 Antikörper wie von PARCHI et al. (1996) beschrieben dargestellt. Das $\mathrm{PrP}^{\text {res }}$ aller Tiere zeigte das gleiche Migrationsverhalten, welches dem CJD-Typ2 entsprach. Das Glykosylierungsmuster des simianen PrP $^{\text {res }}$ aller Tiere entsprach dem des vCJD (COLLINGE et al., 1996) (Abb. 3.10). Dementsprechend waren die Javaneraffen an der simianen Form von vCJD erkrankt.

Der 11C6 Antikörper stellte das Migrationsverhalten des $\mathrm{PrP}^{\mathrm{res}}$ der verschiedenen CJD-Typen ebenfalls wie beschrieben dar (PARCHI et al., 1996). Allerdings zeigte er gegenüber dem 3F4 Antikörper eine veränderte Glykoformspezifität. Hier wurde die monoglykosylierte Bande in allen CJD Typen prominent dargestellt. Trotzdem entspricht das simiane $\mathrm{PrP}^{\text {res }}$ im Glykosylierungsmuster auch hier dem des vCJD (Abb. 3.10). Jedoch kann die für das $\operatorname{PrP}^{\text {res }}$ des vCJD beschriebene Prominenz der diglykosylierten Bande mit dem 11C6 Antikörper nicht bestätigt werden.

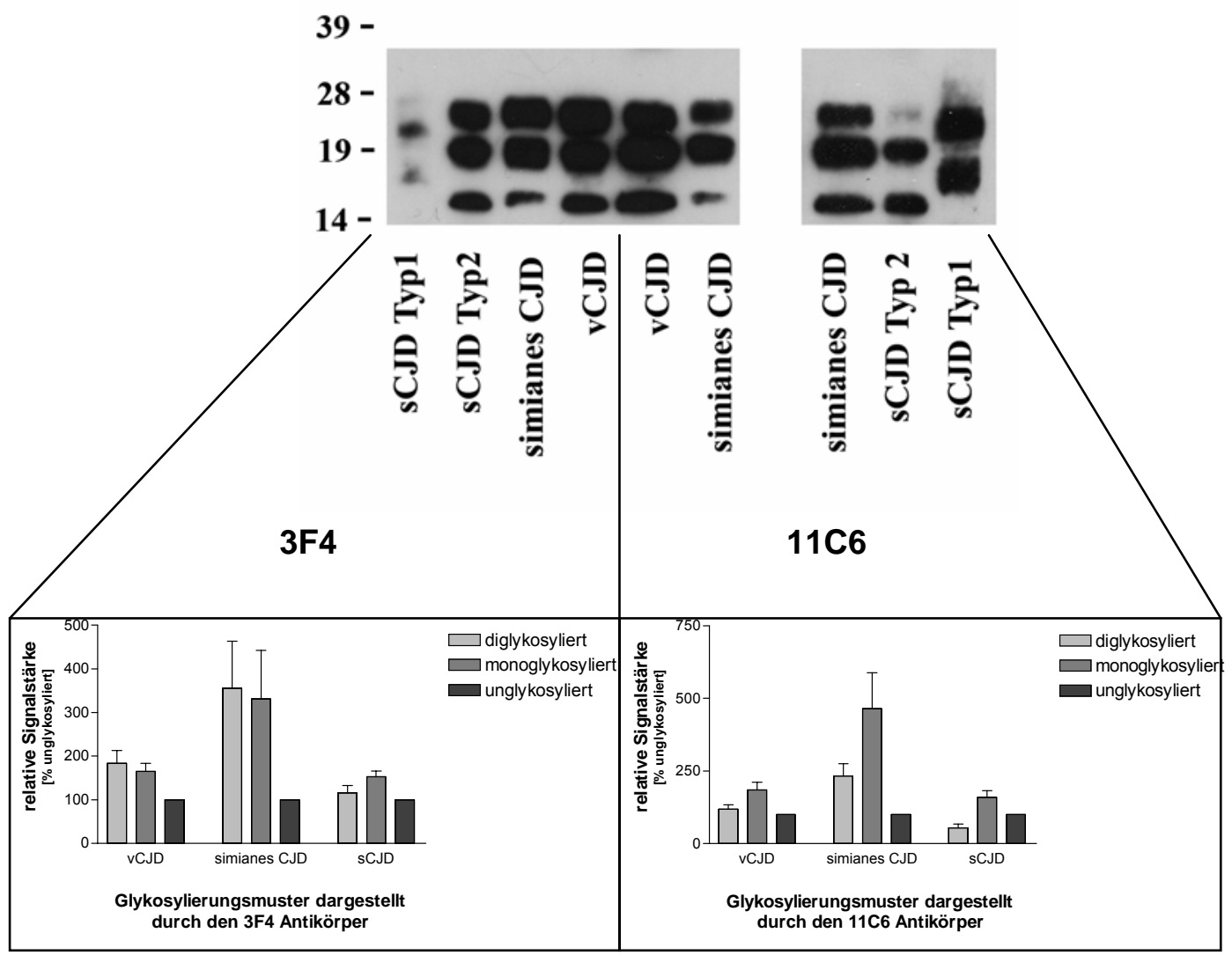

Abbildung 3.10: Migrationsverhalten und Glykosylierungsmuster verschiedener CJD Typen dargestellt durch zwei verschiedene anti-PrP Antikörper

Proteinextrakte aus Hirnhomogenaten von Patienten mit sCJD Typ1, sCJD Typ2 und vCJD und eines BSE infizierten Javaneraffen (Tier A2) wurden vergleichend in Western Blots eingesetzt und mit dem 3F4 und dem 11C6 Antikörper dargestellt. Die Darstellung des PrPres der anderen Tiere entsprach dem des A2. Die Signalstärke der Banden von 4 Western Blots wurde densitometrisch ausgewertet, gegen die monoglykosylierte Form normalisiert und vergleichen in einem Diagramm dargestellt. 


\subsubsection{Intracerebrale Verteilung des simianen $\operatorname{PrP}^{\text {res }}$}

Anhand der unterschiedlichen Inkubationszeiten (3.1) und neuropathologischen Profile (3.2.3) wurden die Tiere in zwei Gruppen eingeteilt. Es sollte untersucht werden, ob diese Gruppen unterschiedliche CJD-Typen ausgebildet hatten. Das $\mathrm{PrP}^{\text {res }}$ der Tiere unterschied sich weder im Glykosylierungsmuster noch im Migrationsverhalten. Daher wurden weitere Marker untersucht, um Aufschluss über unterschiedliche Typen zu erhalten. Der Nachweis von CJD Subtypen kann von den untersuchten Hirnregionen abhängig sein. Im Hirn eines sCJD Typ2 Patienten wurde z.B. im subfrontalen Cortex PrPres des SCJD Typ1 nachgewiesen (HEAD et al., 2004). Für sechs vCJD Patienten wurde eine Subpopulation von CJD Typ1 PrP res u.a. im cerebralen Cortex beschrieben (YULL et al., 2006). Um die Prionenerkrankung der BSE infizierten Javaneraffen näher zu charakterisieren, wurden sieben Hirnregionen (gyrus frontalis, gyrus cinguli, gyrus parietalis, gyrus occipitalis, nucleus caudatus, vermis cerebelli und basis pontis) makroskopisch auf Hirnschnitten identifiziert, Proben entnommen und Western Blot analysiert. Das $\mathrm{PrP}^{\text {res }}$ aller Tiere zeigte in allen Hirnregionen ein CJD Typ2 Migrationsverhalten (Abb. 3.11 A).

PARCHI et al. (1999 und 2000) beschrieb eine Unterscheidung von sCJD Subtypen über die relativen Mengen an $\mathrm{PrP}^{\text {res }}$ in einzelnen Hirnregionen. Dabei wurden die zwei sCJD Subtypen in weitere Subtypen unterteilt (Typ 1: MM1, VV1; Typ2: MM2cortical, MM2-thalamic, MV2 und VV2). Durch Western Blot, Histoblot und Immunohistologie wurden vergleichbare Ergebnisse erzielt, die Untersuchung mittels Western Blot wurde jedoch als sensitivste Methode beschrieben (PARCHI et al., 2000). Die Isolierung des Materials aus den Hirnregionen wurde hier als kritischer Schritt für die genaue Analyse beschrieben und wurde für diese Arbeit nach den beschriebenen Vorgaben durchgeführt (z.B. Entnahmen ausschließlich grauer Substanz, Vermeidung von Kontaminationen mit anderen Hirnregionen). Es wurde für jeden der Javaneraffen $\mathrm{PrP}^{\mathrm{res}}$ aus sieben Hirnregionen isoliert und vergleichend im Western Blot untersucht. Das meiste PrP $^{\text {res }}$ wurde in den zentralen, subkortikalen Regionen (nucleus caudatus, gyrus cinguli, vermis cerebelli und basis pontis) nachgewiesen, während es in den neokortikalen Regionen (gyrus frontalis, gyrus parietalis und gyrus occipitalis) nur gering akkumuliert war (Abb. 3.11 B). Dieses Profil entsprach den Typen MM2-thalamic und VV2 (PARCHI et al., 1999 und 2000). Eine eindeutige Zuordnung war nicht möglich, da aus technischen Gründen nicht alle von PARCHI et al. (1999 und 2000) beschriebenen Hirnregionen untersucht werden konnten. Da die Javaneraffen allerdings dem MM-Genotyp (homozygot für Methionin am Codon 129) entsprechen (ScHÄTZL et al., 1995), ist eine Zuordnung zu dem Typ MM2-thalamic wahrscheinlicher. Das beobachtete Profil wiesen alle Javaneraffen auf. 


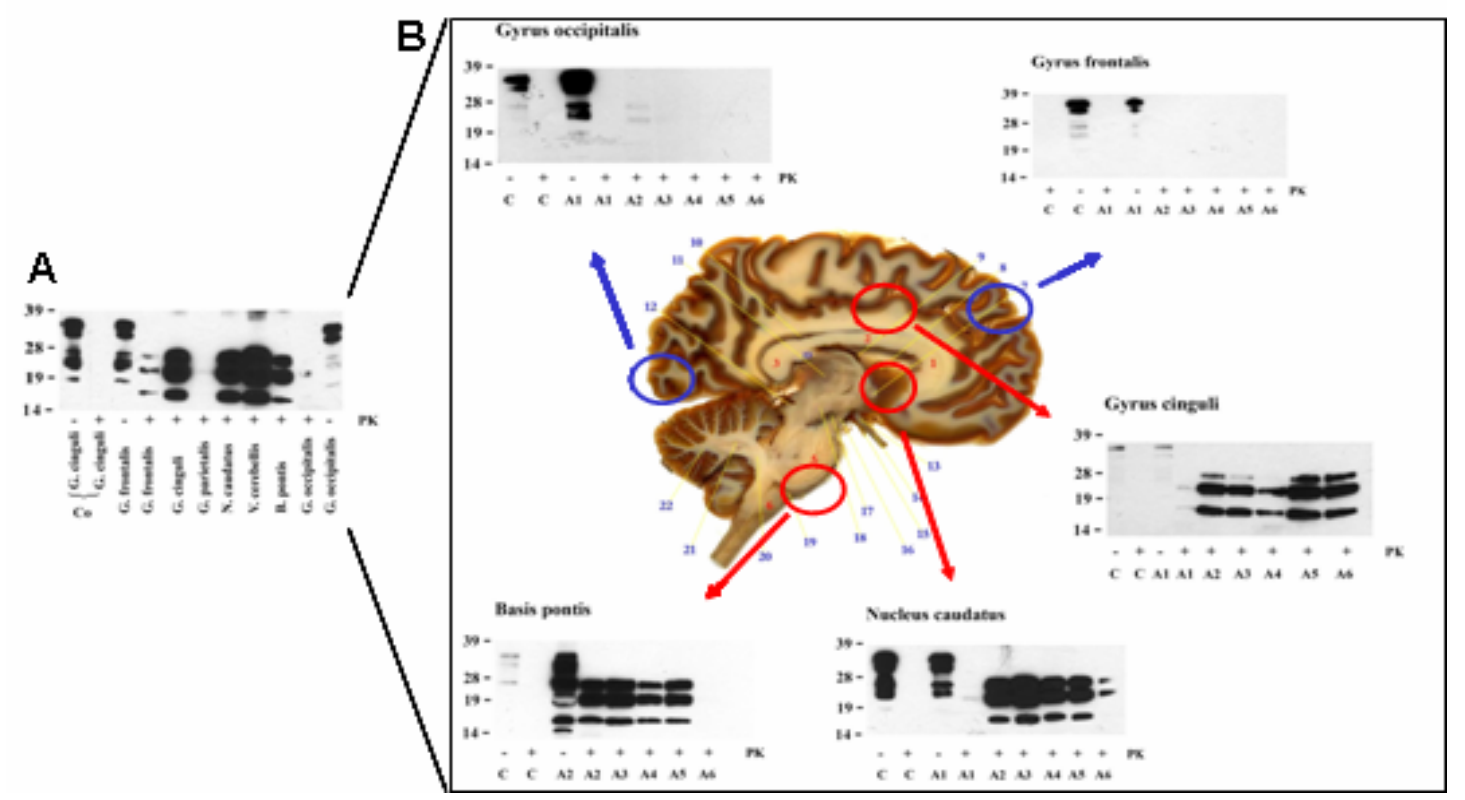

Abbildung 3.11: Western Blots nach PK-Verdau verschiedener Hirnregionen BSEinfizierter Javaneraffen

Proteinextrakte aus Hirnhomogenaten von sieben Hirnregionen von sechs BSE-infizierten Javaneraffen und eines Kontrolltieres wurden mit PK behandelt, elektrophoretisch getrennt und geblottet (je $45 \mu \mathrm{g}$ Äquivalentmenge vor PK-Verdau pro Spur). Als Kontrolle wurden je $20 \mu \mathrm{g}$ unbehandeltes Hirnhomogenat eines infizierten und des nicht infizierten Javaneraffen aufgetragen. A: Vergleichend wurden die Proteinextrakte aus sieben Hirnregionen des Tiers A3 aufgetragen. B: Die Proteinextrakte aller sechs BSE-infizierter Javaneraffen aus fünf Hirnregionen wurden exemplarisch dargestellt. Die korrespondierenden Hirnregionen der Western Blots sind am Modell eines humanen Hirns dargestellt, in blau sind neokortikale in rot subkortikale Regionen gekennzeichnet.

Die Signalstärken der drei Glykoformen des $\mathrm{PrP}^{\text {res }}$ im Western Blot wurde für alle Tiere densitometrisch ermittelt (Image J, Version 1.37v) und als Maß für die relative $\mathrm{PrP}^{\mathrm{res}}$ Menge einsetzt. In die Auswertung wurden die subkortikalen Hirnregionen (gyrus cinguli, nucleus caudatus, vermis cerebelli und basis pontis) einbezogen, deren Signale im Western Blot nicht an der Nachweisgrenze lagen (Abb. 3.11 A). Für die Tiere $A 2, A 3$ und $A 5$ wurde eine größere Menge an $\mathrm{PrP}^{\text {res }}$ ermittelt als für die Tiere A1, A4 und A6 (Abb. 3.12). Der Mittelwert der Signalstärken aus allen drei Glykoformen wurde gegen die Inkubationszeit der Prionenerkrankung jedes Tieres aufgetragen (Abb. 3.12). Tendenziell waren die Signalstärken und damit die PrPres Menge geringer, wenn die Krankheit nach einer Inkubationszeit von weniger als 1100 Tagen zum Ausbruch kam. Nach einer Inkubationszeit von mehr als 1300 Tagen waren die Signalstärken immer stark ausgeprägt. Eine Ausnahme von diesem Trend bildet das Tier A3, für das Signalstärken ermittelt wurden, die vergleichbar mit denen der Tiere mit langer Inkubationszeit waren. 


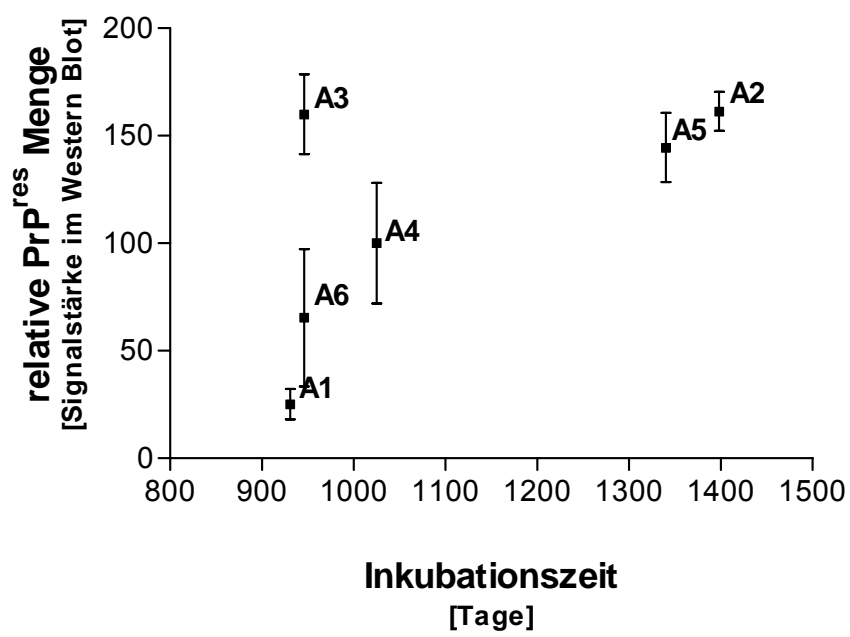

Abb. 3.12: Die Signalstärke des $\operatorname{PrP}^{\text {res }}$ im Western Blot in Abhängigkeit von der Inkubationszeit Die Signalstärken des PrP $^{\text {res }}$ im Western Blot wurden densitometrisch aus Western Blots (45 $\mu \mathrm{g}$ pro Spur, Antikörper 11C6 1:15.000) ermittelt (ImageJ, Version 1.37v). Die Inkubationszeit der Prionenerkrankung der einzelnen Javaneraffen wurde gegen die Signalstärke aufgetragen (Mittelwert \pm SD) GraphPad Prism 3.0). Hierfür wurden alle Glykoformen der Hirnregionen gyrus cinguli, nucleus caudatus, vermis cerebelli und basis pontis einbezogen.

\subsubsection{Konformationelle Stabilität des simianen $\operatorname{PrP}^{\text {res }}$}

Als weiterer Marker für Prionenstämme dient die relative Stabilität des PrP ${ }^{\text {res }}$ gegenüber der Behandlung mit dem denaturierenden Agens Guanidinium Hydrochlorid (GdnHCl) (SAFAR et al., 1998). Das chaotrope Salz GdnHCl löst die Aggregate der pathogenen Isoform des PrP auf (MEYER et al., 1999). Dadurch wird das PrP $^{\text {res }}$ sensitiv gegenüber der PK (KocıSKO et al., 1995) Die Konzentration an $\mathrm{GdnHCl}$, die dazu führt, dass die Hälfte des $\mathrm{PrP}^{\text {res }} \mathrm{PK}$ sensitiv wird $\left(\mathrm{GdnHCl}_{1 / 2}\right)$, dient als Marker für unterschiedliche Prionenstämme (PERETZ et al., 2001). Die Analyse der konformationellen Stabilität des PrP ${ }^{\text {res }}$ wurde exemplarisch an zwei Hirnregionen durchgeführt, in denen in allen Tieren vergleichbare Mengen an $\mathrm{PrP}^{\text {res }}$ nachgewiesen wurden, dem nucleus caudatus und dem gyrus cinguli (3.3.2). Beide Hirnregionen lagen im subkortikalen Bereich. Die Analyse wurde vergleichend an einem Tier mit langer und einem Tier mit kurzer Inkubationszeit durchgeführt. Für den $\mathrm{GdnHCl}_{1 / 2^{-}}$ Wert des CJD-Subtyps MM1 wurde beobachtet, dass dieser unabhängig von der Krankheitsdauer war (CALI et al., 2006). Daher konnte diese Methode exemplarisch an zwei Tieren durchgeführt werden, um in den Javaneraffen verschiedene Subtypen zu diskriminieren, ohne dass die Dauer der klinischen Phase die Ergebnisse verfälschte.

Die Proteinextrakte der Hirnhomogenate wurden mit ansteigenden Konzentrationen an $\mathrm{GdnHCl}$ inkubiert (2.4.7), anschließend mit $\mathrm{PK}$ behandelt (2.4.2) und das 
Markermolekül PrPres im Western Blot mit dem 11C6 Antikörper dargestellt. Die relative Sensitivität gegenüber der PK unterschied sich interindividuell nicht, intraindividuell wurde jedoch eine unterschiedliche Stabilität des $\operatorname{PrP}^{\text {res }}$ gegenüber der Denaturierung mit $\mathrm{GdnHCl}$ festgestellt. Im gyrus cinguli beider Tiere wurde $\mathrm{PrP}^{\text {res }}$ bis zu der Konzentration von 2,5 M GdnHCl nachgewiesen. Im nucleus caudatus hingegen wurde ab einer Konzentration von $1,5 \mathrm{M} \mathrm{GdnHCl}$ kein Signal mehr detektiert (Abb. 3.13).

Um auszuschließen, dass es sich bei dieser Beobachtung um Artefakte des Blottens oder der Antikörperinkubation handelt, wurden denaturierte Proben dieser Hirnregionen (Tier A2) nebeneinander im Western Blot aufgetragen. Der intraindividuelle Unterschied in der Stabilität gegenüber der Denaturierung mit $\mathrm{GdnHCl}$ wurde mit diesem Western Blot bestätigt. Während im gyrus cinguli nach Denaturierung mit 3,0 M GdnHCl noch $\mathrm{PrP}^{\text {res }}$ nachgewiesen wurde, war im nucleus caudatus bereits nach Denaturierung mit 2,1 M kein $\operatorname{PrP}^{\text {res }}$ mehr detektierbar (Abb. 3.14).

A

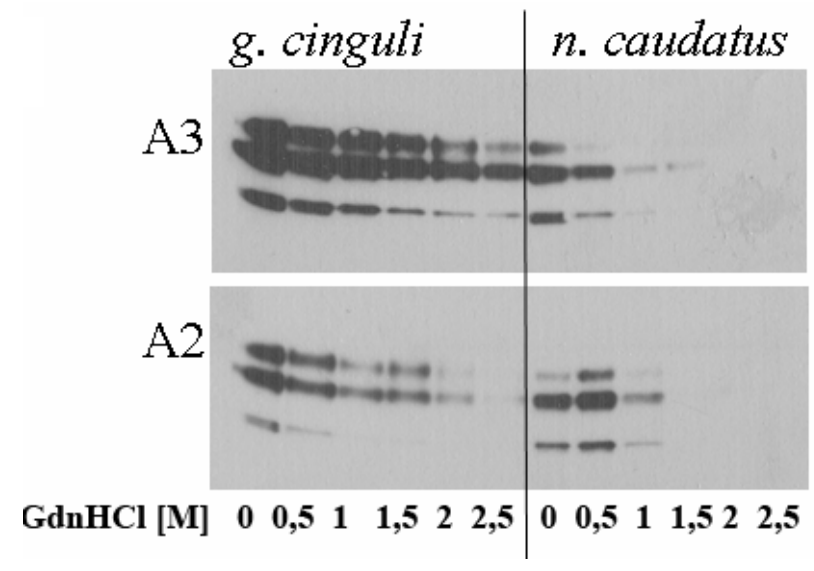

B

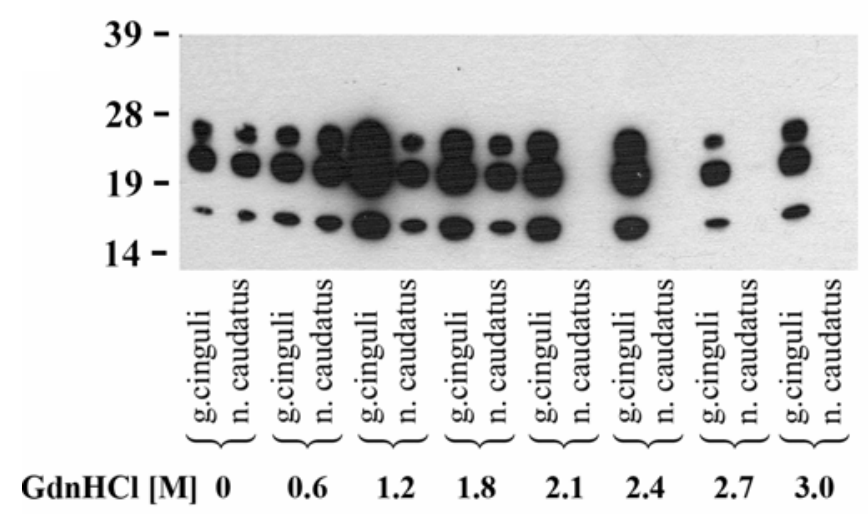

Abbildung 3.13: Inter- und intraindividuelle Unterschieden in der relative Stabilität des $\mathrm{PrP}^{\text {res }}$ gegenüber Denaturierung mit GdnHCl

Proteinextrakte (je $90 \mu \mathrm{g}$ Gesamtprotein) der gyri cinguli und der nuclei caudati zweier BSE-infizierten Javaneraffen wurden mit Konzentrationen von $0 \mathrm{M}$ bis $3 \mathrm{M} \mathrm{GdnHCl}$ denaturiert. Nach anschließendem PK Verdau wurden je $45 \mu \mathrm{g}$ Äquivalentmenge vor Verdau pro Spur elektrophoretisch getrennt und mit dem monoklonalen Antikörper 11C6 nachgewiesen. A: Die denaturierten Proteinextrakte der Tiere A2 und A3 wurden nach Hirnregion sortiert aufgetragen. B: Die denaturierten Proteinextrakte des Tieres A2

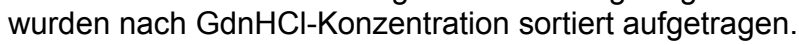


Um die $\mathrm{GdnHCl}_{1 / 2}$-Werte für den gyrus cinguli und den nucleus caudatus exakt zu ermitteln, wurde ein Sandwich-ELISA mit denaturierten Proteinextrakten durchgeführt. Hierzu wurden Extrakte aus den Hirnregionen eines BSE infizierten Primaten (A2) mit $0 \mathrm{M}$ bis $6 \mathrm{M} \mathrm{GdnHCl}$ denaturiert (2.4.7) und im Sandwich-ELISA eingesetzt (2.4.6). Die Signalstärke des $\operatorname{PrP}^{\text {res }}$ im ELISA war invers proportional zu der $\mathrm{GdnHCl}$ Konzentration. Als Funktion aufgetragen ergaben die Ergebnisse einen sigmoiden Graphen (Abb. 3.14). Über eine nicht-lineare Regression (dose-response curve with variable slope) wurde die $\mathrm{GdnHCl}$ Konzentration der halbmaximalen Signalstärke ermittelt. Diese war für den gyrus cinguli bei 3,4 M GdnHCl erreicht, für den nucleus caudatus bei 2,0 M GdnHCl. Somit wurde ein Unterschied von 1,4 M $\mathrm{GdnHCl}_{1 / 2}$ für die relative Stabilität des $\mathrm{PrP}^{\text {res }}$ in den untersuchen Hirnregionen ermittelt.

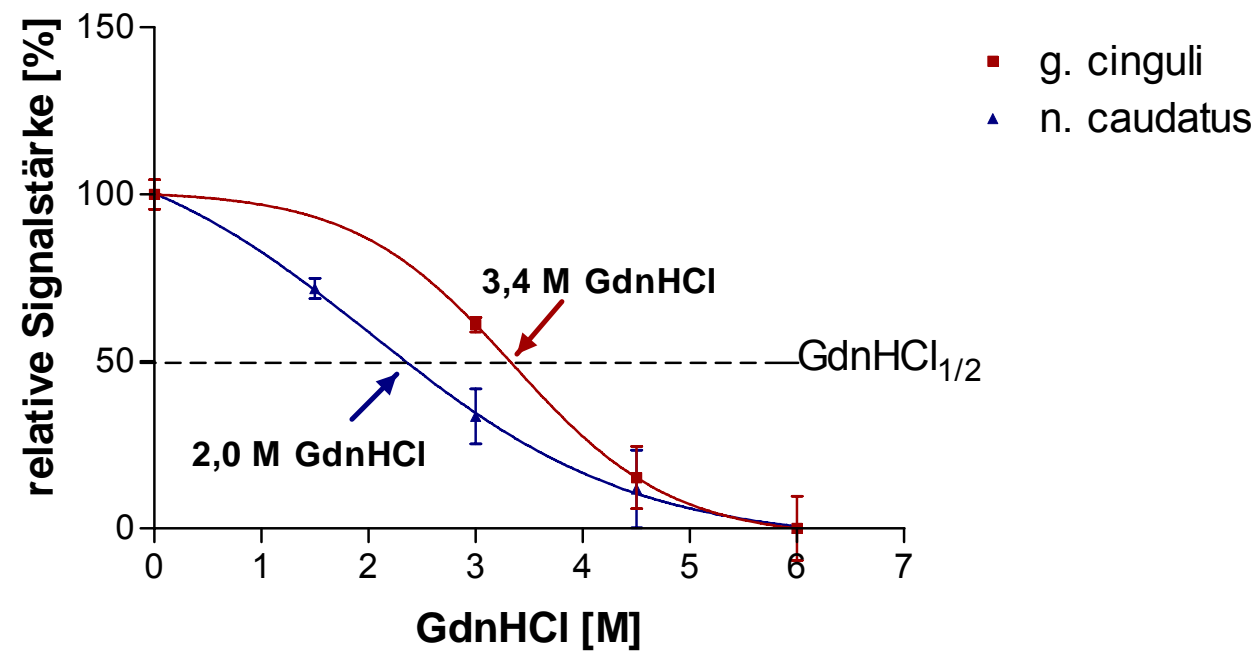

\section{Abbildung 3.14: GdnHCl-abhängige PrP ${ }^{\text {res }}$ Konzentrationen im Sandwich-ELISA}

Hirnhomogenate (je $90 \mu \mathrm{g}$ Gesamtprotein) des gyrus cinguli und des nucleus caudatus eines BSEinfizierten Javaneraffen wurden mit Konzentrationen von 0 bis $6 \mathrm{M} \mathrm{GdnHCl}$ denaturiert. Diese Homogenate wurden nach PK-Verdau $\left(50 \mu \mathrm{g} / \mathrm{ml} \mathrm{PK}, 37^{\circ} \mathrm{C}, 1 \mathrm{~h}\right)$ im Sandwich-ELISA mit dem monoklonalen anti-Prion Antikörpern $12 \mathrm{~F} 10$ als Fängerantikörper und $11 \mathrm{C} 6$ als Detektorantikörper nachgewiesen. Die OD bei $405 \mathrm{~nm}$ wurde gegen 0 und $6 \mathrm{M} \mathrm{GdnHCl}$ normalisiert. Die GdnHClKonzentration, bei der die Hälfte des $\mathrm{PrP}^{\mathrm{res}}$ nicht mehr nachgewiesen werden kann wurde für beide Hirnregionen ermittelt.

Es konnte gezeigt werden, dass eine i.c. BSE-Infektion von Javaneraffen zu einer Prionenerkrankung führt, die dem humanen vCJD entspricht. Das Glykosylierungsmuster des $\mathrm{PrP}^{\text {res }}$, das als Marker für vCJD dient, schien jedoch vom eingesetzten Nachweisantikörper abhängig zu sein. Auffälligerweise zeigten zwei der Tiere eine um über 300 Tage verlängerte Inkubationszeit. Daher wurde untersucht, ob bei diesen Tieren weitere Unterschiede bei Merkmalen für die Prionenerkrankung 
festgestellt werden konnten. Solche Unterschiede konnten für die PrP-Ablagerungen im Hirn nachgewiesen werden. Die Tiere mit einer längeren Inkubationszeit wiesen einen größeren Anteil an komplexen Ablagerungen auf. Außerdem konnte festgestellt werden, dass die relative Menge an $\operatorname{PrP}^{\text {res }}$ tendenziell in Zusammenhang mit einer langen Inkubationszeit anstieg. Die intracerebrale Verteilung an $\mathrm{PrP}^{\text {res }}$ schien jedoch unabhängig von der Inkubationszeit zu sein. Die subkortikalen Regionen (gyrus cinguli, nucleus caudatus, vermis cerebelli und basis pontis) enthielten höhere Mengen an $\mathrm{PrP}^{\mathrm{res}}$, die Regionen des Neocortex (gyrus frontalis, gyrus parietalis und gyrus occipitalis) hingegen geringe Mengen. Auch die konformationelle Stabilität des $\mathrm{PrP}^{\text {res }}$ war sowohl bei langer als auch bei kurzer Inkubationszeit vergleichbar. Jedoch konnte gezeigt werden, dass sie sich in zwei Hirnregionen des gleichen Tiers unterschied. Dieser Unterschied war für die untersuchten Tiere gleich.

\section{4. Übertragung von makakenadaptiertem BSE auf ein Zellkulturmodell}

Eine Übertragung von Scrapie auf murine Zellinien wurde bereits erfolgreich durchgeführt (BUTLER et al., 1988). Die untersuchten Zelllinien waren unterschiedlich suszeptibel für verschiedene Scrapiestämme (NISHIDA et al., 2000) und behielten die biologischen und biochemischen Charakteristika der Stämme bei (ARIMA et al., 2005). Auch waren eine weitere Übertragung der Infektiosität des nun mausadaptiertem Scrapie auf nicht infizierte Zellen erfolgreich (NISHIDA et al., 2000).

Für die Übertragungsstudie wurde die neuronale murine Zelllinie SN56 (BLUSZTAJN et al., 1992) ${ }^{3}$ eingesetzt. Diese Zelllinie ist suszeptibel für mausadaptiertes Scrapie (BARON et al., 2006). Die Übertragung wurde mit simianem vCJD als infektiösem Agens und mausadaptiertem Scrapie (SMB.s15 Zelllinie, CLARK und HAIG, 1970) als Kontrolle für den Erfolg der Übertragung durchgeführt. Als Negativkontrolle diente die Zelllinie SMB.PS, die aus der SMB.s15-Zelllinie generiert wurde, indem diese durch PentosanPolysulfat von der chronischen Scrapie-Infektion geheilt worden war (BRICKETT et al., 2001). Die SMB Zelllinie ist ebenso wie die SN56 Zelllinie murinen Ursprungs. Die SN56 Zellen wurden mit Proteinextrakt aus Zelllysat inkubiert (2.6.2). Im Western Blot wurden die SN56 Zellen (8 Wochen nach Infektion) auf $\mathrm{PrP}^{\text {res }}$ überprüft. Der Nachweis der Prioninfektiosität in den Zellkulturmodellen war unter den gegebenen Möglichkeiten nicht durchführbar. Daher wurde er im Rahmen einer Kooperation von Sabine Gilch (Arbeitsgruppe Prionenforschung, TU München) durchgeführt. Diese Arbeitsgruppe ist

\footnotetext{
${ }^{3}$ Die SN56 Zelllinie wurde freundlicherweise zur Verfügung gestellt von B. Wainer (Emory University School of Medicine, USA).
} 
auf die Erforschung von Prionenerkrankungen in Zellkulturmodellen spezialisiert. Nach PK-Behandlung wurden in den mit SMB.s15 infizierten Zellen drei Banden von 20 kDa bis $29 \mathrm{kDa}$ Molekulargewicht nachgewiesen, nach Inkubation mit den SMB.PS Zellen jedoch nicht (Abb. 3.14). Anschließend wurde die SN56 Zelllinie mit Proteinextrakten aus Hirngewebe BSE infizierter und nicht infizierter Javaneraffen inkubiert (2.6.2). Im Western Blot mit PK-verdautem Zelllysat (8 Wochen nach Infektion) wurde kein PrP res nachgewiesen (Abb. 3.15). Somit wurde eine in vitro Infektion der SN56 Zelllinie mit dem mausadaptierten Scrapie der SMB.s15-Zellen erfolgreich durchgeführt. Diese Zelllinie konnte jedoch nicht mit makakenadaptiertem BSE infiziert werden.

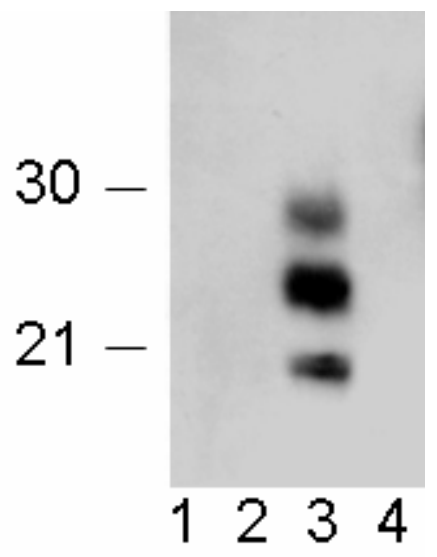

\section{Abbildung 3.15: Infektion von SN56 Zellen mit makakenadaptiertem BSE}

Die murine neuronale Zelllinie SN56 wurde mit 10\% Hirnhomogenat eines BSE infizierten Javaneraffen (Spur 1) und 10\% Zelllysat einer Scrapie infizierten murinen neuronalen Zelllinie SMB.s15 (Spur 3) infiziert. Als Kontrolle diente Hirnhomogenat eines nicht infizierten Javaneraffen (Spur 2) bzw. Zelllysat aus der nicht infizierten SMB.PS Zelllinie (Spur 4). Zellpellets aus der achten Woche nach der Infektion wurden PK behandelt (Spur 1 bis 4) und im Western Blot auf PrP ${ }^{\text {res }}$ untersucht (GILCH et al., 2001, detektiert mit dem monoklonalen anti-Prion Antikörper 4H11). Pro Spur ist Zelllysat aus 3 Millionen Zellen aufgetragen.

\subsection{Expression von mikro RNAs im Hirn BSE infizierter und nicht infizierter}

\section{Javaneraffen}

MikroRNAs (miRNAs) sind 18 bis 25 Nukleotide große RNA-Moleküle. Sie binden mRNA durch unvollständige komplementäre Basenpaarung und inhibieren dadurch deren Translation. Dadurch sind sie in die Regulation vieler Stoffwechselvorgänge (LAU et al., 2001, XU et al., 2003), die Entwicklung (REINHARD et al., 2000), die Onkogenese (CALIN et al., 2002) und in Virusinfektionen (PFEFFER et al., 2004, LECELLIER et al., 2005) involviert. Diese Regulation kann über Kontrolle der Transkription oder der Translation erfolgen (Oulette et al., 2006; Valencia-Sanchez et al., 2006). Einhergehend mit 
Infektionen kommt es zu einer Veränderung der Expression spezifischer miRNAs. Dies ist zum Beispiel für Krebs, aber auch für Infektionskrankheiten wie Herpes oder HIV beschrieben. Die Expressionsänderung kann eine inflamatorische Reaktion sein, z.B. als antivirale Immunantwort (CULLEN et al., 2002) oder als Pathogenesemechanismus des Virus dienen (PFEFFER et al., 2004). In der vorliegenden Arbeit wurde die Regulation von miRNAs in Folge einer BSE Infektion untersucht.

Da über die Expression von miRNAs im Hirn von Javaneraffen noch keine Daten erhältlich sind, wurde zunächst das Expressionsmuster von miRNAs mit einem miRNAMicroArray bestimmt, der u.a. 300 DNA Oligonukleotide mit der antisense-Sequenz humaner miRNAs enthält (mirVana miRNA Probe Set Version 1). Die folgenden Arbeiten wurden in Zusammenarbeit mit dem Transkriptomanalyselabor (Universität Göttingen) unter der Leitung von Reiner Hitt durchgeführt. Zunächst wurde überprüft, ob die miRNAs des Javaneraffen mit den humanen Sequenzen kreuzreagieren und welche miRNAs im Hirn von Javaneraffen exprimiert sind. Dazu wurden miRNAs aus der basis pontis eines nicht infizierten Javaneraffen isoliert, mit den Farbstoffen DYE547 und DYE647 fluoreszenzmarkiert und die Signale der miRNAs auf dem miRNA-MicroArray bestimmt (Abb. 3.16).

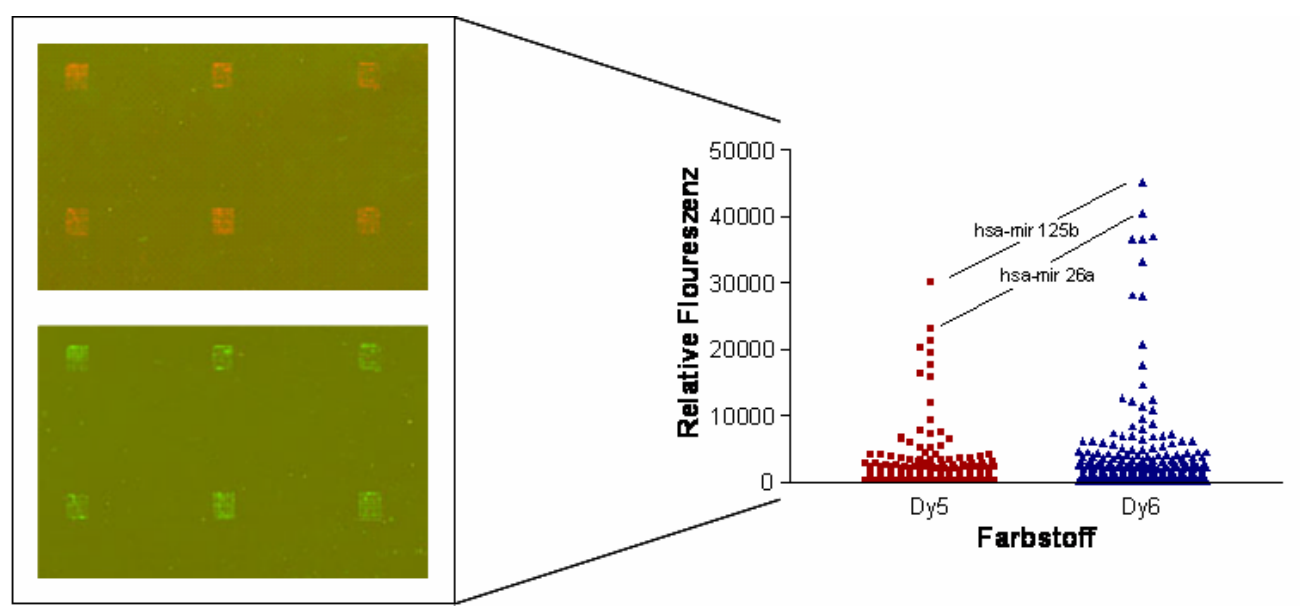

Abb. 3.16: Expression von miRNAs in der basis pontis von Javaneraffen

Eine Präparation der miRNA Fraktion aus der basis pontis eines nicht infizierten Javaneraffen wurde mit den Fluoreszenzfarbstoffen DYE547 und DYE647 markiert. Je 200 ng der markierten miRNA wurden in einem miRNA-MicroArray (Ambion) eingesetzt. Die Fluoreszenzsignale der hybridisierten miRNAs wurden bestimmt. 
Das Experiment wurde drei Mal unabhängig voneinander durchgeführt. Es wurden 56 miRNAs nachgewiesen, die ein höheres Fluoreszenzsignal zeigten als die internen Negativkontrollen des miRNA-MicroArrays. Im Vergleich waren die Signalstärken der mit DYE647 markierten miRNAs um etwa einen Faktor 1,5 höher als nach Markierung mit DYE547, das Expressionsmuster der miRNAs unterschied sich hingegen nicht. Die zehn miRNAs mit den stärksten Signalen sind in Tabelle 3.2 aufgeführt.

Tabelle 3.2: In der basis pontis von Javaneraffen exprimierte miRNAs

\begin{tabular}{ll} 
1. & hsa-miR-125b \\
2. & hsa-miR-26a \\
3. & hsa-let-7a \\
4. & hsa-let-7c \\
5. & hsa-let-7b \\
6. & hsa-miR-124a \\
7. & hsa-miR-107 \\
8. & hsa-let-7d \\
9. & hsa-miR-103 \\
10. & hsa_miR_181a \\
\hline
\end{tabular}

Anschließend wurde die Expression in BSE infizierten und nicht infizierten Makaken in dem gleichen System miteinander verglichen. Dazu wurde die miRNA aus der basis pontis eines infizierten (A4) und eines nicht infizierten Tieres im miRNA-MicroArray eingesetzt. Die miRNA beider Tiere wurde mit beiden Farbstoffen markiert. Anschließend wurden jeweils die DYE547 markierte miRNA des infizierten Tieres mit der DYE647 markierten miRNA (und umgekehrt) zu gleichen Teilen in einem miRNA-MicroArray eingesetzt. Die Signalstärken der miRNAs wurden ermittelt und die des infizierten Tieres wurden mit denen des nicht infizierten Tieres verglichen. Dazu wurde zunächst die Autofluoreszenz der DNA auf dem Array bestimmt. Dazu wurde der Median aller Signale und dessen Standardabweichung ermittelt. In die Auswertung wurden nur miRNAs einbezogen, deren Signalstärke oberhalb des Medians zuzüglich der doppelten Standardabweichung lag. Von diesen miRNAs wurde das Verhältnis aus den Signalstärken des BSE infizierten und des nicht infizierten Tieres gebildet. Die sechs miRNAs mit dem höchsten Expressionsunterschied wurden weiter untersucht (Abb. 3.17). Die miRNAs hsa-miR26a, hsa-miR124a und hsa-miR342 zeigten in der basis pontis des infizierten Javaneraffen ein stärkeres Signal als in dem des nicht infizierten (hochreguliert), die miRNAs hsa-miR143, hsa-miR145 und hsa-miR494 hingegen ein niedrigeres (herunterreguliert). 


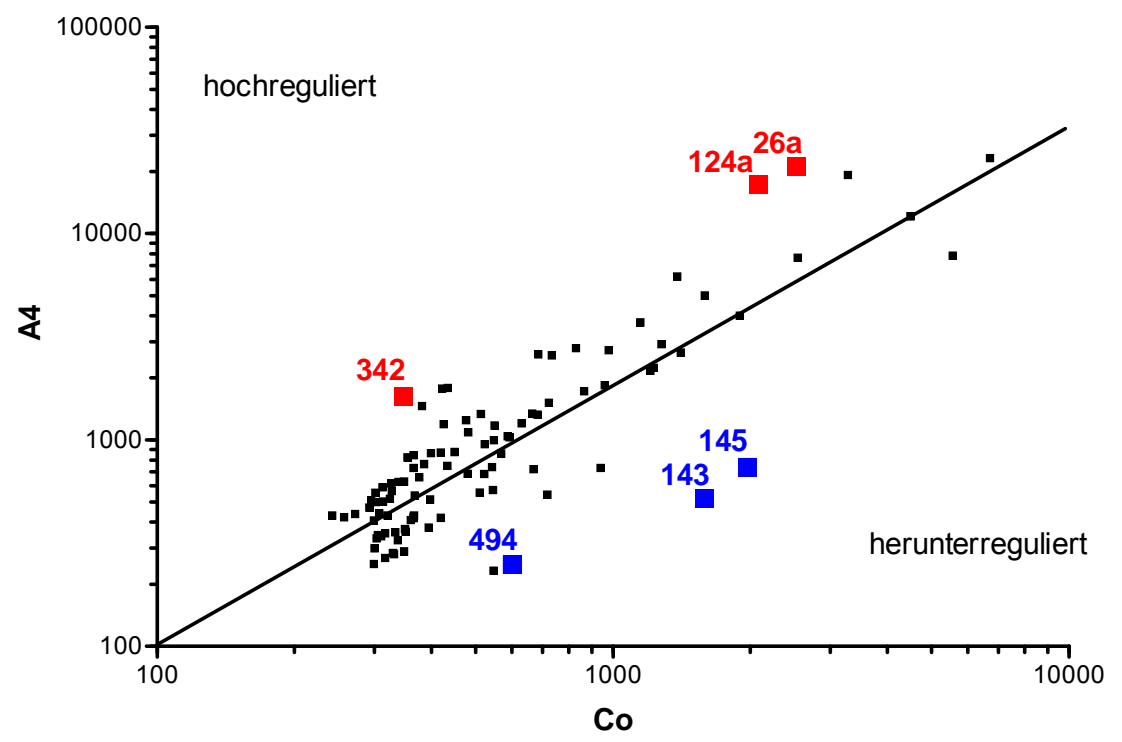

Abbildung 3.17: Differentielle Expression von miRNAs in der basis pontis in Zusammenhang mit makakenadaptiertem BSE

Die miRNA Fraktionen aus der basis pontis eines BSE infizierten (A4) und eines nicht infizierten (Co) Javaneraffen wurden fluoreszenzmarkiert und die Expression einzelner miRNAs wurde in einem miRNA-MicroArray untersucht. Die relativen Fluoreszenzen jeder miRNA des infizierten und des nicht infizierten Javaneraffen wurden gegeneinander aufgetragen. Die miRNAs mit einer höheren Expression im infizierten Tier sind rot markiert, die mit einer höheren Expression im nicht infizierten Tier sind blau markiert.

Die Ergebnisse des miRNA-MicroArray wurden durch quantitative Real Time PCR (qRT$P C R$ ) validiert. Aus den miRNA Fraktionen wurde cDNA je einer miRNA generiert (2.5.4). Die relative Menge an cDNA in infizierten und nicht infizierten Tieren wurde in der qRTPCR ermittelt und miteinander verglichen. Die Daten wurden als Zyklus der Fluoreszenzänderung am Schwellenwert der PCR $\left(\mathbf{C}_{\mathrm{T}}\right)$ erfasst. Der $\mathrm{C}_{\mathrm{T}}$-Wert dient als Maß für die relative RNA Konzentration. Um aus diesen Daten den Regulationsfaktor zu berechnen, wurde die $\Delta \Delta \mathrm{C}_{\mathrm{T}}$-Methode (WINER et al., 1999) angewendet. Der $\mathrm{C}_{\mathrm{T}}$-Wert der miRNA wurden zunächst gegen den des house-keeping Gens RNU66 normalisiert $\left(\Delta \mathbf{C}_{\mathrm{T}}\right)^{4}$. Durch dieses Verfahren sollen eventuelle Abweichungen der relativen RNA Menge in den einzelnen Ansätzen ausgeglichen werden. Dazu wurden der Mittelwert der $\mathrm{C}_{\mathrm{T}}$-Werte der Replikate und die Standardabweichung gebildet und für die Errechnung des $\Delta \mathrm{C}_{\mathrm{T}}$-Wertes eingesetzt. Die $\Delta \mathrm{C}_{\mathrm{T}}$-Werte der infizierten bzw. nicht infizierten Tiere einer Messung

\footnotetext{
${ }^{4} \Delta \mathrm{C}_{\mathrm{T}}=\mathrm{C}_{\mathrm{T}}$ (miRNA) $-\mathrm{C}_{\mathrm{T}}$ (house-keeping Gen)
}

Die Standardabweichung der Differenz ermittelt sich nach folgender Formel:

$$
S D_{(A-B)}=\left(S D_{A}^{2} / n_{A}+S^{2}{ }_{B} / n_{B}\right)^{1 / 2}
$$


wurden wiederum gemittelt und daraus die gepoolte Standardabweichung ${ }^{5}$ ermittelt. Anschließend wurde die Differenz aus den $\Delta \mathrm{C}_{\mathrm{T}}$-Werten der BSE infizierten Javaneraffen und der Kontrolltiere gebildet $\left(\Delta \Delta \mathbf{C}_{\mathrm{T}}\right)^{6}$. Diese gibt an, um wie viele Zyklen sich die Bildung eines PCR Produkts durch die BSE Infektion verändert und dient als Maß für den Unterschied der relativen miRNA Menge. Der Mittelwert und die gepoolte Standardabweichung der $\Delta \Delta \mathrm{C}_{\mathrm{T}}$-Werte aller Messungen wurden gebildet. Mit Hilfe des student t-test with Welch's correction wurde ermittelt, ob die beobachteten Unterschiede in der Expression signifikant waren. Da in einer PCR Reaktion die Menge an DNA pro Zyklus verdoppelt werden soll, errechnet sich der Regulationsfaktor ${ }^{7}$ als Potenz des $\Delta \Delta \mathrm{C}_{\mathrm{T}}$-Werts zur Basis 2.

Für eine herunterregulierte miRNA in BSE infizierter basis pontis wird somit ein Regulationsfaktor $<1$, für eine hochregulierte ein Regulationsfaktor $>1$ ermittelt.

Für die Untersuchung wurden miRNA-Fraktionen eingesetzt, die aus der basis pontis von sechs BSE infizierten und einem nicht infizierten Javaneraffen isoliert worden waren. Die relative Menge der miRNAs hsa-miR26a, hsa-miR124a, miRNA143a, hsa-miR145, hsamiR342, hsa-miR494 und des house-keeping Gens RNU66 wurde mittels qRT-PCR untersucht. Je $1 \mathrm{ng}$ der miRNA Fraktionen wurden für die cDNA Synthese eingesetzt, die anschließend in einer qRT-PCR vergleichend untersucht wurde (TaqMan MicroRNA Assays, Fa. Applied Biosystems). Die $\mathrm{C}_{\mathrm{T}}$-Werte wurden jeweils parallel in einen Experiment mit je 2 Replikaten bestimmt und daraus $\Delta \Delta \mathrm{C}_{\mathrm{T}}$ ermittelt. Der Mittelwert der $\Delta \Delta \mathrm{C}_{\mathrm{T}}$-Werte wurde mit dem des nicht infizierten Javaneraffen verglichen. Für die miRNAs hsa-miR26a, hsa-miR342 und hsa-miR494 wurden bei einer BSE Infektion signifikant unterschiedliche $\Delta \Delta \mathrm{C}_{\mathrm{T}}$ nachgewiesen (student t-test with Welch's correction). Die miRNA Menge der hsa-miR494 lag in diesen Untersuchungen jedoch an der Nachweisgrenze. Zusätzlich wurden die Untersuchungen mit dem housekeeping Gen RNU48 im Vergleich durchgeführt. Die Ergebnisse waren vergleichbar.

Um diese Ergebnisse zu bestätigen, wurde das gleiche Experiment für die miRNAs hsamiR26a, hsa-miR342 und hsa-miR494 mit miRNA in biologischen Replikaten aus der basis pontis der sechs BSE infizierten und fünf nicht infizierter Javaneraffen wiederholt. Die $\Delta \Delta \mathrm{C}_{\mathrm{T}}$ aller Experimente wurden miteinander verglichen. Die miRNAs hsa-miR26a, hsa-miR342 und hsa-miR494 wurden in miRNA-Fraktionen aus der basis pontis von BSE infizierten Javaneraffen in signifikant größerer Menge als in denen nicht infizierter

\footnotetext{
${ }^{5}$ Gepoolte Standardabweichung (SDp) von k Experimenten mit je $n$ Replikaten:

$\operatorname{SDp}\left[\mathrm{n}_{1-k}\right]=\left(\left(\mathrm{n}_{1}-1\right)^{*} \mathrm{SD}_{1}{ }^{2}+\left(\mathrm{n}_{2}-1\right)^{*} \mathrm{SD}_{2}{ }^{2}+\ldots+\left(\mathrm{n}_{\mathrm{k}}-1\right)^{*} \mathrm{SD}_{\mathrm{k}}{ }^{2} / \Sigma\left[\mathrm{n}_{1-k}\right]-k\right)^{1 / 2}$

${ }^{6} \Delta \Delta \mathrm{C}_{\mathrm{T}}=\Delta \mathrm{C}_{\mathrm{T}}$ (miRNA der nicht infizierten Makaken) $-\Delta \mathrm{C}_{\mathrm{T}}$ (miRNA der BSE infizierten Makaken)

${ }^{7}$ Regulationsfaktor $=2^{\Delta \Delta C}{ }_{\mathrm{T}}$
} 
Javaneraffen nachgewiesen ( $p<0,001$, student-t-test with Welch's correction) (Abb. 3.18). Die relative Konzentration der miRNA hsa-miR342 wurde zusätzlich in humanem Gewebe untersucht. Die miRNA Fraktion wurde aus der basis pontis eines sCJD Typ1, eines sCJD Typ2 Patienten und eines nicht CJD erkrankten Menschen isoliert und für die quantitative Real Time PCR eingesetzt. Aus den Schwellenwerten der PCR wurde der $\Delta \Delta \mathrm{C}_{\mathrm{T}}$ Wert der hsa-miR342 für die CJD Patienten gebildet. Diese unterschieden sich signifikant $(p<0,01)$ von dem des nicht CJD infizierten Menschen (Abb. 3.18). Aus den $\Delta \Delta C_{T}$ Werten wurde dann der Regulationsfaktor ermittelt (Abb. 3.18). Alle drei miRNAs sind in der basis pontis von Individuen, die an einer Prionenerkrankung erkrankt sind hochreguliert.

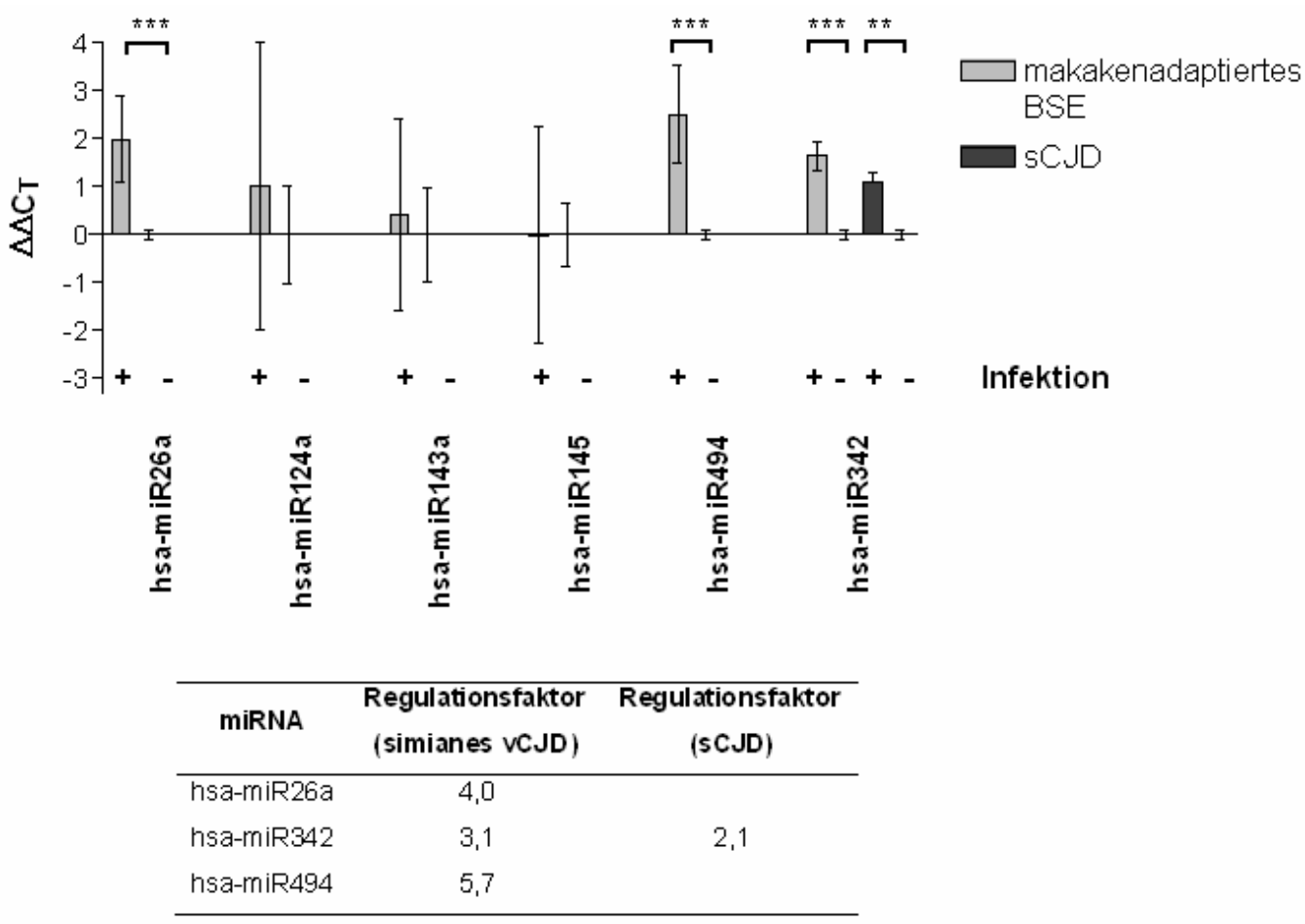

Abbildung 3.18: Untersuchung von miRNAs in der basis pontis BSE infizierter und nicht infizierter Javaneraffen mittels qRT-PCR

Je $1 \mathrm{ng}$ der miRNA-Fraktionen aus basis pontis von sechs infizierten Javaneraffen wurden für die TaqMan MicroRNA Assays (Fa. Applied Biosystems) eingesetzt. Als Kontrolle diente ein nicht infiziertes Tier. Dargestellt ist der Mittelwert der Fluoreszenzänderung am Schwellenwert der PCR $\left(\mathrm{C}_{\mathrm{T}}\right)$ der infizierten im Verhältnis zu dem house-keeping Gen $\left(\Delta \mathrm{C}_{\mathrm{T}}\right)$ und zu dem nicht infizierten Javaneraffen $\left(\Delta \Delta \mathrm{C}_{\mathrm{T}}\right)$. Die Signifikanzen bezogen auf das nicht infizierte Tier wurden durch den student-t-test ermittelt (GraphPad Prism 3.0) und sind mit $\left(^{* * *}\right) p<0,001$ angegeben, die Standardabweichungen als SD. Die miRNA hsa-miR342 wurde zusätzlich in der basis pontis von sCJD Patienten im Vergleich zu einem nicht infizierten Menschen untersucht. Aus den $\Delta \Delta \mathrm{C}_{\mathrm{T}^{-}}$ Werten wurden die Regulationsfaktoren ermittelt. 
In dieser Arbeit konnte gezeigt werden, dass ein für die Detektion humaner miRNAs angefertigter miRNA-MicroArray auch für den Nachweis von miRNAs aus Javaneraffen eingesetzt werden konnte. In der basis pontis eines nicht infizierten Javaneraffen konnten 56 exprimierte miRNAs nachgewiesen werden. In einem BSE-infizierten Tier wurden sechs miRNAs identifiziert, die abweichend exprimiert waren. Mit einer qRT-PCR wurden die miRNAs hsa-miR26a, hsa-miR342 und hsa-miR494 auch bei sechs weiteren BSEinfizierten Tieren als hochreguliert bestätigt. Die Expression der hsa-miR342 war auch in der basis pontis von humanen SCJD Patienten hochreguliert. 


\section{Diskussion}

\subsection{Prionenerkrankung in BSE-infizierten Primaten}

In der vorliegenden Arbeit sollte die Übertragung von BSE auf Javaneraffen (Macaca fascicularis) als Modell für vCJD im Menschen analysiert und charakterisiert werden. Die Arbeit ist Teil der EU-Studie QLK1-CT-2002-01096, die das Risiko für Menschen ermitteln soll, durch Aufnahme BSE-kontaminierter Nahrungsmittel an vCJD zu erkranken. Eine Verbindung von BSE zu vCJD wurde bereits früh aufgrund biochemischer und epidemiologischer Hinweise vermutet (COLLINGE et al., 1996, WILL et al., 1996; HILL et al., 1997). Die Theorie wurde über eine erfolgreiche Infektion nicht humaner Primaten mit vCJD durch Verfütterung BSE-kontaminierten Rinderhirns erhärtet (LASMÉZAS et al., 2005). Die EU-Studie QLK1-CT-2002-01096 soll unter anderem die minimale Dosis an BSE-infektiösen Agens ermitteln, durch die vCJD im Javaneraffen ausgelöst wird. Diese Ergebnisse sollen anschließend auf den Menschen übertragen werden.

Diese Arbeit beschäftigte sich mit zwei Aufgabenbereichen. Erstens sollte die Untersuchung der Prionenerkrankung in nicht humanen Primaten etabliert und als passendes Modell für vCJD bestätigt werden. Die Prionenerkrankung sollte anschließend charakterisiert werden. In einem zweiten Teil sollte nach neuen Markern für Prionenerkrankungen gesucht werden.

Im Rahmen der EU-Studie wurde sechs Javaneraffen $50 \mathrm{mg}$ Hirnhomogenat BSE infizierter Rinder intracerebral injiziert. Dies diente als Kontrolle für die orale Infektion von Javaneraffen mit BSE-Hirn und der Etablierung der Nachweismethoden. Javaneraffen wurden schon früher als Tiermodell für die intracerebrale Übertragung von Scrapie (GIBBS et al., 1972) und BSE (LASMÉZAS et al., 1996) eingesetzt. In der vorliegenden Studie wurde erstmals eine statistisch relevante Anzahl von Tieren infiziert und untersucht.

\subsubsection{Nachweis von simianem vCJD in BSE-infizierten Javaneraffen}

Bereits während der klinischen Phase wurden Übereinstimmungen mit humanen Prionenerkrankungen deutlich. Die Symptome der Tiere (Ataxie, Schreckhaftigkeit, Demenz) (3.1) entsprachen denen von CJD Patienten (CREUTZFELDT, 1920; JAKOB, 1921a und 1921b). Neuropathologisch war die simiane Prionenerkrankung gekennzeichnet durch komplexe PrP-Ablagerungen im Bereich absterbender Neurone, die von Spongiformität umgeben waren (3.2.3). Diese neuropathologischen 
Strukturen sind den floriden Plaques des vCJD (WILL et al., 1996) sehr ähnlich. Es wäre möglich, dass diese Strukturen im simianen Modell den humanen floriden Plaques entsprechen. Dafür spricht auch, dass der biochemische Vergleich des simianen $\operatorname{PrP}^{\text {res }}$ mit dem PrP ${ }^{\text {res }}$ verschiedener CJD-Typen ergab, dass die simiane Prionenerkrankung dem humanen vCJD (COLLINGE et al., 1996) entsprach (3.3.1). Ein solches biochemisches Profil wird für die Übertragung von BSE auf Javaneraffen von LASMÉZAS et al. (1996) bestätigt. Nach diesen Kriterien waren die Javaneraffen an simianem vCJD erkrankt.

Wie bereits beschrieben wird vermutet, dass das humane vCJD durch die Aufnahme BSE-kontaminierter Lebensmittel entstanden ist. In der vorliegenden Arbeit sind viele Hinweise gefunden worden, dass simianes VCJD auch durch i.c. Infektion hervorgerufen werden kann. Demnach wird dieser CJD-Subtyp nicht durch den Übertragungsweg, sondern durch das infektiöse Agens festgelegt. Dies legen auch Ergebnisse aus Übertragungsstudien von Scrapie auf Mausmodelle nahe, da subtypspezifische Charakteristika nach Infektion über die orale und die intracerebrale Route (INOUE et al., 2005) und auch nach der Übertragung auf unterschiedliche Mausstämme erhalten bleiben (BRUCE et al., 1993). Daher können die Ergebnisse der Analyse der i.c. infizierten Javaneraffen auf humanes vCJD übertragen werden.

Für die Untersuchung der CJD-Subtypen wurden zwei verschiedene Antikörper eingesetzt. Der 3F4 Antikörper zeigte in dieser Arbeit ein Glykosylierungsmuster wie in der Literatur beschrieben (COLLINGE et al., 1996). Der 11C6 Antikörper hingegen zeigte eine abweichende Glykoformspezifität (3.3.1). Für diesen Antikörper wird ein konformationelles Epitop vermutet (KRASEMANN et al., 1996). Die Vermutung konnte auch in dieser Arbeit bestätigt werden (3.2.1). Die Spezifität des $11 \mathrm{C} 6$ Antikörpers zum PrP konnte mit mehreren Experimenten bekräftigt werden. Er stellte PrP ${ }^{\text {res }}$ wie von BOLTON et al. (1982) beschrieben im Western Blot und zusätzlich im SandwichELISA dar (3.2.2). Nach Deglykosylierung wies er nur die von HARAGUCHI et al. (1989) beschriebene unglykosylierte Isoform nach (3.2.3). Außerdem war er in der Lage, sCJD Typ1 und sCJD Typ2 anhand ihres Migrationsverhaltens (PARCHI et al., 1996) zu unterscheiden (3.3.1). Für VCJD wurde bisher immer ein distinktes Glykosylierungsmuster beschrieben, allerdings wurden diese Studien zumeist mit dem 3F4-Antikörper durchgeführt (COLLINGE et al., 1996; HILL et al., 1997; PARCHI et al., 2000b; YULL et al., 2006). Es wurde jüngst beschrieben, dass das Glykosylierungsmuster des $\mathrm{PrP}^{\mathrm{C}}$ in Abhängigkeit vom Nachweisantikörper variiert (KuCzIUS et al., 2007). Demnach scheint das distinkte Glykosylierungsmuster des $\mathrm{PrP}^{\mathrm{res}}$ bei vCJD weniger auf die Glykosylierung des $\mathrm{PrP}^{\mathrm{res}}$ (COLLINGE et al., 1996), sondern viel mehr auf den Nachweis selbst zurückzuführen zu sein. 


\subsubsection{Charakterisierung von $\operatorname{PrP}^{\text {res }}$ bei simianem vCJD}

Für das simiane vCJD wurden unterschiedliche Inkubationszeiten beobachtet. Anhand dieser Tendenzen wurden die Tiere in eine schnell und eine langsam progressierende Gruppe eingeteilt (3.1). Auch für Kuru, eine erworbene humane Prionenerkrankung, wurden Fälle beschrieben, die erst nach einer stark verlängerten Inkubationszeit auftraten (COLLINGE et al., 2006). Unterschiedliche Inkubationszeiten nach Infektion mit dem gleichen Agens können durch verschiedene Genotypen des Wirts-PrP verursacht werden (DICKINSON et al., 1971; PARCHI et al., 1999). Bei CJD sind diese Varianzen zumeist auf einen Polymorphismus des Codons 129 zurückzuführen (PARCHI et al., 1999). In dem hier gewählten Tiermodell kann der PrP-Genotyp keinen Einfluss auf die Inkubationszeit genommen haben, da die Javaneraffen eine identische PrP-Sequenz aufwiesen (3.1).

Es ist möglich, dass die unterschiedlichen Inkubationszeiten der Javaneraffen auf unterschiedliche Subtypen von Prionenerkrankungen (Prionenstämme) zurückzuführen sind. Prionenstämme bezeichnen unterschiedliche Phänotypen der gleichen Prionenerkrankung. Für die Übertragung von Scrapie auf Mäuse und Hamster wurde beschrieben, dass die Inkubationszeiten spezifisch für einzelne Scrapiestämme (Fraser et al., 1968; BRUCE et al., 1991) und für die Wirtsspezies (LOWENSTEIN et al., 1990) waren. Neben den unterschiedlichen Inkubationszeiten zeichnen sich Prionenstämme durch Unterschiede im Migrationsverhalten (PARCHI et al., 1996), Glykosylierungsmuster (COLLINGE et al., 1996) oder der konformationellen Stabilität (SAFAR et al., 1998) von $\operatorname{PrP}^{\text {res }}$ oder durch die intracerebrale Verteilung der Spongiformität (FRASER et al., 1968), der PrP-Ablagerungen (Bruce et al., 1991) und des PrPres (TARABoulos et al., 1992; DeARMOND et al., 1997; PARCHI et al., 1999) aus. Die Theorie, das die Javaneraffen unterschiedliche Prionenstämme ausgebildet haben, wird dadurch gestützt, dass die Inkubationszeit der Tiere der ersten Gruppe (Mittelwert: 138 Wochen (3.1)) auch von LASMÉZAS et al. (1996) beschrieben wird. Daher scheint diese Inkubationszeit spezifisch für die Infektion von Javaneraffen mit BSE zu sein (FRASER et al., 1968; BRUCE et al., 1991). Die zweite Gruppe könnte einen anderen Prionenstamm ausgebildet haben, der mit einer längeren Inkubationszeit (Mittelwert: 196 Wochen (3.1)) korreliert. Es wäre möglich, dass dieser strain in Javaneraffen bisher aufgrund der geringen Anzahl infizierter Tiere nicht beobachtet werden konnte (LASMÉZAS et al., 1996 und 2005). Es könnte aber auch sein, dass in dieser Studie bereits im Inokulum unterschiedliche Stämme vorlagen. Es wurde lange Zeit angenommen, dass BSE nur einen strain ausbildet und dass VCJD aus diesem Grund ein distinktes Profil zeigt (HEAD et al., 2004). 
Mittlerweile werden jedoch auch für BSE mehrere Prionenstämme diskutiert (CASALONE et al., 2004, BuSCHMANN et al., 2004). Diese zeigen nach einer Übertragung auf transgene Mäuse, die das bovine PrP überexprimieren, verkürzte oder verlängerte Inkubationszeiten (BUSCHMANN et al., 2006). Die verlängerte Inkubationszeit des simianen VCJD in der zweiten Gruppe könnte also ein erster Hinweis auf die Übertragung eines zweiten BSE-Stämme auf Primaten darstellen. Außerdem wurden die Javaneraffen mit einem Gemisch aus Hirnhomogenaten von 11 Rindern infiziert. Da zum Zeitpunkt der Infektion der Javaneraffen nur ein BSE strain bekannt war, wurde das Inokulum nicht auf die Existenz unterschiedlicher Stämme untersucht. Aber auch die humane Infektion mit BSE ist wahrscheinlich durch den Konsum von Fleisch verschiedener BSE-erkrankter Rinder erfolgt (COLLEE et al., 2006). Sollte sich daher die Hypothese bestätigen, dass die Javaneraffen mehrere vCJD Subtypen oder Prionenstämme ausgebildet haben, wäre dies auch für die humanen vCJD Fälle zu erwarten. Dann müsste mit weiteren vCJD-Patienten gerechnet werden, die erst nach einer längeren Inkubationszeit erkranken.

Erst in der letzten Zeit zeigten sich Hinweise, dass im Hirn von vCJD Patienten Stämme koexistieren können. Diese können mit subtypspezifischen Antikörpern nachgewiesen werden (YULL et al., 2006). Dies ist auch für das simiane VCJD wahrscheinlich. Es wäre möglich, dass sich die Inkubationszeiten der vCJD-Fälle und auch die simianen VCJD mit der Existenz eines weiteren Prionenstämme korreliert. Dies konnte nicht überprüft werden, da die Inkubationszeit bzw. der genaue Zeitpunkt der Infektion bei humanen vCJD-Fällen nicht bekannt ist (COLLEE et al., 2006) und ein subtypspezifischer Antikörper zur Überprüfung im simianen Modell nicht zur Verfügung stand. Die Hypothese von unterschiedlichen Prionenstämme bei simianem vCJD konnte dadurch gestützt werden, dass die beiden Gruppen durch ihr neuropathologisches Profil (3.2.3) voneinander unterschieden werden konnten, wie dies für Scrapiestämme beschrieben wurde (DEARMOND et al., 1997). Außerdem zeichnet sich das simiane vCJD mit längerer Inkubationszeit durch eine tendenziell größere Menge an $\mathrm{PrP}^{\text {res }}$ pro Hirnäquivalentmenge (3.3.2) aus. Über die intracerebrale Verteilung des $\mathrm{PrP}^{\text {res }}$ konnten jedoch keine Stämme des simianen vCJD unterschieden werden (3.3.2). Für VCJD ist bisher kein $\mathrm{PrP}^{\text {res }}$ Verteilungs-Profil beschrieben, es scheint nach den Ergebnissen dieser Arbeit dem sCJD-MM2thalamic Phänotyp (PARCH et al., 1999) zu entsprechen und unabhängig von der Inkubationszeit zu sein. Unterschiedliche Scrapiestämme können durch die Konformationelle Stabilität des PrPres unterschieden werden (SAFAR et al., 1998; PERETZ et al., 2001). Diese Beobachtung konnte für das simiane vCJD nicht bestätigt werden, die konformationelle Stabilität des $\operatorname{PrP}^{\text {res }}$ korrelierte nicht mit der 
Inkubationszeit und dem Neuroprofil (3.3.3). Die Konformation des $\operatorname{PrP}^{\text {res }}$ scheint nach den Ergebnissen dieser Arbeit aber von der Hirnregion abhängig zu sein (3.3.3). Es wäre demnach möglich, dass in den Hirnregionen unterschiedliche Stämme vorliegen. Für SCJD wurde über das Migrationsverhalten des $\mathrm{PrP}^{\mathrm{res}}$ ermittelt, dass in einzelnen Hirnregionen eines Patienten unterschiedliche SCJD-Phänotypen existieren können (PUOTI et al., 1999; HEAD et al., 2004, IRONSIDE et al., 2005, POLYMENIDOU et al., 2005). Für VCJD wurde dies jedoch nicht bestätigt (HEAD et al., 2004), und auch für das simiane vCJD wurde in allen Hirnregionen unabhängig vom der konformationellen Stabilität ebenfalls nur ein Phänotyp identifiziert (3.3.2). Die

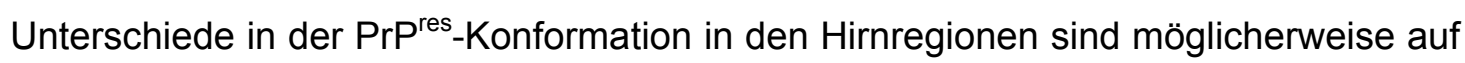
unterschiedliche pH-Werte zurückzuführen. Dafür spricht, dass diese sowohl durch Metall-Ionen (WADSWORTH et al., 1999) als auch über den pH-Wert beeinflusst (ZANUSSO et al., 2001) werden und in Hirnhomogenaten aus unterschiedlichen Hirnregionen desselben CJD Patienten verschiedene $\mathrm{pH}$-Werte nachgewiesen wurden (NOTARI et al., 2004). Die Stabilität scheint zusätzlich, zumindest im simianen CJD, spezifisch für die jeweiligen Hirnregionen zu sein. Bisherige vergleichende Typisierungen mit Hilfe der konformationellen Stabilität des $\mathrm{PrP}^{\text {res }}$ wurden unabhängig von den Hirnregionen (ZOU et al., 2004) oder an unterschiedlichen Hirnregionen zweier Individuen (XIE et al., 2006) durchgeführt. Nach den Ergebnissen dieser Arbeit ist ein solcher Vergleich nicht aussagekräftig. Daher sollten in Zukunft eine Typisierung über die konformationelle Stabilität des $\operatorname{PrP}^{\text {res }}$ nur in Abhängigkeit von den Hirnregionen durchgeführt werden.

Eindeutig könnte die Existenz von zwei verschiedenen Prionenstämme im simianen vCJD durch eine weitere Übertragung nachgewiesen werden (KIMBERLIN et al., 1987 und 1989, BRUCE et al., 2003). Es wäre zu erwarten, dass die potentiellen Prionenstämme des simianen vCJD nach einer Übertragung des infektiösen Agens auf weitere Javaneraffen eindeutig zu unterscheiden sind. Eine zweite Passage von simianem vCJD würde in vivo aber weitere 1000 bis 1400 Tage in Anspruch nehmen. Um dieses Problem zu umgehen, sollte ein Zellkultursystem für die serielle Übertragung von simianem vCJD etabliert werden. Die Infektion einer murinen Zelllinie konnte mit mausadaptiertem Scrapie erfolgreich durchgeführt werden, mit simianem vCJD jedoch nicht (3.4). Die Übertragung des simianen vCJD auf ein murines Zellkulturmodell war wahrscheinlich nicht möglich, da die Speziesbarriere hier nicht überwunden werden konnte (PATTISON et al., 1965). Diese Theorie wird dadurch bestätigt, dass CJD bisher nur auf eine humane Neuroblastomazelllinie erfolgreich übertragen werden konnte (LADOGANA et al., 1995), nicht jedoch auf murine Zellen. Eine Übertragung von CJD auf Wildtypmäuse ist zwar möglich 
(MANUELIDIS et al., 1978), aber die Inkubationszeit der resultierenden Prionenerkrankung ist in der ersten Passage sehr lang und wird erst nach einer weiteren intra-Spezies Übertragung kürzer (MURAMOTO et al., 1992). Eine Übertragung von simianem VCJD auf eine humane Zellinie wäre wahrscheinlich Erfolg versprechender, da der Nachweis der Prionenerkrankung in den Zellkulturmodellen jedoch aus technischen Gründen nicht etabliert werden konnte (3.4), wurde dieser Ansatz nicht weiter verfolgt.

In der vorliegenden Arbeit konnte gezeigt werden, dass die i.c. Infektion von nicht humanen Primaten mit BSE zu einer Prionenerkrankung führt, die mit humanem vCJD vergleichbar ist (WILL et al., 1996; CoLLINGE et al., 1996). Dies belegt, dass die Ergebnisse dieser Arbeit auf humanes VCJD übertragen werden können. Die Ergebnisse der Typisierung legen aber nahe, dass der Marker für vCJD, das Glykosylierungsmuster des $\mathrm{PrP}^{\text {res }}$ im Western Blot, von der Nachweismethode abhängig ist. Zusätzlich konnte in dieser Arbeit gezeigt werden, dass die konformationelle Stabilität des $\mathrm{PrP}^{\mathrm{res}}$ spezifisch für bestimmte Hirnregionen ist. Daher sollten zukünftige Typisierungen über die konformationelle Stabilität nur gleiche Hirnregionen für einen Vergleich heranziehen.

Zum ersten Mal wurden in dieser Arbeit unterschiedliche Inkubationszeiten für simianes VCJD beschrieben. Diese könnten auf unterschiedliche Prionenstämme in dieser Krankheit hinweisen. Da in dieser Studie erstmals eine statistisch relevante Anzahl von Tieren infiziert wurde, könnte dieses Phänomen in den vorherigen Studien verpasst worden sein (Lasmézas et al., 1996; 2005). Es ist aber auch möglich, dass bereits im Inokulum verschiedene BSE-Stämme (CASALONE et al., 2004; BUSCHMANN et al., 2004) vorhanden waren. Für die Typisierung von vCJDStämme stehen noch keine etablierten Methoden zur Verfügung, da erst in letzter Zeit Hinweise auf verschiedene Stämme bei dieser Prionenerkrankung gefunden wurden (YULL et al., 2006). Im simianen Modell konnte das neurologische Profil und die relative $\operatorname{PrP}^{\text {res }}$ Menge mit der Inkubationszeit korreliert werden, die intracerebrale Verteilung und die konformationelle Stabilität des $\operatorname{PrP}^{\text {res }}$ war für beide potentiellen Stämme vergleichbar. Da vCJD z.B. über Bluttransfusionen von Mensch zu Mensch übertragen werden kann (LLEWELYN et al., 2004), stellen asymptomatische Träger der Krankheit ein großes Risiko dar. Die Ergebnisse dieser Arbeit legen nahe, dass in Zukunft weitere vCJD-Fälle zu erwarten sind, die erst nach einer längeren Inkubationszeit zum Ausbruch kommen. Das Wissen um diese potentiellen Fälle sollte in die Risikoabschätzung von vCJD für die nächsten Jahre miteinbezogen werden. 


\subsection{Prionenerkrankungen und mikroRNAs}

Der zweite Teil dieser Arbeit beschäftigte sich mit der Suche nach neuen Markern für Prionenerkrankungen, die unabhängig von $\mathrm{PrP}^{\text {res }}$ sind. PrPres kann derzeit nur post mortem nachgewiesen werden, da die Sensitivität der zugelassenen Tests nicht ausreicht, um den Erreger z.B. im Blut nachzuweisen. Da aber ein Risiko besteht, besonders vCJD z.B. über Bluttransfusionen zu übertragen (LLEWELYN et al., 2004), wird ein Marker benötigt, der bereits intra vitam eine Prionenerkrankung nachweisen kann.

In den letzten Jahren wurde der Einfluss von miRNAs sowohl auf die Ontogenese (REINHART et al., 2000) und Stoffwechselvorgänge (LAU et al., 2001, XU et al., 2003; PoY et al., 2004; TELEMAN et al., 2006) als auch auf Virusinfektionen (PFEFFER et al., 2004, LECELLIER et al., 2005) und Krebs (CALIN et al., 2002) beschrieben. Eine Wechselwirkung von Prionen und miRNAs wäre auf verschiedene Weisen denkbar. So könnte die Expression von miRNAs als Reaktion auf die Krankheit reguliert werden. Andererseits könnten miRNAs auch direkt in den Krankheitsverlauf involviert sein. Disregulierte miRNA-Expression bei Krankheiten wurde in Bezug auf die Erforschung humaner Krebserkrankungen (CALIN et al., 2002; MICHAEL et al., 2003; METZLER et al., 2004; HE et al., 2005), aber auch in anderen Erkrankungen wie z.B. dem Tourette-Syndrom (ABELSON et al., 2005) untersucht. Für Prionenerkrankungen wurde bisher noch keine Studie über den Einfluss von miRNAs beschrieben. Jedoch wurden in den letzten Jahren Interaktionen des PrP mit RNA Molekülen beschrieben. Schon länger ist bekannt, dass RNA Aptamere spezifisch an das PrP binden (WEISs et al., 1997). Die Struktur der PrP bindenden Aptamere ist der von miRNAs nicht unähnlich (MERCEY et al., 2006). Zusätzlich wurde von zwei Arbeitsgruppen unabhängig voneinander beschrieben, dass RNAs die Konversion von $\operatorname{PrP}^{C}$ zu PrP ${ }^{S c}$ beeinflussen können (PROSKE et al., 2002; DELEAULT et al., 2003). Daher wurde in dieser Arbeit die Expression von miRNAs bei Prionenerkrankungen untersucht.

\subsubsection{Expression von miRNAs in der basis pontis von Javaneraffen}

Die Expression von miRNAs im Hirn von Javaneraffen wurde bisher in keiner Studie untersucht. Derartige Expressionsprofile werden zumeist mit Hilfe von miRNAMicroArrays durchgeführt, da sie weitaus weniger RNA als z.B. Northern Blots und Klonierungsstrategien benötigen (LIU et al., 2004) und weniger zeitaufwendig sind (BABAK et al., 2004). In der vorliegenden Arbeit wurde ein miRNA-MicroArray eingesetzt, der für die Analyse von humanen miRNAs entwickelt wurde (mirVana miRNA Probe Set Version 1). In der miRNA-Fraktion aus der basis pontis eines nicht 
BSE-infizierten Javaneraffen wurden 56 exprimierte miRNAs nachgewiesen (3.5). Ein Teil dieser miRNAs sind auch im humanen und murinen Hirn exprimiert (Tab. 4.1; BABAK et al., 2004; LIU et al., 2004; SEMPERE et al., 2004). Diese Ergebnisse legen nahe, dass miRNAs des Javaneraffen spezifisch mit dem miRNA-MicroArray nachgewiesen werden können. Dies wird auch dadurch bestätigt, dass MicroArrays mit humanen makroRNA-Sequenzen erfolgreich mit RNA von Javaneraffen getestet wurden (WALKER et al., 2006). Da das Genom der Javaneraffen eine große Homologie zu dem des Menschen aufweist (SCHÄTZL et al., 1995), ist die Wahrscheinlichkeit hoch, dass auch ein miRNA-MicroArray mit humanen Sequenzen spezifische Ergebnisse über die miRNA-Expression in Javaneraffen liefert. Die bisherigen Studien zeigen leicht voneinander abweichende miRNAExpressionsprofile und wurden unabhängig von Hirnregionen durchgeführt (BABAK et al., 2004; LIU et al., 2004; SEMPERE et al., 2004). Daher ist zu vermuten, dass auch in dieser Arbeit miRNAs identifiziert wurden, deren Expression im Hirn bisher noch nicht beschrieben ist. Tatsächlich wurden 10 miRNAs identifiziert, deren Expression bisher nur für andere Gewebe beschrieben war (BABAK et al., 2004; LIU et al., 2004; SEMPERE et al., 2004) (Tab. 4.1). Demnach könnten sie spezifisch in der basis pontis exprimiert sein. Zusätzlich wurden 4 miRNAs identifiziert, für die bisher noch nicht überprüft wurde, ob sie im Hirn exprimiert sind. Von diesen ist aber für die hsamiR342 ist eine Expression in Neuronen beschrieben (KIM et al., 2004). Daher können diese sowohl allgemein im Hirn oder im auch spezifisch in der basis pontis exprimiert sein. 
Tabelle 4.1: Exprimierte miRNAs in der basis pontis von Javaneraffen

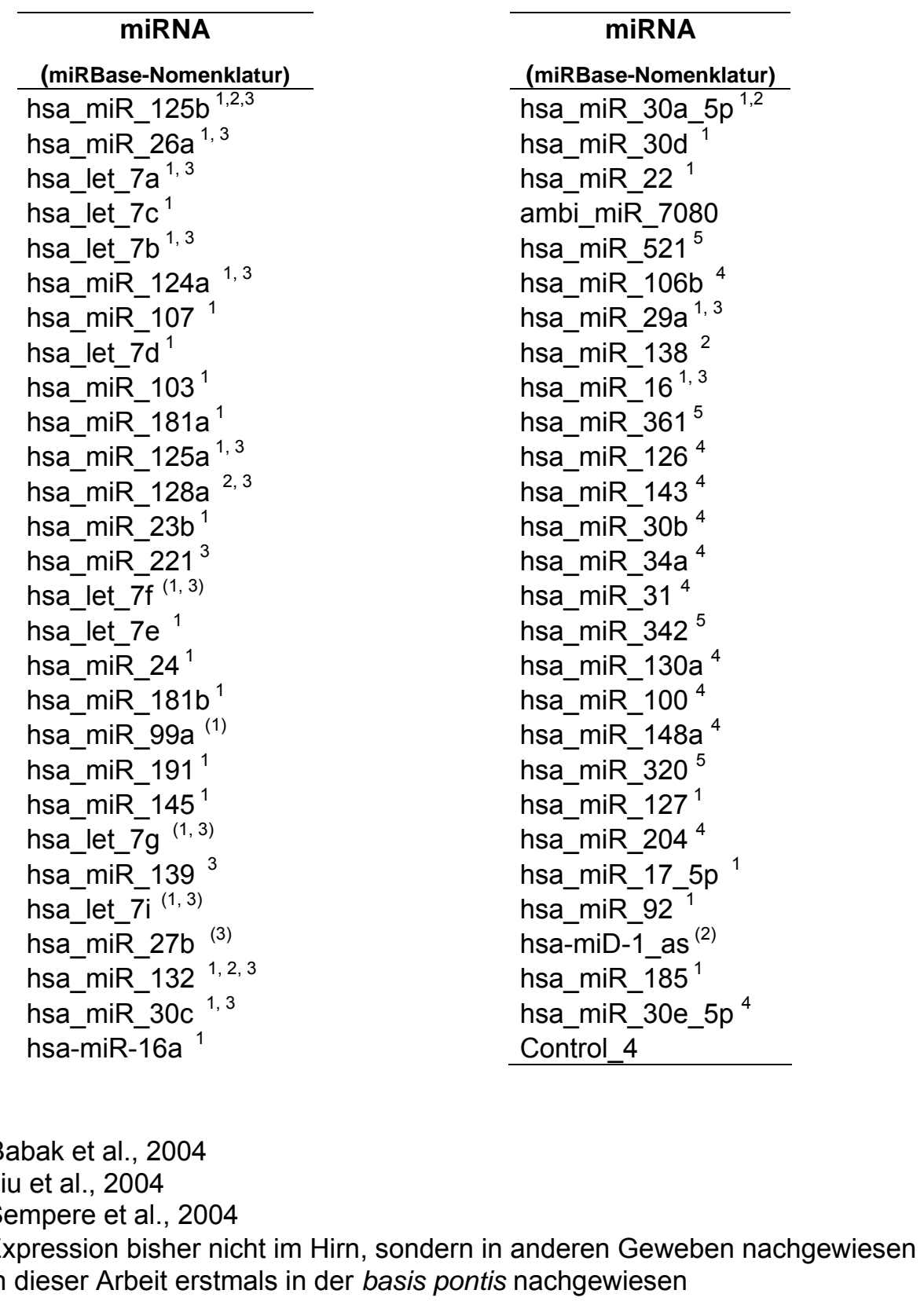




\subsubsection{Nachweis von differentiell exprimierten miRNAs bei simianem vCJD}

Da viele essentielle Prozesse des Stoffwechsels über miRNAs reguliert werden, ist es wahrscheinlich, dass eine abweichende miRNA-Expression einen Einfluss auf verschiedene Krankheiten nimmt (DI LEVA et al., 2006). Zum Beispiel ist die Disregulation von miRNAs mit malignem Wachstum von Zellen verknüpft (ESQUELAKerscher und Slack, 2006; Hammond, 2006; CAlin und Croce, 2006). Das PrP, das in der Pathogenese dieser Erkrankungen eine zentrale Rolle spielt, interagiert spezifisch mit synthetischen RNA-Aptameren (WEISS et al., 1997; SEKIYA et al., 2005; MERCEY et al., 2006). Deren Struktur ist mit der von miRNAs vergleichbar. Zusätzlich wurde die Hypothese aufgestellt, dass die Konversion des PrP abhängig von RNAMolekülen ist (DELEAULT et al., 2003). Konsistent damit wurden RNA-Aptamere isoliert, die diese Konversion beeinflussen können (PROSKE et al., 2002). Da angenommen wird, dass die Konversion einen zentralen Aspekt der Pathogenese von Prionenerkrankungen darstellt, könnte die Disregulation von RNAs wie z.B. miRNAs im Zusammenhang mit Prionenerkrankungen stehen. In der basis pontis eines an simianem VCJD erkrankten Javaneraffen wurden sechs disregulierte miRNAs entdeckt (3.5). In biologischen Replikaten konnten die miRNAs hsa-miR26a, hsa-miR342 und hsa-miR494 als differentiell reguliert bestätigt werden (3.5). Die Expression der miRNAs ist bei simianem vCJD hochreguliert, bzw. erst in Folge der Erkrankung nachweisbar (3.5). Ein möglicher Zusammenhang dieser miRNAs mit Prionenerkrankungen wird dadurch bekräftigt, dass die Disregulation der hsa-miR342 im Rahmen dieser Arbeit auch in der basis pontis von humanen SCJD Patienten nachgewiesen werden konnte (3.5). Außerdem gibt es Hinweise, dass im Hirn von Scrapie-infizierten Mäusen die hsa-miR342 ebenfalls hochreguliert ist (SABA und BоOTH, persönliche Mitteilung und Poster PA-46 auf dem Kongress „Prion 2006“ in Turin).

\subsubsection{Charakterisierung differentiell exprimierter miRNAs bei simianem vCJD}

Über die Identifizierung potentieller Zielgene der disregulierten miRNAs könnte die Hypothese, dass diese in einem Zusammenhang mit Prionenerkrankungen stehen unterstützt werden. Die Identifizierung solcher Zielgene wird durch die geringe Länge der miRNAs und die unvollständige Bindung der miRNA an die Ziel-mRNA erschwert. Hinzu kommt, dass eine miRNA die Expression mehrerer Gene regulieren kann (LIM et al., 2005). Es wurden einige Algorithmen entwickelt, um die mRNA:miRNA Bindung zu berechnen (LEWIS et al., 2003; JOHN et al., 2004; 
KIRIAKIDOU et al., 2004). Diesen liegen jedoch verschiedene Prämissen für die Berechnungen zu Grunde, daher liefern sie unterschiedliche Ergebnisse (XU et al., 2007). Diese sind in den Datenbanken Targetscan (LEWIS et al., 2003 und 2005) miRBaseTarget (GRIFFITH-JONES et al., 2006) oder PicTar-Vert (KREK et al., 2005) zugänglich. Eine exemplarische Auflistung der potentiellen Zielgene ist in Tabelle 4.2 zusammengesellt. Eine Gruppe von Zielgenen aller bei simianem vCJD disregulierten miRNAs kodierte für Transkriptionsfaktoren und neuronal exprimierte Proteine. Die miRNAs regulieren demnach möglicherweise die Transkription dieser Gene in Neuronen, die während der Prionenerkrankung degenerieren. Das Ziel dieser Expressionsanalyse war es, miRNAs zu identifizieren, die im Zusammenhang mit Prionenerkrankungen stehen. Tatsächlich konnten die hsa-miR26a, hsa-miR342 und hsa-miR494 identifiziert werden, die bei simianem vCJD differentiell exprimiert waren. Es wird angenommen, dass das PrP die zelluläre Antwort auf oxidativen Stress reguliert (BROWN et al., 1997) und die Apoptose beeinflusst (KURSCHNER et al., 1995; SPIELHAUPTER et al., 2001; PAITEL et al., 2002). Auch die differentiell exprimierten miRNAs könnten über ihre Zielgene (Tab. 4.2) diese Stoffwechselwege regulieren. Daher könnten die Wirkmechanismen des PrP während einer Prionenerkrankung disreguliert sein, was sich in der miRNA-Expression widerspiegelt. Des Weiteren wurden für alle miRNAs Zielgene aus der Familie der solute carrier families identifiziert. Ein Zusammenhang mit dem PrP oder Prionenerkrankungen bzw. anderen neurodegenerativen Krankheiten ist bisher nicht beschrieben. Diese Wechselwirkung müsste näher untersucht werden.

Tabelle 4.2: Potentielle Zielgene der bei simianem vCJD disregulierten miRNAs

\begin{tabular}{|c|c|c|c|}
\hline & $\begin{array}{l}\text { hsa-miR26a } \\
\text { (4x hochreguliert) }\end{array}$ & $\begin{array}{l}\text { hsa-miR342 } \\
\text { (3x hochreguliert) }\end{array}$ & $\begin{array}{l}\text { hsa-miR494 } \\
\text { (6x hochreguliert) }\end{array}$ \\
\hline Apoptose & $\begin{array}{l}\text { DAPK1 } \\
\text { BAK1 }\end{array}$ & MRFAP1 & $\begin{array}{l}\text { MORF4L2 } \\
\text { API5 }\end{array}$ \\
\hline Oxidativer Stress & STK39 & CSK & \\
\hline Neuronal & CAST & $\begin{array}{l}\text { GRM8 } \\
\text { NBEA }\end{array}$ & $\begin{array}{l}\text { GRIK2 } \\
\text { GABAR5 } \\
\text { NBEA }\end{array}$ \\
\hline $\begin{array}{l}\text { Transkriptions- } \\
\text { faktoren }\end{array}$ & NAP1L5 & E2F3 & ELF2 \\
\hline $\begin{array}{l}\text { Solute carrier } \\
\text { (Carrier Proteine) }\end{array}$ & $\begin{array}{l}\text { SLC25A16 } \\
\text { SLC38A2 } \\
\text { SLC9A2 }\end{array}$ & SLC6A8 & $\begin{array}{l}\text { SLC25A16 } \\
\text { SLC26A3 }\end{array}$ \\
\hline $\begin{array}{l}\text { F-Box Protein } \\
\text { (Ubiquitin-Protein- } \\
\text { Ligasen) } \\
\text { neurodegenerative } \\
\text { Krankheiten }\end{array}$ & $\begin{array}{l}\text { FBX011 } \\
\text { FBX019 }\end{array}$ & $\begin{array}{l}\text { FBXO33 } \\
\text { ATXN2L }{ }^{1}\end{array}$ & $\begin{array}{l}\text { FBXO11 } \\
\text { FBXO28 } \\
\text { FBXO33 } \\
\text { HIP2 }\left(E 2_{25 K}\right)^{2}\end{array}$ \\
\hline
\end{tabular}

${ }^{1}$ Steht in Verbindung mit Spinozerebelläre Ataxie Typ 2 (SCA2)

${ }^{2}$ Steht in Verbindung mit Chorea-Huntington 
Interessanterweise wurden für alle miRNAs mRNA von F-Box-Proteinen als mögliche Zielgene gefunden. Diese Gruppe von Proteinen bezeichnet Ubiquitin-ProteinLigasen. Im Mausmodell wurde nachgewiesen, dass eine knock-out Mutation der potentiellen E3-Ubiquitin-Protein-Ligase Mahogunin zu einer nicht übertragbaren spongiformen Neurodegeneration führt (YOON-KIM et al., 2007). Für die miRNA hsamiR494 wurde zusätzlich das Gen, das für das huntingtin interacting protein 2 (HIP2 oder E2 $25 k$ ) kodiert, als Zielgen gefunden. Dieses Protein besitzt ebenfalls eine Ubiquitin-Protein-Ligase-Aktivität und interagiert mit dem Huntingtin-Protein (KALCHMAN et al., 1996), einem Protein, dessen Mutation zur Ausbildung der neurodegenerativen Krankheit Chorea-Huntington führt (RUBINZSTEIN et al., 1996). Es wird vermutet, dass der Verlust der E2 $25 k$ :Huntingtin Interaktion dazu führt, dass das Huntingtin-Protein nicht mehr abgebaut wird (KALCHMAN et al., 1996) und sich Proteinaggregate bilden (DE PRIL et al., 2007). Das E2 $2_{25 \mathrm{~K}}$ ist auch an der Bildung amyloider $\beta$-Peptide und einer dadurch vermittelten Neurodegeneration beteiligt und wird deshalb mit Alzheimer in Verbindung gebracht (SONG et al., 2003). Daher scheint eine Beteiligung von Ubiquitin-Protein-Ligasen auch an Prionenerkrankungen denkbar. Im Verlauf der Prionenerkrankung könnten die hochregulierten miRNAs die mRNA der Ubiquitin-Protein-Ligasen binden und die Translation inhibieren. Dadurch könnte eine Spongiformität hervorgerufen werden, wie dies für das Mahogunin oder bei Chorea-Huntington beschrieben ist. Auch für die miRNA hsa-miR342 wurde eine mögliche Verbindung zu neurodegenerativen Erkrankungen entdeckt. Sie scheint mit der mRNA des Ataxin 2-like Proteins zu interagieren. Die Funktion dieses Proteins ist noch ungeklärt, aber das homologe Protein Ataxin 2 führt in seiner mutierten Form zu der neurodegenerativen Krankheit Spinozerebelläre Ataxie Typ 2 (SCA2) (PULST et al., 1996; ZOGHBI et al., 2000). Das mutierte Ataxin 2 nimmt eine veränderte Konformation an und aggregiert zu Fibrillen, die eine Neurodegeneration auslösen (Ross et al., 2004). Das Ataxin 2 bindet an das Endophilin A3 (RALSER et al., 2005), ein Protein, mit dem auch das Huntingtin-Protein interagiert (SITTLER et al., 1998). Daher werden für das Ataxin 2 und das Huntingtin-Protein ähnliche Wirkmechanismen angenommen (RALSER et al., 2005). Es ist wahrscheinlich, dass auch die miRNAs, die diese Proteine regulieren, einen vergleichbaren Einfluss auf die Pathogenese von neurodegenerativen Krankheiten nehmen. Da das Ataxin 2-like Protein eine hohe Homologie zu dem Ataxin 2 aufweist, wirkt die miRNA hsa-miR342 wahrscheinlich ähnlich wie die hsa-miR494 auf die Bildung neurodegenerativer Krankheiten. Es wäre möglich, dass diese miRNAs allgemein in neurodegenerativen Krankheiten hochreguliert sind. Das Expressionsprofil kann aber auch spezifisch für 
Prionenerkrankungen sein und nur ähnlichen Mechanismen unterliegen wie in anderen neurodegenerativen Erkrankungen.

Für Prionenerkrankungen gibt es keinen zugelassenen intra vitam Test. Da diese Erkrankungen übertragbar sind, stellen undiagnostizierte Fälle ein hohes Risiko bei Transplantationen, Bluttransfusionen oder chirurgischen Eingriffen dar (LLEWELYN et al., 2004). Da miRNAs während verschiedener Krankheiten eine abweichende Expression zeigen (DI LEVA et al., 2006), wäre es möglich, Prionenerkrankungen über ein spezifisches Expressionsprofil zu diagnostizieren. Ein Einfluss von miRNAs auf die Pathogenese von Prionenerkrankungen ist daher möglich. 


\section{Zusammenfassung}

Das Ziel dieser Arbeit war die Charakterisierung der Prionenerkrankung BSE-infizierter nicht humaner Primaten (Macaca fascicularis) als Modell für die humane Prionenerkrankung vCJD. Durch den Konsum BSE-kontaminierter Nahrungsmittel entstand im Menschen eine neue Variante der Creutzfeldt-Jakob-Krankheit (vCJD). Die genaue Anzahl der infizierten Menschen ist unbekannt, da es keine intra vitam Tests für Prionenerkrankungen gibt. Und obwohl eine Neuinfektion mit BSE durch Sicherheitsvorschriften unwahrscheinlich geworden ist, können neue Fälle von vCJD nicht ausgeschlossen werden, da weder die Inkubationszeit noch der Zeitpunkt der Infektion genau bestimmt werden können. Nicht diagnostizierte Fälle stellen ein großes Risiko dar, vCJD auf andere Menschen zu übertragen. Im Rahmen dieser Arbeit sollte die Eignung des Tiermodells für vCJD bestätigt werden und die Tiere auf unterschiedliche Subtypen der Krankheit (Prionenstämme) untersucht werden. In einem zweiten Ansatz sollten mikroRNAs (miRNAs) identifiziert werden, die mit der Prionenerkrankung in Verbindung stehen und als Marker dienen können.

In dieser Arbeit konnte die i.c. Infektion von Javaneraffen als Tiermodell für humanes vCJD bestätigt werden. Nachdem die Nachweismethoden erfolgreich an das simiane Modell adaptiert wurden, konnte die Prionenerkrankung in einem Vergleich mit mehreren humanen CJD-Typen dem vCJD zugeordnet werden. Zusätzlich konnten für das simiane vCJD bei 2/6 Tieren Charakteristika nachgewiesen werden, die auf einen zweiten Prionenstamm hinweisen (längere Inkubationszeit, neuropathologisches Profil, $\mathrm{PrP}^{\text {res }}$-Menge), obschon weitere Merkmale vergleichbar waren (intercerebrale Verteilung und konformationelle Stabilität des $\left.\operatorname{PrP}^{\text {res}}\right)$. Die Existenz dieses Stämme müsste in einer zweiten Passage bestätigt werden. Ein Zellkulturmodell für diese Fragestellung konnte aus technischen Gründen nicht etabliert werden. Die Ergebnisse legen aber nahe, dass ein zweiter Prionenstamm für vCJD erwartet werden kann, durch den weitere Menschen erkranken werden. Diese undiagnostizierten Fälle könnten auf weitere Menschen übertragen werden.

Während dieser Arbeit wurden drei miRNAs (hsa-miR26a, hsa-miR342, hsa-miR494) identifiziert, die im Zusammenhang mit simianem vCJD differentiell exprimiert waren. Deren potentielle Zielgene wiesen zusätzlich eine Verbindung zu neurodegenerativen Erkrankungen auf. Da die hsa-miR342 auch bei SCJD disreguliert war und auch gezeigt werden konnte, dass das hirnspezifische miRNA-Expressionsprofil der Javaneraffen mit dem humanen vergleichbar war, können die Ergebnisse wahrscheinlich auf humane Prionenerkrankungen übertragen werden. Die disregulierten miRNAs könnten daher von hohem diagnostischen Wert sein, wenn sie auch in anderem Geweben disreguliert sind, die zur intra vitam Diagnostik herangezogen werden können. 


\section{Literaturverzeichnis}

Abelson, JF, Kwan, KY, O'Roak, BJ, Baek, DY, Stillman, AA, Morgan, tM, Mathews, CA, Pauls, DL, Rasin, MR, Gunel, M, Davis, NR, ERCan-Sencicek, AG, Guez, DH, Spertus, JA, LeCKman, JF, Dure, LSt, Kurlan, R, Singer, HS, Gilbert, DL, Farhi, A, Louvi, A, Lifton, RP, Sestan, $\mathrm{N}$, and STATE, MW (2005), Sequence variants in SLITRK1 are associated with Tourette's syndrome. Science, 310 (5746), 317-20

AKowitz, A, SkLAVIADIS, T, and Manuelidis, L (1994), Endogenous viral complexes with long RNA cosediment with the agent of Creutzfeldt-Jakob disease. Nucleic Acids Res, 22 (6), 1101-7

Alper, T, Cramp, WA, Haig, DA, and Clarke, MC (1967), Does the agent of scrapie replicate without nucleic acid? Nature, 214 (5090), 764-6

Altschul, SF, Madden, TL, Schaffer, AA, Zhang, J, Zhang, Z, Miller, W, and Lipman, DJ (1997), Gapped BLAST and PSI-BLAST: a new generation of protein database search programs. Nucleic Acids Res, 25 (17), 3389-402

Ambros, V, Bartel, B, Bartel, DP, Burge, CB, Carrington, JC, Chen, X, Dreyfuss, G, Eddy, SR, Griffiths-Jones, S, Marshall, M, Matzke, M, Ruvkun, G, and Tuschl, T (2003), A uniform system for microRNA annotation. Rna, 9 (3), 277-9

Ambros, V, Lee, RC, Lavanway, A, Williams, PT, and Jewell, D (2003), MicroRnAs and other tiny endogenous RNAs in C. elegans. Curr Biol, 13 (10), 807-18

Anderson, RM, Donnelly, CA, Ferguson, NM, Woolhouse, ME, Watt, CJ, Udy, HJ, MaWhinney, S, Dunstan, SP, Southwood, TR, Wilesmith, JW, Ryan, JB, Hoinville, LJ, Hillerton, JE, Austin, AR, and Wells, GA (1996), Transmission dynamics and epidemiology of BSE in British cattle. Nature, 382 (6594), 779-88

Andl, T, Murchison, EP, Liu, F, Zhang, Y, Yunta-Gonzalez, M, Tobias, JW, Andl, CD, Seykora, JT, HANNON, GJ, and MILLAR, SE (2006), The miRNA-processing enzyme dicer is essential for the morphogenesis and maintenance of hair follicles. Curr Biol, 16 (10), 1041-9

Arima, K, Nishida, N, Sakaguchi, S, Shigematsu, K, Atarashi, R, Yamaguchi, N, Yoshikawa, D, Yoon, J, Watanabe, K, Kobayashi, N, Mouillet-Richard, S, Lehmann, S, and Katamine, S (2005), Biological and biochemical characteristics of prion strains conserved in persistently infected cell cultures. J Virol, 79 (11), 7104-12

Babak, T, Zhang, W, Morris, Q, Blencowe, BJ, and Hughes, TR (2004), Probing microRNAs with microarrays: tissue specificity and functional inference. Rna, 10 (11), 1813-9

Baron, GS, Magalhaes, AC, Prado, MA, and Caughey, B (2006), Mouse-adapted scrapie infection of SN56 cells: greater efficiency with microsome-associated versus purified PrPres. J Virol, 80 (5), 2106-17

BARTEL, DP (2004), MicroRNAs: genomics, biogenesis, mechanism, and function. Cell, 116 (2), 281-97

BARTEL, DP, and CHEN, CZ (2004), Micromanagers of gene expression: the potentially widespread influence of metazoan microRNAs. Nat Rev Genet, 5 (5), 396-400 
Basler, K, Oesch, B, Scott, M, Westaway, D, Walchli, M, Groth, DF, McKinley, MP, Prusiner, SB, and WeIssmann, C (1986), Scrapie and cellular PrP isoforms are encoded by the same chromosomal gene. Cell, 46 (3), 417-28

Belay, ED, Gambetti, P, Schonberger, LB, Parchi, P, Lyon, DR, Capellari, S, McQuiston, JH, Bradley, K, Dowdle, G, Crutcher, JM, and Nichols, CR (2001), Creutzfeldt-Jakob disease in unusually young patients who consumed venison. Arch Neurol, 58 (10), 1673-8

Bennasser, Y, Le, SY, Yeung, ML, and Jeang, KT (2004), HIV-1 encoded candidate microRNAs and their cellular targets. Retrovirology, 1 (1), 43

BENTWICH, I (2005), Prediction and validation of microRNAs and their targets. FEBS Lett, $\mathbf{5 7 9}$ (26), 5904-10

Bernstein, E, Kim, SY, Carmell, MA, Murchison, EP, Alcorn, H, Li, MZ, Mills, AA, Elledge, SJ, ANDERSON, KV, and HANNON, GJ (2003), Dicer is essential for mouse development. Nat Genet, 35 (3), 215-7

Bessen, RA, Kocisko, DA, Raymond, GJ, Nandan, S, Lansbury, PT, and Caughey, B (1995), Non-genetic propagation of strain-specific properties of scrapie prion protein. Nature, $\mathbf{3 7 5}$ (6533), 698-700

BESSEN, RA, and MARSH, RF (1992), Biochemical and physical properties of the prion protein from two strains of the transmissible mink encephalopathy agent. J Virol, 66 (4), 2096101

BIgnAmI, A, and PARRY, HB (1971), Aggregations of 35-nanometer particles associated with neuronal cytopathic changes in natural scrapie. Science, 171 (969), 389-90

Birkett, CR, Hennion, RM, Bembridge, DA, Clarke, MC, Chree, A, Bruce, ME, and Bostock, CJ (2001), Scrapie strains maintain biological phenotypes on propagation in a cell line in culture. Embo J, 20 (13), 3351-8

Blusztajn, JK, Venturini, A, Jackson, DA, Lee, HJ, and Wainer, BH (1992), Acetylcholine synthesis and release is enhanced by dibutyryl cyclic AMP in a neuronal cell line derived from mouse septum. J Neurosci, 12 (3), 793-9

BOEHM, M, and SLACK, F (2005), A developmental timing microRNA and its target regulate life span in C. elegans. Science, 310 (5756), 1954-7

Bolton, DC, McKInLEY, MP, and PrusineR, SB (1982), Identification of a protein that purifies with the scrapie prion. Science, 218 (4579), 1309-11

BRADFORD, MM (1976), A rapid and sensitive method for the quantitation of microgram quantities of protein utilizing the principle of protein-dye binding. Anal Biochem, 72 24854

BRADLEY, R (1993), The research programme on transmissible spongiform encephalopathies in Britain with special reference to bovine spongiform encephalopathy. Dev Biol Stand, 80 157-70

Britton, TC, al-Sarraj, S, Shaw, C, Campbell, T, and Collinge, J (1995), Sporadic CreutzfeldtJakob disease in a 16-year-old in the UK. Lancet, 346 (8983), 1155 
Brown, DR, Qin, K, Herms, JW, Madlung, A, Manson, J, Strome, R, Fraser, Pe, Kruck, T, von Bohlen, A, Schulz-Schaeffer, W, Giese, A, Westaway, D, and Kretzschmar, H (1997), The cellular prion protein binds copper in vivo. Nature, 390 (6661), 684-7

Brown, DR, Schulz-Schaeffer, WJ, Schmidt, B, and Kretzschmar, HA (1997), Prion proteindeficient cells show altered response to oxidative stress due to decreased SOD-1 activity. Exp Neurol, 146 (1), 104-12

Brown, DR, Wong, BS, Hafiz, F, Clive, C, Haswell, SJ, and Jones, IM (1999), Normal prion protein has an activity like that of superoxide dismutase. Biochem J, 344 Pt 1 1-5

Brown, P, and GAJDusek, DC (1991), Survival of scrapie virus after 3 years' interment. Lancet, 337 (8736), 269-70

BRUCE, ME (1993), Scrapie strain variation and mutation. Br Med Bull, 49 (4), 822-38

BRUCE, ME (2003), TSE strain variation. Br Med Bull, 66 99-108

Bruce, ME, McConnell, I, Fraser, H, and Dickinson, AG (1991), The disease characteristics of different strains of scrapie in Sinc congenic mouse lines: implications for the nature of the agent and host control of pathogenesis. J Gen Virol, 72 ( Pt 3) 595-603

Budka, H, Aguzzi, A, Brown, P, Brucher, JM, Bugiani, O, Gullotta, F, Haltia, M, Hauw, JJ, IRONSIDE, JW, JELLINGER, K, and ET AL. (1995), Neuropathological diagnostic criteria for Creutzfeldt-Jakob disease (CJD) and other human spongiform encephalopathies (prion diseases). Brain Pathol, 5 (4), 459-66

Bueler, H, Aguzzi, A, Saller, A, Greiner, RA, Autenried, P, Aguet, M, and Weissmann, C (1993), Mice devoid of PrP are resistant to scrapie. Cell, 73 (7), 1339-47

Buschmann, A, Biacabe, AG, Ziegler, U, Bencsik, A, Madec, Jy, Erhardt, G, Luhken, G, Baron, T, and Groschup, MH (2004), Atypical scrapie cases in Germany and France are identified by discrepant reaction patterns in BSE rapid tests. J Virol Methods, 117 (1), 2736

Buschmann, A, Gretzschel, A, Biacabe, Ag, Schiebel, K, Corona, C, Hoffmann, C, Eiden, M, Baron, T, CAsalone, C, and Groschup, MH (2006), Atypical BSE in Germany--proof of transmissibility and biochemical characterization. Vet Microbiol, 117 (2-4), 103-16

CAl, X, Hagedorn, CH, and Cullen, BR (2004), Human microRnAs are processed from capped, polyadenylated transcripts that can also function as mRNAs. Rna, 10 (12), 195766

Cali, I, Castellani, R, Yuan, J, Al-Shekhlee, A, Cohen, Ml, Xiao, X, Moleres, FJ, Parchi, P, Zou, WQ, and GAMBETTI, P (2006), Classification of sporadic Creutzfeldt-Jakob disease revisited. Brain, 129 (Pt 9), 2266-77

Calin, GA, Dumitru, CD, Shimizu, M, Bichi, R, Zupo, S, Noch, E, Aldler, H, Rattan, S, Keating, M, RaI, K, Rassenti, L, Kipps, T, Negrini, M, Bullrich, F, and Croce, CM (2002), Frequent deletions and down-regulation of micro- RNA genes miR15 and miR16 at 13q14 in chronic lymphocytic leukemia. Proc Natl Acad Sci U S A, 99 (24), 15524-9

Carleton, A, Tremblay, P, Vincent, JD, and Lledo, PM (2001), Dose-dependent, prion protein (PrP)-mediated facilitation of excitatory synaptic transmission in the mouse hippocampus. Pflugers Arch, 442 (2), 223-9 
Carlson, GA, Kingsbury, DT, Goodman, PA, Coleman, S, Marshall, ST, DeArmond, S, WestaWAY, D, and PRUSINER, SB (1986), Linkage of prion protein and scrapie incubation time genes. Cell, 46 (4), 503-11

Casalone, C, Zanusso, G, Acutis, P, Ferrari, S, Capucci, L, Tagliavini, F, Monaco, S, and CARAmelLI, M (2004), Identification of a second bovine amyloidotic spongiform encephalopathy: molecular similarities with sporadic Creutzfeldt-Jakob disease. Proc Natl Acad Sci U S A, 101 (9), 3065-70

Castagna, A, Campostrini, N, Farinazzo, A, Zanusso, G, Monaco, S, and Righetti, PG (2002), Comparative two-dimensional mapping of prion protein isoforms in human cerebrospinal fluid and central nervous system. Electrophoresis, 23 (2), 339-46

Caughey, BW, Dong, A, Bhat, KS, Ernst, D, Hayes, SF, and Caughey, WS (1991), Secondary structure analysis of the scrapie-associated protein PrP 27-30 in water by infrared spectroscopy. Biochemistry, 30 (31), 7672-80

CHAN, JA, KRICHEVSkY, AM, and KosIK, KS (2005), MicroRNA-21 is an antiapoptotic factor in human glioblastoma cells. Cancer Res, 65 (14), 6029-33

Chapman, EJ, Prokhnevsky, Al, Gopinath, K, Dolja, VV, and Carrington, JC (2004), Viral RNA silencing suppressors inhibit the microRNA pathway at an intermediate step. Genes Dev, 18 (10), 1179-86

Chen, C, Ridzon, DA, Broomer, AJ, Zhou, Z, Lee, DH, Nguyen, JT, Barbisin, M, Xu, NL, Mahuvakar, VR, Andersen, MR, Lao, KQ, LivaK, KJ, and Guegler, KJ (2005), Real-time quantification of microRNAs by stem-loop RT-PCR. Nucleic Acids Res, 33 (20), e179

Chen, J, LI, WX, XIE, D, PENG, JR, and DING, SW (2004), Viral virulence protein suppresses RNA silencing-mediated defense but upregulates the role of microrna in host gene expression. Plant Cell, 16 (5), 1302-13

Chesebro, B (2003), Introduction to the transmissible spongiform encephalopathies or prion diseases. Br Med Bull, 66 1-20

Chesebro, B, Race, R, Wehrly, K, Nishio, J, Bloom, M, Lechner, D, Bergstrom, S, Robbins, K, MAYER, L, KEITH, JM, and ET AL. (1985), Identification of scrapie prion protein-specific mRNA in scrapie-infected and uninfected brain. Nature, 315 (6017), 331-3

ClaRke, MC, and HaIG, DA (1970), Multiplication of scrapie agent in cell culture. Res Vet Sci, $11(5), 500-1$

Collee, JG, Bradley, R, and Liberski, PP (2006), Variant CJD (vCJD) and bovine spongiform encephalopathy (BSE): 10 and 20 years on: part 2. Folia Neuropathol, 44 (2), 102-10

Collinge, J, Sidle, KC, Meads, J, Ironside, J, and Hill, AF (1996), Molecular analysis of prion strain variation and the aetiology of 'new variant' CJD. Nature, 383 (6602), 685-90

Collinge, J, Whitfield, J, McKintosh, E, Beck, J, Mead, S, Thomas, DJ, and Alpers, MP (2006), Kuru in the 21st century--an acquired human prion disease with very long incubation periods. Lancet, 367 (9528), 2068-74

Collinge, J, Whittington, MA, Sidle, KC, Smith, CJ, Palmer, MS, Clarke, AR, and Jefferys, JG (1994), Prion protein is necessary for normal synaptic function. Nature, 370 (6487), 295-7 
CREUTZFELDT, HG (1920), Über eine eigenartige herdförmige Erkrankung des Zentralnervensystems. Z. ges. Neurol. Psychat., 57 1-18

Cui, C, Griffiths, A, Li, G, Silva, LM, Kramer, MF, Gaasterland, T, Wang, XJ, and Coen, DM (2006), Prediction and identification of herpes simplex virus 1 -encoded microRNAs. J Virol, 80 (11), 5499-508

Cullen, BR (2002), RNA interference: antiviral defense and genetic tool. Nat Immunol, 3 (7), $597-9$

David-FerreiRA, JF, DAVID-Ferreira, KL, GibBs, CJ, JR., and Morris, JA (1968), Scrapie in mice: ultrastructural observations in the cerebral cortex. Proc Soc Exp Biol Med, 127 (1), 31320

De PriL, R, Fischer, DF, Roos, RA, and van Leeuwen, FW (2007), Ubiquitin-conjugating enzyme $\mathrm{E} 2-25 \mathrm{~K}$ increases aggregate formation and cell death in polyglutamine diseases. Mol Cell Neurosci, 34 (1), 10-9

DeArmond, SJ, McKinley, MP, Barry, RA, Braunfeld, MB, McColloch, JR, and Prusiner, SB (1985), Identification of prion amyloid filaments in scrapie-infected brain. Cell, 41 (1), 22135

DeArmond, SJ, Sanchez, H, Yehiely, F, Qiu, Y, Ninchak-Casey, A, Daggett, V, Camerino, AP, Cayetano, J, Rogers, M, Groth, D, Torchia, M, Tremblay, P, Scott, Mr, Cohen, FE, and PRUSINER, SB (1997), Selective neuronal targeting in prion disease. Neuron, 19 (6), 133748

Deleault, NR, LucAssen, RW, and Supattapone, S (2003), RNA molecules stimulate prion protein conversion. Nature, 425 (6959), 717-20

Di Leva, G, Calin, GA, and Croce, CM (2006), MicroRNAs: fundamental facts and involvement in human diseases. Birth Defects Res C Embryo Today, 78 (2), 180-9

DickINSON, AG, and MEIKLE, VM (1971), Host-genotype and agent effects in scrapie incubation: change in allelic interaction with different strains of agent. Mol Gen Genet, $112(1), 73-9$

DiCKINSON, AG, MEIKLE, VM, and FRASER, H (1968), Identification of a gene which controls the incubation period of some strains of scrapie agent in mice. J Comp Pathol, 78 (3), 293-9

DOENCH, JG, and SHARP, PA (2004), Specificity of microRNA target selection in translational repression. Genes Dev, 18 (5), 504-11

Doerr, HW, Cinatl, J, Sturmer, M, and Rabenau, HF (2003), Prions and orthopedic surgery. Infection, 31 (3), 163-71

Duffy, P, Wolf, J, Collins, G, DeVoe, AG, Streeten, B, and Cowen, D (1974), Letter: Possible person-to-person transmission of Creutzfeldt-Jakob disease. N Engl J Med, 290 (12), $692-3$

Edenhofer, F, Rieger, R, Famulok, M, Wendler, W, Weiss, S, and Winnacker, EL (1996), Prion protein PrPc interacts with molecular chaperones of the Hsp60 family. J Virol, 70 (7), $4724-8$ 
EIGEN, M (1996), Prionics or the kinetic basis of prion diseases. Biophys Chem, 63 (1), A1-18

Endo, T, Groth, D, Prusiner, SB, and Kobata, A (1989), Diversity of oligosaccharide structures linked to asparagines of the scrapie prion protein. Biochemistry, 28 (21), 83808

Ford, MJ, Burton, LJ, MorRIS, RJ, and HALL, SM (2002), Selective expression of prion protein in peripheral tissues of the adult mouse. Neuroscience, 113 (1), 177-92

Fournier, JG, Escaig-Haye, F, Billette de Villemeur, T, Robain, O, Lasmezas, Cl, Deslys, JP, DORMONT, D, and BRown, P (1998), Distribution and submicroscopic immunogold localization of cellular prion protein (PrPc) in extracerebral tissues. Cell Tissue Res, 292 (1), 77-84

Fradkin, Je, Schonberger, LB, Mills, JL, Gunn, WJ, Piper, JM, Wysowski, DK, Thomson, R, DuRAKo, S, and BROWN, P (1991), Creutzfeldt-Jakob disease in pituitary growth hormone recipients in the United States. Jama, 265 (7), 880-4

FrAser, H, and Dickinson, AG (1968), The sequential development of the brain lesion of scrapie in three strains of mice. J Comp Pathol, 78 (3), 301-11

Fu, HJ, Zhu, J, Yang, M, Zhang, ZY, Tie, Y, JiAng, H, Sun, ZX, and Zheng, XF (2006), A novel method to monitor the expression of microRNAs. Mol Biotechnol, 32 (3), 197-204

Gabriel, JM, Oesch, B, Kretzschmar, H, Scott, M, and Prusiner, SB (1992), Molecular cloning of a candidate chicken prion protein. Proc Natl Acad Sci U S A, 89 (19), 9097-101

Gajdusek, C, GibBs, CJ, and Alpers, M (1967), Slow-acting virus implicated in kuru. Jama, 199 (7), 34

GARNETT, AP, and VILES, JH (2003), Copper binding to the octarepeats of the prion protein. Affinity, specificity, folding, and cooperativity: insights from circular dichroism. J Biol Chem, 278 (9), 6795-802

Gerstmann, J, StRÄUsLeR, E. UND SCHEINKER, I. (1939), Über eine eigenartige hereditär-familiäre Erkrankung des Zentralnervensystems. Zugleich ein Beitrag zur Frage des vorzeitigen Alterns. Z. ges. Neurol. Psychat., 154 736-62

Gething, MJ, Bye, J, Skehel, J, and Waterfield, M (1980), Cloning and DNA sequence of double-stranded copies of haemagglutinin genes from $\mathrm{H} 2$ and $\mathrm{H} 3$ strains elucidates antigenic shift and drift in human influenza virus. Nature, 287 (5780), 301-6

GiBBS, CJ, JR., and GAJDUSEK, DC (1972), Transmission of scrapie to the cynomolgus monkey (Macaca fascicularis). Nature, 236 (5341), 73-4

GiBBS, CJ, JR., GaJdUSEK, DC, and LATARJET, R (1978), Unusual resistance to ionizing radiation of the viruses of kuru, Creutzfeldt-Jakob disease, and scrapie. Proc Natl Acad Sci U S A, 75 (12), 6268-70

Giraldez, AJ, Cinalli, RM, Glasner, ME, Enright, AJ, Thomson, JM, Baskerville, S, Hammond, SM, BARTEL, DP, and SCHIER, AF (2005), MicroRNAs regulate brain morphogenesis in zebrafish. Science, 308 (5723), 833-8

GRIFFITH, JS (1967), Self-replication and scrapie. Nature, 215 (5105), 1043-4 
Griffiths-Jones, S, Grocock, RJ, van Dongen, S, BAteman, A, and EnRight, AJ (2006), miRBase: microRNA sequences, targets and gene nomenclature. Nucleic Acids Res, 34 (Database issue), D140-4

Gupta, A, Gartner, JJ, Sethupathy, P, Hatzigeorgiou, AG, and Fraser, NW (2006), Antiapoptotic function of a microRNA encoded by the HSV-1 latency-associated transcript. Nature, 442 (7098), 82-5

Hammond, DN, Lee, HJ, Tonsgard, JH, and Wainer, BH (1990), Development and characterization of clonal cell lines derived from septal cholinergic neurons. Brain Res, 512 (2), 190-200

Haraguchi, T, Fisher, S, Olofsson, S, Endo, T, Groth, D, Tarentino, A, Borchelt, DR, Teplow, D, Hood, L, Burlingame, A, and ET AL. (1989), Asparagine-linked glycosylation of the scrapie and cellular prion proteins. Arch Biochem Biophys, 274 (1), 1-13

Harfe, BD, McManus, MT, Mansfield, JH, Hornstein, E, and Tabin, CJ (2005), The RNaselli enzyme Dicer is required for morphogenesis but not patterning of the vertebrate limb. Proc Natl Acad Sci U S A, 102 (31), 10898-903

Hariharan, M, Scaria, V, Pillal, B, and Brahmachari, SK (2005), Targets for human encoded microRNAs in HIV genes. Biochem Biophys Res Commun, 337 (4), 1214-8

Harris, KS, Zhang, Z, McManus, MT, Harfe, BD, and Sun, X (2006), Dicer function is essential for lung epithelium morphogenesis. Proc Natl Acad Sci U S A, 103 (7), 2208-13

He, H, Jazdzewski, K, Li, W, Liyanarachchi, S, Nagy, R, Volinia, S, Calin, Ga, Liu, CG, Franssila, K, Suster, S, Kloos, RT, Croce, CM, and de la Chapelle, A (2005), The role of microRNA genes in papillary thyroid carcinoma. Proc Natl Acad Sci U S A, 102 (52), 19075-80

Head, MW, Bunn, TJ, Bishop, MT, McLoughin, V, Lowrie, S, McKimmie, CS, Williams, MC, McCardle, L, MacKenzIe, J, KNIGHT, R, WiLl, RG, and IRONSide, JW (2004), Prion protein heterogeneity in sporadic but not variant Creutzfeldt-Jakob disease: UK cases 19912002. Ann Neurol, 55 (6), 851-9

Hill, AF, Desbruslais, M, Joiner, S, Sidle, KC, Gowland, I, Collinge, J, Doey, LJ, and Lantos, P (1997), The same prion strain causes vCJD and BSE. Nature, 389 (6650), 448-50, 526

Holland, PM, Abramson, RD, Watson, R, and Gelfand, DH (1991), Detection of specific polymerase chain reaction product by utilizing the $5^{\prime}----3^{\prime}$ exonuclease activity of Thermus aquaticus DNA polymerase. Proc Natl Acad Sci U S A, 88 (16), 7276-80

Hsiao, KK, Groth, D, Scott, M, Yang, SL, Serban, H, Rapp, D, Foster, D, Torchia, M, DEARMOND, SJ, and PRUSINER, SB (1994), Serial transmission in rodents of neurodegeneration from transgenic mice expressing mutant prion protein. Proc Natl Acad Sci U S A, 91 (19), 9126-30

Hundt, C, Peyrin, JM, Haik, S, Gauczynski, S, Leucht, C, Rieger, R, Riley, ML, Deslys, JP, DORMONT, D, LASMEZAS, CI, and WeISS, S (2001), Identification of interaction domains of the prion protein with its 37-kDa/67-kDa laminin receptor. Embo J, 20 (21), 5876-86

Hutvagner, G, Mclachlan, J, Pasquinelli, AE, Balint, E, Tuschl, T, and Zamore, PD (2001), A cellular function for the RNA-interference enzyme Dicer in the maturation of the let-7 small temporal RNA. Science, 293 (5531), 834-8 
Inoue, Y, Yamakawa, Y, Sakudo, A, Kinumi, T, Nakamura, Y, Matsumoto, Y, Saeki, K, Kamiyama, T, ONODERA, T, and NISHIJIMA, M (2005), Infection route-independent accumulation of splenic abnormal prion protein. Jpn J Infect Dis, 58 (2), 78-82

IRONSIDE, JW, RITCHIE, DL, and HeAD, MW (2005), Phenotypic variability in human prion diseases. Neuropathol Appl Neurobiol, 31 (6), 565-79

Jackson, GS, Murray, I, Hosszu, LL, Gibbs, N, Waltho, JP, Clarke, AR, and Collinge, J (2001), Location and properties of metal-binding sites on the human prion protein. Proc Natl Acad Sci U S A, 98 (15), 8531-5

JAKOB, A (1921), Über eigenartige Erkrankungen des Zentralnervensystems mit bemerkenswerten anatomischen Befunden (spastische PseudoskleroseEncephalomyelopathie disseminierten Degenerationsherden). Dtsch. Z. Nervenheilk., 70 132

JАKOB, A (1921), Über eine der multiplen Sklerose klinisch nahestehenden Erkrankung der Zentralnervensystems (spastische Pseudosklerose) mit bemerkenswerten anatomischen Befunde: Mitteilung eines vierten Falls. Med. Klein., 17372

John, B, Enright, AJ, Aravin, A, Tuschl, T, Sander, C, and Marks, DS (2004), Human MicroRNA targets. PLoS Biol, 2 (11), e363

Johnson, CJ, Phillips, KE, Schramm, PT, McKenzie, D, Aiken, JM, and Pedersen, JA (2006), Prions adhere to soil minerals and remain infectious. PLoS Pathog, 2 (4), e32

Kalchman, MA, Graham, RK, Xia, G, Koide, HB, Hodgson, JG, Graham, KC, Goldberg, YP, GiETZ, RD, PICKART, CM, and HAYDEN, MR (1996), Huntingtin is ubiquitinated and interacts with a specific ubiquitin-conjugating enzyme. J Biol Chem, 271 (32), 19385-94

Kato, K, Hamaguchi, Y, Okawa, S, Ishikawa, E, and Kobayashi, K (1977), Use of rabbit antiboty IgG bound onto plain and aminoalkylsilyl glass surface for the enzyme-linked sandwich immunoassay. J Biochem (Tokyo), 82 (1), 261-6

Kellings, K, Meyer, N, Mirenda, C, Prusiner, SB, and Riesner, D (1992), Further analysis of nucleic acids in purified scrapie prion preparations by improved return refocusing gel electrophoresis. J Gen Virol, 73 ( Pt 4) 1025-9

Kellings, K, Prusiner, SB, and Riesner, D (1994), Nucleic acids in prion preparations: unspecific background or essential component? Philos Trans R Soc Lond B Biol Sci, 343 (1306), 425-30

Ketting, RF, Fischer, SE, Bernstein, E, Sijen, T, Hannon, GJ, and Plasterk, RH (2001), Dicer functions in RNA interference and in synthesis of small RNA involved in developmental timing in C. elegans. Genes Dev, 15 (20), 2654-9

Khvorova, A, Reynolds, A, and Jayasena, SD (2003), Functional siRNAs and miRNAs exhibit strand bias. Cell, 115 (2), 209-16

Kim, J, Krichevsky, A, Grad, Y, Hayes, GD, Kosik, KS, Church, GM, and Ruvkun, G (2004), Identification of many microRNAs that copurify with polyribosomes in mammalian neurons. Proc Natl Acad Sci U S A, 101 (1), 360-5

KImBeRLIN, RH, Cole, S, and WALKER, CA (1987), Temporary and permanent modifications to a single strain of mouse scrapie on transmission to rats and hamsters. J Gen Virol, 68 
(Pt 7) 1875-81

Kimberlin, RH, WaLKer, CA, and Fraser, H (1989), The genomic identity of different strains of mouse scrapie is expressed in hamsters and preserved on reisolation in mice. $J$ Gen Virol, 70 ( Pt 8) 2017-25

Kiriakidou, M, Nelson, PT, Kouranov, A, Fitziev, P, Bouyioukos, C, Mourelatos, Z, and HATZIGEORGIOU, A (2004), A combined computational-experimental approach predicts human microRNA targets. Genes Dev, 18 (10), 1165-78

Klatzo, I, Gajdusek, DC, and Zigas, V (1959), Pathology of Kuru. Lab Invest, 8 (4), 799-847

Kocisko, DA, Priola, SA, Raymond, GJ, Chesebro, B, Lansbury, PT, JR., and Caughey, B (1995), Species specificity in the cell-free conversion of prion protein to proteaseresistant forms: a model for the scrapie species barrier. Proc Natl Acad Sci U S A, 92 (9), 3923-7

Krasemann, S, Groschup, MH, Harmeyer, S, Hunsmann, G, and Bodemer, W (1996), Generation of monoclonal antibodies against human prion proteins in PrP0/0 mice. Mol Med, 2 (6), 725-34

Kuczius, T, Grassi, J, Karch, H, and Groschup, MH (2007), Binding of N- and C-terminal antiprion protein antibodies generates distinct phenotypes of cellular prion proteins $(\operatorname{PrP}(\mathrm{C}))$ obtained from human, sheep, cattle and mouse. Febs J, 274 (6), 1492-502

KuRschner, C, and Morgan, Jl (1995), The cellular prion protein (PrP) selectively binds to Bcl2 in the yeast two-hybrid system. Brain Res Mol Brain Res, 30 (1), 165-8

Ladogana, A, LIU, Q, XI, YG, and Pocchiari, M (1995), Proteinase-resistant protein in human neuroblastoma cells infected with brain material from Creutzfeldt-Jakob patient. Lancet, 345 (8949), 594-5

LAEMMLI, UK (1970), Cleavage of structural proteins during the assembly of the head of bacteriophage T4. Nature, 227 (5259), 680-5

Lagos-Quintana, M, Rauhut, R, Lendeckel, W, and Tuschl, T (2001), Identification of novel genes coding for small expressed RNAs. Science, 294 (5543), 853-8

LAI, EC, TAM, B, and RUBIN, GM (2005), Pervasive regulation of Drosophila Notch target genes by GY-box-, Brd-box-, and K-box-class microRNAs. Genes Dev, 19 (9), 1067-80

Landgrebe, J, Welzl, G, Metz, T, van Gaalen, MM, Ropers, H, Wurst, W, and Holsboer, F (2002), Molecular characterisation of antidepressant effects in the mouse brain using gene expression profiling. J Psychiatr Res, 36 (3), 119-29

Lasmezas, Cl, Deslys, JP, Demaimay, R, Adjou, KT, Lamoury, F, Dormont, D, Robain, O, IRONSIDE, J, and HAUW, JJ (1996), BSE transmission to macaques. Nature, 381 (6585), 743-4

LAU, NC, Lim, LP, Weinstein, EG, and BARTEL, DP (2001), An abundant class of tiny RNAs with probable regulatory roles in Caenorhabditis elegans. Science, 294 (5543), 858-62

Lecellier, CH, Dunoyer, P, Arar, K, Lehmann-Che, J, Eyquem, S, Himber, C, Saib, A, and VOINNET, O (2005), A cellular microRNA mediates antiviral defense in human cells. Science, 308 (5721), 557-60 
Lee, RC, Feinbaum, RL, and Ambros, V (1993), The C. elegans heterochronic gene lin-4 encodes small RNAs with antisense complementarity to lin-14. Cell, 75 (5), 843-54

Lee, Y, Ahn, C, Han, J, Chol, H, Kim, J, Yim, J, Lee, J, Provost, P, Radmark, O, Kim, S, and Kim, VN (2003), The nuclear RNase III Drosha initiates microRNA processing. Nature, 425 (6956), 415-9

Legname, G, Baskakov, IV, Nguyen, HO, Riesner, D, Cohen, Fe, DeArmond, SJ, and Prusiner, SB (2004), Synthetic mammalian prions. Science, 305 (5684), 673-6

Lewis, BP, Shih, IH, Jones-Rhoades, MW, Bartel, DP, and Burge, CB (2003), Prediction of mammalian microRNA targets. Cell, 115 (7), 787-98

Li, M, Jones-Rhoades, MW, Lau, NC, Bartel, DP, and Rougvie, AE (2005), Regulatory mutations of mir-48, a C. elegans let-7 family MicroRNA, cause developmental timing defects. Dev Cell, 9 (3), 415-22

Li, R, Liu, D, Zanusso, G, Liu, T, Fayen, JD, Huang, JH, Petersen, RB, Gambetti, P, and Sy, MS (2001), The expression and potential function of cellular prion protein in human lymphocytes. Cell Immunol, 207 (1), 49-58

LIBERSKI, PP (2004), Amyloid plaques in transmissible spongiform encephalopathies (prion diseases). Folia Neuropathol, 42 Suppl B 109-19

Lim, LP, Lau, NC, Weinstein, EG, Abdelhakim, A, Yekta, S, Rhoades, MW, Burge, CB, and BARTEL, DP (2003), The microRNAs of Caenorhabditis elegans. Genes Dev, 17 (8), 991 1008

Lin, SY, Johnson, SM, Abraham, M, Vella, MC, Pasquinelli, A, Gamberi, C, Gottlieb, E, and SLACK, FJ (2003), The C elegans hunchback homolog, hbl-1, controls temporal patterning and is a probable microRNA target. Dev Cell, 4 (5), 639-50

Liu, CG, Calin, Ga, Meloon, B, Gamliel, N, Sevignani, C, Ferracin, M, Dumitru, CD, Shimizu, M, Zupo, S, Dono, M, Alder, H, Bullrich, F, Negrini, M, and Croce, CM (2004), An oligonucleotide microchip for genome-wide microRNA profiling in human and mouse tissues. Proc Natl Acad Sci U S A, 101 (26), 9740-4

Llewelyn, CA, Hewitt, PE, Knight, RS, Amar, K, Cousens, S, Mackenzie, J, and Will, RG (2004), Possible transmission of variant Creutzfeldt-Jakob disease by blood transfusion. Lancet, 363 (9407), 417-21

Lowenstein, DH, Butler, DA, Westaway, D, McKinley, MP, DeArmond, SJ, and Prusiner, SB (1990), Three hamster species with different scrapie incubation times and neuropathological features encode distinct prion proteins. Mol Cell Biol, 10 (3), 1153-63

Lugaresi, E, Medori, R, Montagna, P, Baruzzi, A, Cortelli, P, Lugaresi, A, Tinuper, P, Zucconi, $M$, and GAMBETTI, $P$ (1986), Fatal familial insomnia and dysautonomia with selective degeneration of thalamic nuclei. N Engl J Med, 315 (16), 997-1003

MANUelidis, EE, Gorgacz, EJ, and MANUelidis, L (1978), Transmission of Creutzfeldt-Jakob disease with scrapie-like syndromes to mice. Nature, 271 (5647), 778-9

Manuelidis, L, Yu, ZX, Banquero, N, and Mullins, B (2007), Cells infected with scrapie and Creutzfeldt-Jakob disease agents produce intracellular $25-\mathrm{nm}$ virus-like particles. Proc 
Natl Acad Sci U S A, 104 (6), 1965-70

Mercey, R, Lantier, I, Maurel, MC, Grosclaude, J, Lantier, F, and Marc, D (2006), Fast, reversible interaction of prion protein with RNA aptamers containing specific sequence patterns. Arch Virol, 151 (11), 2197-214

Merz, PA, Somerville, RA, Wisniewski, HM, and lqbal, K (1981), Abnormal fibrils from scrapieinfected brain. Acta Neuropathol (Berl), 54 (1), 63-74

Metzler, M, Wilda, M, Busch, K, Viehmann, S, and Borkhardt, A (2004), High expression of precursor microRNA-155/BIC RNA in children with Burkitt lymphoma. Genes Chromosomes Cancer, 39 (2), 167-9

Meyer, RK, Oesch, B, Fatzer, R, Zurbriggen, A, and Vandevelde, M (1999), Detection of bovine spongiform encephalopathy-specific $\operatorname{PrP}(\mathrm{Sc})$ by treatment with heat and guanidine thiocyanate. J Virol, 73 (11), 9386-92

Michael, MZ, SM, OC, van Holst Pellekaan, NG, Young, GP, and James, RJ (2003), Reduced accumulation of specific microRNAs in colorectal neoplasia. Mol Cancer Res, 1 (12), 88291

Miele, G, Alejo Blanco, AR, Baybutt, H, Horvat, S, Manson, J, and Clinton, M (2003), Embryonic activation and developmental expression of the murine prion protein gene. Gene Expr, 11 (1), 1-12

Monari, L, Chen, SG, Brown, P, Parchi, P, Petersen, RB, Mikol, J, Gray, F, Cortelli, P, MontAgnA, P, GHetti, B, and ET AL. (1994), Fatal familial insomnia and familial CreutzfeldtJakob disease: different prion proteins determined by a DNA polymorphism. Proc Natl Acad Sci U S A, 91 (7), 2839-42

Mouillet-Richard, S, Ermonval, M, Chebassier, C, Laplanche, JL, Lehmann, S, Launay, JM, and Kellermann, O (2000), Signal transduction through prion protein. Science, 289 (5486), 1925-8

Muramoto, T, Kitamoto, T, TAteISHI, J, and Goto, I (1992), The sequential development of abnormal prion protein accumulation in mice with Creutzfeldt-Jakob disease. Am J Pathol, 140 (6), 1411-20

NANDI, PK (1997), Interaction of prion peptide HuPrP106-126 with nucleic acid. Arch Virol, 142 (12), 2537-45

Nazor, Ke, Kuhn, F, Seward, T, Green, M, Zwald, D, Purro, M, Schmid, J, Biffiger, K, Power, AM, Oesch, B, Raeber, AJ, and Telling, GC (2005), Immunodetection of diseaseassociated mutant PrP, which accelerates disease in GSS transgenic mice. Embo J, 24 (13), 2472-80

Nishida, N, Harris, DA, Vilette, D, Laude, H, Frobert, Y, Grassi, J, Casanova, D, Milhavet, O, and LeHMANN, S (2000), Successful transmission of three mouse-adapted scrapie strains to murine neuroblastoma cell lines overexpressing wild-type mouse prion protein. $J$ Virol, 74 (1), 320-5

Notari, S, Capellari, S, Giese, A, Westner, I, Baruzzi, A, Ghetti, B, Gambetti, P, Kretzschmar, $H A$, and PARCHI, P (2004), Effects of different experimental conditions on the PrPSc core generated by protease digestion: implications for strain typing and molecular classification of CJD. J Biol Chem, 279 (16), 16797-804 
Obernosterer, G, Leuschner, PJ, Alenius, M, and Martinez, J (2006), Post-transcriptional regulation of microRNA expression. Rna, 12 (7), 1161-7

Oesch, B, Westaway, D, Walchli, M, McKinley, MP, Kent, SB, Aebersold, R, Barry, RA, Tempst, P, Teplow, DB, Hood, LE, and Et Al. (1985), A cellular gene encodes scrapie PrP 27-30 protein. Cell, 40 (4), 735-46

Ouellet, DL, Perron, MP, Gobeil, LA, Plante, P, and Provost, P (2006), MicroRnAs in Gene Regulation: When the Smallest Governs It All. J Biomed Biotechnol, 2006 (4), 69616

Paitel, E, Alves da Costa, C, Vilette, D, Grassi, J, and Checler, F (2002), Overexpression of PrPc triggers caspase 3 activation: potentiation by proteasome inhibitors and blockade by anti-PrP antibodies. J Neurochem, 83 (5), 1208-14

Pan, KM, Baldwin, M, Nguyen, J, Gasset, M, Serban, A, Groth, D, Mehlhorn, I, Huang, Z, FLeTterick, RJ, COHEN, FE, and ET AL. (1993), Conversion of alpha-helices into beta-sheets features in the formation of the scrapie prion proteins. Proc Natl Acad Sci U S A, 90 (23), 10962-6

Parchi, P, Capellari, S, and Gambetti, P (2000), Intracerebral distribution of the abnormal isoform of the prion protein in sporadic Creutzfeldt-Jakob disease and fatal insomnia. Microsc Res Tech, 50 (1), 16-25

Parchi, P, Castellani, R, Capellari, S, Ghetti, B, Young, K, Chen, SG, Farlow, M, Dickson, DW, Sima, AA, Trojanowski, JQ, Petersen, RB, and Gambetti, P (1996), Molecular basis of phenotypic variability in sporadic Creutzfeldt-Jakob disease. Ann Neurol, 39 (6), 767-78

Parchi, P, Giese, A, Capellari, S, Brown, P, Schulz-Schaeffer, W, Windl, O, Zerr, I, Budka, H, Kopp, N, Piccardo, P, Poser, S, Rojiani, A, Streichemberger, N, Julien, J, Vital, C, Ghetti, B, Gambettı, P, and Kretzschmar, H (1999), Classification of sporadic Creutzfeldt-Jakob disease based on molecular and phenotypic analysis of 300 subjects. Ann Neurol, 46 (2), 224-33

Parchi, P, Zou, W, Wang, W, Brown, P, Capellari, S, Ghetti, B, Kopp, N, Schulz-Schaeffer, WJ, Kretzschmar, HA, Head, MW, Ironside, JW, Gambetti, P, and Chen, SG (2000), Genetic influence on the structural variations of the abnormal prion protein. Proc Natl Acad Sci U S A, 97 (18), 10168-72

Pasquinelli, AE, Reinhart, BJ, Slack, F, Martindale, MQ, Kuroda, Mi, Maller, B, Hayward, DC, Ball, EE, Degnan, B, Muller, P, Spring, J, Srinivasan, A, Fishman, M, Finnerty, J, Corbo, J, LeVIne, M, Leahy, P, Davidson, E, and Ruvkun, G (2000), Conservation of the sequence and temporal expression of let-7 heterochronic regulatory RNA. Nature, 408 (6808), 86-9

PAtTISon, IH (1965), Scrapie in the welsh mountain breed of sheep and its experimental transmission to goats. Vet Rec, 77 (47), 1388-90

Peretz, D, Scott, Mr, Groth, D, Williamson, RA, Burton, DR, Cohen, Fe, and Prusiner, SB (2001), Strain-specified relative conformational stability of the scrapie prion protein. Protein Sci, 10 (4), 854-63

Pfeffer, S, Zavolan, M, Grasser, FA, Chien, M, Russo, JJ, Ju, J, John, B, Enright, AJ, Marks, D, SANDER, C, and Tuschl, T (2004), Identification of virus-encoded microRNAs. Science, 304 (5671), 734-6 
Pillai, RS, Bhattacharyya, SN, Artus, CG, Zoller, T, Cougot, N, Basyuk, E, Bertrand, E, and FILIPOWICZ, W (2005), Inhibition of translational initiation by Let-7 MicroRNA in human cells. Science, 309 (5740), 1573-6

Polymenidou, M, Stoeck, K, Glatzel, M, Vey, M, Bellon, A, and Aguzzi, A (2005), Coexistence of multiple PrPSc types in individuals with Creutzfeldt-Jakob disease. Lancet Neurol, 4 (12), 805-14

Poy, mN, Eliasson, L, Krutzfeldt, J, Kuwajima, S, Ma, X, Macdonald, Pe, Pfeffer, S, Tuschl, T, RaJeWsky, N, RoRsman, $P$, and Stoffel, M (2004), A pancreatic islet-specific microRNA regulates insulin secretion. Nature, 432 (7014), 226-30

Proske, D, Gilch, S, Wopfner, F, Schatzl, HM, Winnacker, EL, and Famulok, M (2002), Prionprotein-specific aptamer reduces PrPSc formation. Chembiochem, 3 (8), 717-25

Prusiner, SB, McKinley, MP, Bowman, KA, Bolton, DC, Bendheim, PE, Groth, DF, and GLENNER, GG (1983), Scrapie prions aggregate to form amyloid-like birefringent rods. Cell, 35 (2 Pt 1), 349-58

Pulst, SM, Nechiporuk, A, Nechiporuk, T, Gispert, S, Chen, XN, Lopes-Cendes, I, Pearlman, S, Starkman, S, Orozco-Diaz, G, Lunkes, A, DeJong, P, Rouleau, GA, Auburger, G, Korenberg, JR, FigueroA, C, and SAHBA, S (1996), Moderate expansion of a normally biallelic trinucleotide repeat in spinocerebellar ataxia type 2. Nat Genet, 14 (3), 269-76

Puoti, G, Giaccone, G, Rossi, G, Canciani, B, Bugiani, O, and Tagliavini, F (1999), Sporadic Creutzfeldt-Jakob disease: co-occurrence of different types of $\operatorname{PrP}(\mathrm{Sc})$ in the same brain. Neurology, 53 (9), 2173-6

Ralser, M, Nonhoff, U, Albrecht, M, Lengauer, T, Wanker, Ee, Lehrach, $\mathrm{H}$, and Krobitsch, $\mathrm{S}$ (2005), Ataxin-2 and huntingtin interact with endophilin-A complexes to function in plastin-associated pathways. Hum Mol Genet, 14 (19), 2893-909

Reinhart, BJ, Slack, FJ, Basson, M, Pasquinelli, AE, Bettinger, JC, Rougvie, AE, Horvitz, HR, and RuvkUN, G (2000), The 21-nucleotide let-7 RNA regulates developmental timing in Caenorhabditis elegans. Nature, 403 (6772), 901-6

Rieger, R, Edenhofer, F, LAsmezAs, Cl, and Weiss, S (1997), The human 37-kDa laminin receptor precursor interacts with the prion protein in eukaryotic cells. Nat Med, 3 (12), $1383-8$

Riek, R, Hornemann, S, Wider, G, Billeter, M, Glockshuber, R, and Wuthrich, K (1996), NMR structure of the mouse prion protein domain $\operatorname{PrP}(121-321)$. Nature, 382 (6587), 180-2

Riesner, D (1997), Prions and their biophysical background. Biophys Chem, 66 (2-3), 259-68

Roesler, R, Walz, R, Quevedo, J, de-Paris, F, Zanata, SM, Graner, E, Izquierdo, I, Martins, VR, and BRENTANI, RR (1999), Normal inhibitory avoidance learning and anxiety, but increased locomotor activity in mice devoid of $\operatorname{PrP}(\mathrm{C})$. Brain Res Mol Brain Res, 71 (2), 349-53

Ross, CA, and PoIRIER, MA (2004), Protein aggregation and neurodegenerative disease. Nat Med, 10 Suppl S10-7

Ross, RA, Spengler, BA, and Biedler, JL (1983), Coordinate morphological and biochemical interconversion of human neuroblastoma cells. J Natl Cancer Inst, 71 (4), 741-7 
Rubenstein, R, Kascsak, RJ, Merz, PA, Papini, MC, Carp, RI, Robakis, NK, and Wisniewski, HM (1986), Detection of scrapie-associated fibril (SAF) proteins using anti-SAF antibody in non-purified tissue preparations. J Gen Virol, 67 ( Pt 4) 671-81

Rubinsztein, DC, Leggo, J, Coles, R, Almqvist, E, Biancalana, V, Cassiman, JJ, Chotal, K, Connarty, M, Crauford, D, Curtis, A, Curtis, D, Davidson, MJ, Differ, AM, Dode, C, Dodge, A, Frontali, M, Ranen, NG, Stine, OC, Sherr, M, Abbott, MH, Franz, ML, Graham, CA, Harper, PS, Hedreen, JC, Hayden, MR, and et Al. (1996), Phenotypic characterization of individuals with 30-40 CAG repeats in the Huntington disease (HD) gene reveals HD cases with 36 repeats and apparently normal elderly individuals with $36-39$ repeats. Am J Hum Genet, 59 (1), 16-22

Rudd, PM, Endo, T, Colominas, C, Groth, D, Wheeler, SF, Harvey, DJ, Wormald, MR, Serban, H, Prusiner, SB, Kobata, A, and DWeK, RA (1999), Glycosylation differences between the normal and pathogenic prion protein isoforms. Proc Natl Acad Sci U S A, 96 (23), 130449

SAfar, J, Roller, PP, Gajdusek, DC, and GibBs, CJ, JR. (1993), Conformational transitions, dissociation, and unfolding of scrapie amyloid (prion) protein. J Biol Chem, 268 (27), 20276-84

Safar, J, Wille, H, Itri, V, Groth, D, Serban, H, Torchia, M, Cohen, Fe, and Prusiner, SB (1998), Eight prion strains have $\operatorname{PrP}(\mathrm{Sc})$ molecules with different conformations. Nat Med, 4 (10), 1157-65

Saiki, RK, Scharf, S, Faloona, F, Mullis, KB, Horn, GT, Erlich, HA, and Arnheim, N (1985), Enzymatic amplification of beta-globin genomic sequences and restriction site analysis for diagnosis of sickle cell anemia. Science, 230 (4732), 1350-4

Schatzl, HM, Da Costa, M, Taylor, L, Cohen, FE, and Prusiner, SB (1995), Prion protein gene variation among primates. J Mol Biol, 245 (4), 362-74

Schulz-Schaeffer, WJ, Tschoke, S, Kranefuss, N, Drose, W, Hause-Reitner, D, Giese, A, Groschup, MH, and KRETZSCHMAR, HA (2000), The paraffin-embedded tissue blot detects $\operatorname{PrP}(\mathrm{Sc})$ early in the incubation time in prion diseases. Am J Pathol, 156 (1), 51-6

Schwarz, DS, Hutvagner, G, Du, T, Xu, Z, Aronin, N, and Zamore, PD (2003), Asymmetry in the assembly of the RNAi enzyme complex. Cell, 115 (2), 199-208

Scott, M, Foster, D, Mirenda, C, Serban, D, Coufal, F, Walchli, M, Torchia, M, Groth, D, CARLson, G, DeArmond, SJ, and ET AL. (1989), Transgenic mice expressing hamster prion protein produce species-specific scrapie infectivity and amyloid plaques. Cell, 59 (5), 847-57

Scott, MR, Butler, DA, Bredesen, DE, Walchli, M, Hsiao, KK, and Prusiner, SB (1988), Prion protein gene expression in cultured cells. Protein Eng, 2 (1), 69-76

Sekiya, S, Nishikawa, F, Noda, K, Kumar, PK, Yokoyama, T, and Nishikawa, S (2005), In vitro selection of RNA aptamers against cellular and abnormal isoform of mouse prion protein. Nucleic Acids Symp Ser (Oxf), (49), 361-2

Sempere, LF, Freemantle, S, Pitha-Rowe, I, Moss, E, Dmitrovsky, E, and Ambros, V (2004), Expression profiling of mammalian microRNAs uncovers a subset of brain-expressed microRNAs with possible roles in murine and human neuronal differentiation. Genome Biol, 5 (3), R13 
Sigurdsson, B, Palsson, P, and Grimsson, H (1957), Visna, a demyelinating transmissible disease of sheep. J Neuropathol Exp Neurol, 16 (3), 389-403

Sittler, A, Walter, S, Wedemeyer, N, Hasenbank, R, Scherzinger, E, Eickhoff, H, Bates, GP, LEHRACH, H, and WANKER, EE (1998), SH3GL3 associates with the Huntingtin exon 1 protein and promotes the formation of polygln-containing protein aggregates. Mol Cell, 2 (4), 427-36

SkLAVIADIS, T, Dreyer, R, and MANuelidis, L (1992), Analysis of Creutzfeldt-Jakob disease infectious fractions by gel permeation chromatography and sedimentation field flow fractionation. Virus Res, 26 (3), 241-54

Song, S, Kim, SY, Hong, YM, Jo, DG, Lee, JY, Shim, SM, Chung, CW, Seo, SJ, Yoo, YJ, Koh, JY, LEE, MC, YATES, AJ, ICHIJO, H, and JUNG, YK (2003), Essential role of E2-25K/Hip-2 in mediating amyloid-beta neurotoxicity. Mol Cell, 12 (3), 553-63

Spielhaupter, C, and Schatzl, HM (2001), PrPC directly interacts with proteins involved in signaling pathways. J Biol Chem, 276 (48), 44604-12

Stahl, N, Borchelt, DR, Hsiao, K, and Prusiner, SB (1987), Scrapie prion protein contains a phosphatidylinositol glycolipid. Cell, 51 (2), 229-40

Taraboulos, A, Jendroska, K, Serban, D, Yang, SL, DeArmond, SJ, and Prusiner, SB (1992), Regional mapping of prion proteins in brain. Proc Natl Acad Sci U S A, 89 (16), 7620-4

TAylor, DR, Watt, NT, Perera, WS, and Hooper, NM (2005), Assigning functions to distinct regions of the $\mathrm{N}$-terminus of the prion protein that are involved in its copper-stimulated, clathrin-dependent endocytosis. J Cell Sci, 118 (Pt 21), 5141-53

Teleman, AA, Maitra, S, and Cohen, SM (2006), Drosophila lacking microRNA miR-278 are defective in energy homeostasis. Genes Dev, 20 (4), 417-22

Telling, GC, Parchi, P, DeArmond, SJ, Cortelli, P, Montagna, P, Gabizon, R, Mastrianni, J, Lugaresi, E, Gambetti, P, and Prusiner, SB (1996), Evidence for the conformation of the pathologic isoform of the prion protein enciphering and propagating prion diversity. Science, 274 (5295), 2079-82

Telling, GC, Scott, M, Hsiao, KK, Foster, D, Yang, SL, Torchia, M, Sidle, KC, Collinge, J, DeArmond, SJ, and Prusiner, SB (1994), Transmission of Creutzfeldt-Jakob disease from humans to transgenic mice expressing chimeric human-mouse prion protein. Proc Natl Acad Sci U S A, 91 (21), 9936-40

Tobler, I, Gaus, Se, Deboer, T, Achermann, P, Fischer, M, Rulicke, T, Moser, M, Oesch, B, McBRIDE, PA, and MANSON, JC (1996), Altered circadian activity rhythms and sleep in mice devoid of prion protein. Nature, 380 (6575), 639-42

Towbin, H, Staehelin, T, and Gordon, J (1979), Electrophoretic transfer of proteins from polyacrylamide gels to nitrocellulose sheets: procedure and some applications. Proc Natl Acad Sci U S A, 76 (9), 4350-4

Triboulet, R, Mari, B, Lin, YL, Chable-Bessia, C, Bennasser, Y, Lebrigand, K, Cardinaud, B, Maurin, T, Barbry, P, Baillat, V, Reynes, J, Corbeau, P, Jeang, KT, and Benkirane, M (2007), Suppression of MicroRNA-Silencing Pathway by HIV-1 During Virus Replication. Science, 
Valencia-Sanchez, MA, Liu, J, Hannon, GJ, and Parker, R (2006), Control of translation and mRNA degradation by miRNAs and siRNAs. Genes Dev, 20 (5), 515-24

Wadsworth, JD, Hill, AF, Joiner, S, Jackson, GS, Clarke, AR, and Collinge, J (1999), Strainspecific prion-protein conformation determined by metal ions. Nat Cell Biol, 1 (1), 55-9

Waggoner, DJ, Drisaldi, B, Bartnikas, tB, Casareno, RL, Prohaska, JR, Gitlin, JD, and HARRIS, DA (2000), Brain copper content and cuproenzyme activity do not vary with prion protein expression level. J Biol Chem, 275 (11), 7455-8

Walker, SJ, Wang, Y, Grant, KA, Chan, F, and Hellmann, GM (2006), Long versus short oligonucleotide microarrays for the study of gene expression in nonhuman primates. $J$ Neurosci Methods, 152 (1-2), 179-89

Watts, JC, BaLAchandRan, A, and Westaway, D (2006), The expanding universe of prion diseases. PLoS Pathog, 2 (3), e26

Weiss, S, Proske, D, Neumann, M, Groschup, MH, Kretzschmar, HA, Famulok, M, and WINNACKER, EL (1997), RNA aptamers specifically interact with the prion protein PrP. J Virol, 71 (11), 8790-7

Wells, GA, Scott, AC, Johnson, CT, Gunning, RF, Hancock, RD, Jeffrey, M, Dawson, M, and BRADLEY, R (1987), A novel progressive spongiform encephalopathy in cattle. Vet Rec, 121 (18), 419-20

Wienholds, E, Koudius, MJ, van Eeden, FJ, Cuppen, E, and Plasterk, RH (2003), The microRNA-producing enzyme Dicer1 is essential for zebrafish development. Nat Genet, 35 (3), 217-8

WILL, RG (1993), Epidemiology of Creutzfeldt-Jakob disease. Br Med Bull, 49 (4), 960-70

Will, RG, Ironside, JW, Zeidler, M, Cousens, SN, Estibeiro, K, Alperovitch, A, Poser, S, Pocchiari, M, Hofman, A, and SMITH, PG (1996), A new variant of Creutzfeldt-Jakob disease in the UK. Lancet, 347 (9006), 921-5

Winer, J, JUNG, CK, ShACKeL, I, and WiLliAms, PM (1999), Development and validation of realtime quantitative reverse transcriptase-polymerase chain reaction for monitoring gene expression in cardiac myocytes in vitro. Anal Biochem, 270 (1), 41-9

WUTHRICH, K, and RIEK, R (2001), Three-dimensional structures of prion proteins. Adv Protein Chem, $\mathbf{5 7}$ 55-82

Xie, Z, O'Rourke, KI, Dong, Z, Jenny, AL, Langenberg, JA, Belay, ED, Schonberger, LB, Petersen, RB, Zou, W, Kong, Q, Gambetti, P, and Chen, SG (2006), Chronic wasting disease of elk and deer and Creutzfeldt-Jakob disease: comparative analysis of the scrapie prion protein. J Biol Chem, 281 (7), 4199-206

Xu, P, Vernooy, SY, Guo, M, and Hay, BA (2003), The Drosophila microRNA Mir-14 suppresses cell death and is required for normal fat metabolism. Curr Biol, 13 (9), 790-5

$\mathrm{Xu}, \mathrm{X}(2007)$, Same computational analysis, different miRNA target predictions. Nat Methods, $4(3), 191$

YI, R, QIN, Y, MACARA, IG, and Cullen, BR (2003), Exportin-5 mediates the nuclear export of pre-microRNAs and short hairpin RNAs. Genes Dev, 17 (24), 3011-6 
Yoon KIm, B, Olzmann, JA, Barsh, GS, ChIn, LS, and LI, L (2007), Spongiform Neurodegeneration-associated E3 Ligase Mahogunin Ubiquitylates TSG101 and Regulates Endosomal Trafficking. Mol Biol Cell,

Yull, HM, Ritchie, DL, LANGeVeld, JP, VAN ZiJdeRVELd, FG, Bruce, ME, Ironside, JW, and HeAd, MW (2006), Detection of type 1 prion protein in variant Creutzfeldt-Jakob disease. Am J Pathol, 168 (1), 151-7

Zahn, R, Liu, A, Luhrs, T, Riek, R, von Schroetter, C, Lopez Garcia, F, Billeter, M, Calzolai, L, WIDER, G, and WUTHRICH, K (2000), NMR solution structure of the human prion protein. Proc Natl Acad Sci U S A, 97 (1), 145-50

Zanata, SM, Lopes, MH, Mercadante, AF, Haju, GN, Chiarini, LB, Nomizo, R, Freitas, AR, Cabral, AL, Lee, KS, Juliano, MA, de Oliveira, E, Jachieri, SG, Burlingame, A, Huang, L, LINDEN, R, BRENTANI, RR, and MARTINS, VR (2002), Stress-inducible protein 1 is a cell surface ligand for cellular prion that triggers neuroprotection. Embo J, 21 (13), 3307-16

Zanusso, G, Farinazzo, A, Fiorini, M, Gelati, M, Castagna, A, Righetti, PG, Rizzuto, N, and MonACO, S (2001), pH-dependent prion protein conformation in classical CreutzfeldtJakob disease. J Biol Chem, 276 (44), 40377-80

ZoGHBI, HY, and ORR, HT (2000), Glutamine repeats and neurodegeneration. Annu Rev Neurosci, 23 217-47

Zou, WQ, Zheng, J, Gray, DM, Gambettı, P, and Chen, SG (2004), Antibody to DNA detects scrapie but not normal prion protein. Proc Natl Acad Sci U S A, 101 (5), 1380-5 


\section{Anhang}

\subsection{MiRNA-Expressionsprofil in der basis pontis von Javaneraffen}

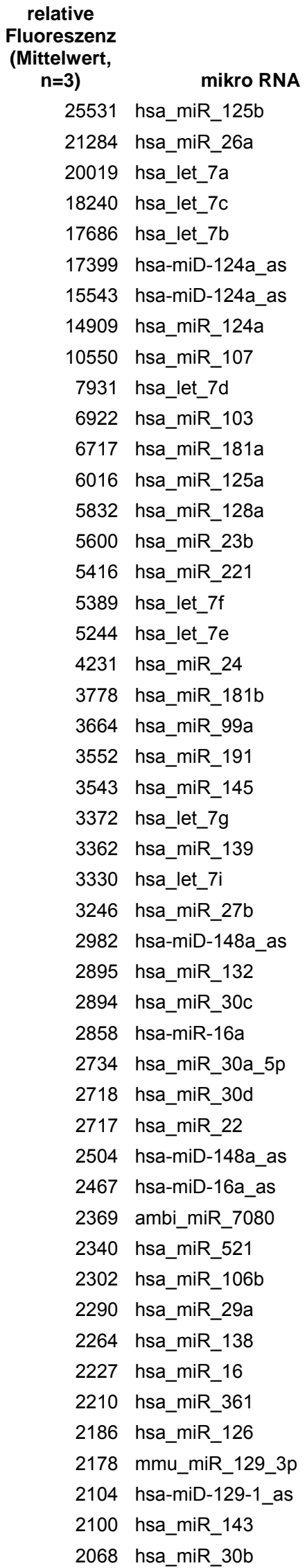

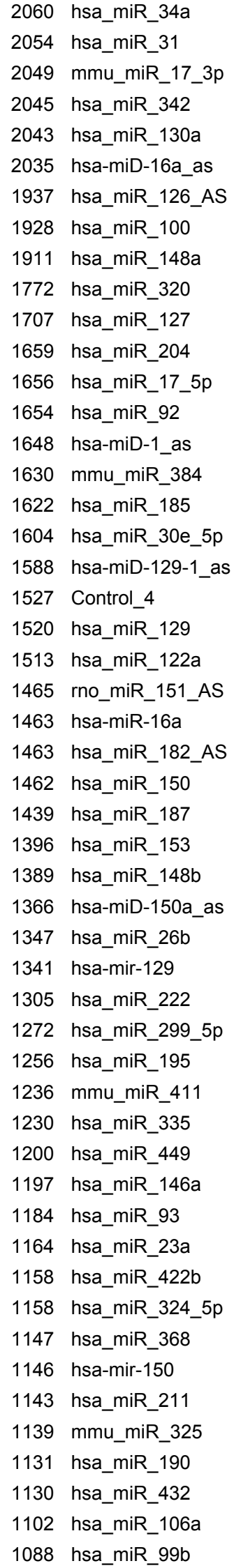

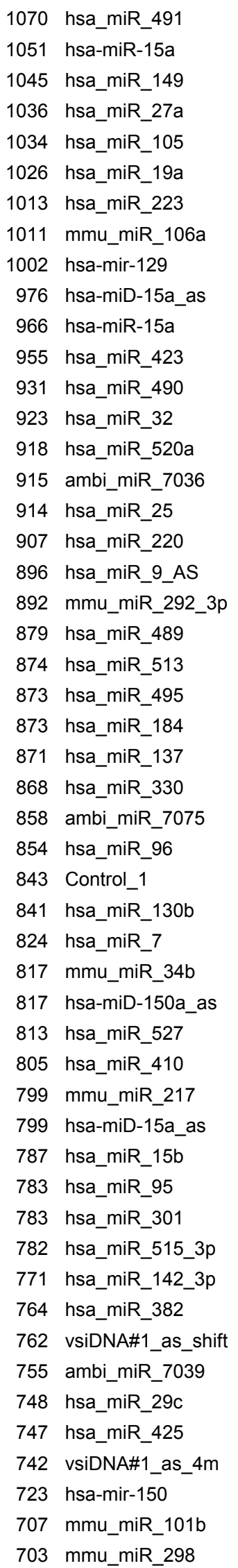




\begin{tabular}{|c|c|}
\hline 701 & rno_miR_327 \\
\hline & hsa_miR_502 \\
\hline 993 & Control_2 \\
\hline 91 & ambi_miR_7105 \\
\hline 89 & hsa_miR_224 \\
\hline 37 & ambi_miR_7101 \\
\hline 80 & hsa_miR_499 \\
\hline 73 & hsa_miR_208 \\
\hline 71 & hsa_miR_193a \\
\hline 66 & ambi_miR_7029 \\
\hline 662 & hsa_miR_369_3p \\
\hline 61 & hsa-miD-133a_as \\
\hline 655 & hsa_miR_338 \\
\hline 554 & hsa_miR_520b \\
\hline 53 & hsa_miR_199a \\
\hline & hsa_miR_450 \\
\hline 17 & hsa_miR_29b \\
\hline 645 & ambi_miR_7054 \\
\hline 37 & hsa_miR_20a \\
\hline 35 & hsa_miR_514 \\
\hline & hsa_miR_101 \\
\hline 633 & hsa_miR_194 \\
\hline 30 & buffer \\
\hline 625 & hsa_miR_371 \\
\hline 622 & hsa_miR_296 \\
\hline 622 & mmu_miR_424 \\
\hline 620 & hsa_miR_9 \\
\hline 619 & hsa_miR_197 \\
\hline 19 & hsa_miR_500 \\
\hline 612 & Control_1 \\
\hline 610 & hsa_miR_181c \\
\hline 603 & hsa_miR_133a \\
\hline 603 & hsa_miR_30e_3p \\
\hline 595 & hsa_miR_505 \\
\hline 595 & hsa_miR_452 \\
\hline 592 & hsa_miR_383 \\
\hline 588 & rno_miR_344 \\
\hline 587 & mmu_miR_383 \\
\hline 584 & hsa_miR_21 \\
\hline 583 & hsa_miR_519e_A \\
\hline 583 & mmu_miR_337 \\
\hline 581 & hsa_miR_365 \\
\hline 580 & hsa_miR_507 \\
\hline 580 & hsa_miR_520e \\
\hline 579 & hsa_miR_15a \\
\hline 578 & mmu_miR_294 \\
\hline 578 & mmu_miR_7b \\
\hline 576 & hsa_miR_182 \\
\hline 574 & mmu_miR_290 \\
\hline 574 & rno_miR_421 \\
\hline 573 & hsa_miR_510 \\
\hline 564 & mmu_miR_346 \\
\hline 561 & hsa_miR_375 \\
\hline 560 & hsa_miR_18a \\
\hline 557 & ambi_miR_7098 \\
\hline
\end{tabular}

556 mmu_miR_300

555 ambi_miR_7026

555 vsiDNA\#1_as_2m

552 mmu_miR_291_3p

552 hsa_miR_432_AS

551 hsa_miR_522

546 hsa_miR_377

540 ambi_miR_7081

540 hsa_miR_374

536 hsa-mir-148a

535 hsa-miR-1

534 hsa-mir-133a

528 ambi_miR_7058

528 hsa-mir-133a

526 hsa_miR_494

522 hsa_miR_519c

519 hsa-miD-122a_as

518 hsa-mir-148a

517 hsa_miR_136

514 mmu_miR_155

513 hsa_miR_373_AS

510 hsa_miR_152

506 hsa_miR_302d

501 mmu_miR_344

498 hsa_miR_34b

497 vsiDNA\#1_as

489 ambi_miR_7059_1

489 hsa_miR_497

480 mmu_miR_341

479 mmu_miR_322

476 ambi_miR_7095

475 mmu_miR_376b

472 mmu_miR_199b

471 hsa_miR_135b

466 hsa_miR_517a

465 ambi_miR_7085

463 vsiDNA\#1_as_4m

453 ambi_miR_7084

452 mmu_miR_207

452 hsa_miR_141

450 hsa_miR_331

450 hsa_miR_381

446 hsa_miR_509

444 rno_miR_20_AS

439 hsa_miR_498

439 hsa_miR_346

438 hsa_miR_154

438 mmu_miR_330

437 rno_miR_7_AS

435 hsa_miR_218

432 hsa_miR_98

428 hsa_miR_199a_AS

424 hsa_miR_525

424 mmu_miR_140_AS

423 hsa_miR_337
421 hsa_miR_200a

416 hsa_miR_151

416 hsa_miR_33

415 hsa_miR_196b

415 hsa_miR_525_AS

415 hsa-miD-133a_as

414 Control_1

413 hsa_miR_378

412 ambi_miR_7086

411 hsa_miR_379

410 ambi_miR_7083

407 hsa_miR_200c

404 mmu_miR_292_5p

402 hsa_miR_380_5p

401 ambi_miR_7089

399 buffer

393 mmu_miR_351

392 hsa_miR_488

391 hsa_miR_323

386 hsa_miR_134

384 hsa_miR_372

382 hsa_miR_19b

380 hsa_miR_10a

376 hsa_miR_501

376 ambi_miR_7070

373 vsiDNA\#1_C3

370 hsa_miR_519e

367 hsa_miR_212

366 hsa_miR_328

360 ambi_miR_7074

352 hsa_miR_216

348 hsa_miR_210

343 hsa_miR_34c

343 hsa_miR_340

343 hsa_miR_380_3p

343 mmu_miR_201

341 ambi_miR_7027

339 hsa_miR_324_3p

337 hsa_miR_518e

328 hsa_miR_523

325 hsa_miR_215

324 hsa_miR_302b

320 hsa_miR_219

319 hsa_miR_30a_3p

316 ambi_miR_7062

316 hsa_miR_10b

314 hsa_miR_188

314 hsa_miR_183

313 ambi_miR_7038_1

313 hsa_miR_517_AS

310 vsiDNA\#4_as

305 rno_miR_352

304 hsa_miR_520c

300 hsa_miR_325

298 hsa-miD-122a_as 


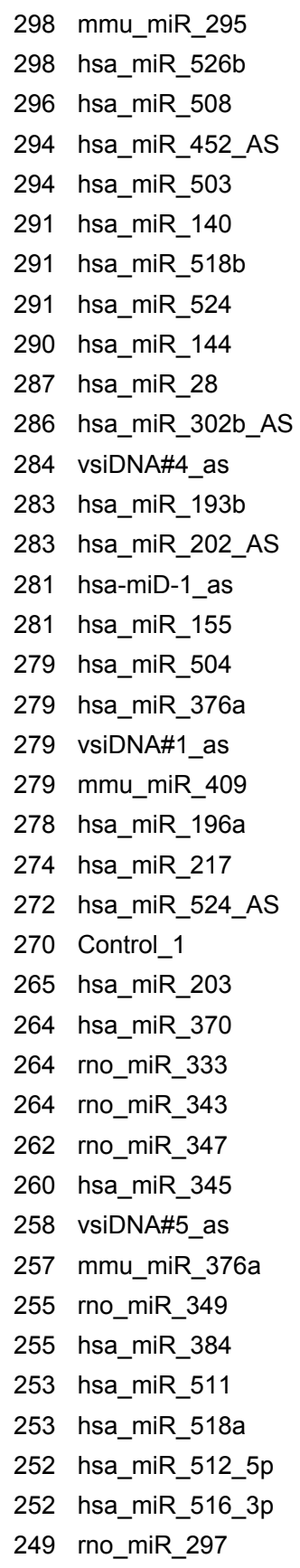

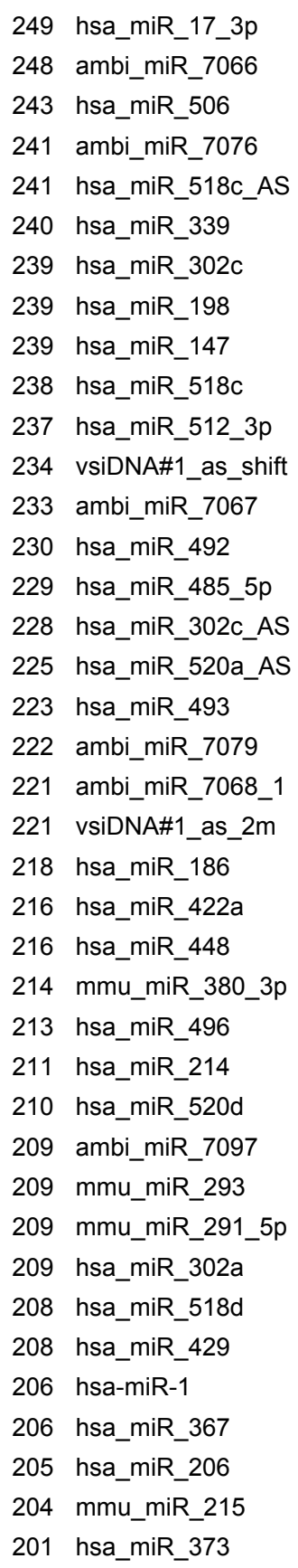

\author{
201 rno_miR_346 \\ 201 hsa_miR_1 \\ 199 hsa_miR_520d_AS \\ 198 hsa_miR_205 \\ 197 mmu_miR_297 \\ 197 Control_3 \\ 195 hsa_miR_135a \\ 193 mmu_miR_429 \\ 192 hsa_miR_519d \\ 192 hsa_miR_526b_AS \\ 191 ambi_miR_7103 \\ 190 mmu_let_7d_AS \\ 189 mmu_miR_192 \\ 188 hsa_miR_200b \\ 185 vsiDNA\#5_as \\ 185 vsiDNA\#1_C3 \\ 182 mmu_miR_211 \\ 180 ambi_miR_7055 \\ 179 hsa_miR_213 \\ 176 hsa_miR_326 \\ 172 hsa_miR_515_5p \\ 166 hsa_miR_142_5p \\ 166 mmu_miR_151 \\ 163 hsa_miR_518f \\ 163 hsa_miR_519b \\ 162 mmu_miR_345 \\ 161 mmu_miR_350 \\ 160 hsa_miR_192 \\ 159 hsa_miR_526c \\ 158 hsa_miR_424 \\ 158 hsa_miR_189 \\ 156 hsa_miR_518f_AS \\ 156 mmu_miR_329 \\ 148 ambi_miR_7100 \\ 147 hsa_miR_520h \\ 146 mmu_miR_202 \\ 146 hsa_miR_412 \\ 130 hsa_miR_199b \\ 119 rno_miR_336
}




\section{DANKSAGUNG}

Ich bedanke mich herzlich bei Herrn Prof. Dr. H.-J. Fritz für die Übernahme des Referats und bei Herrn Prof. Dr. W. Liebl für die Übernahme des Korreferats dieser Arbeit im Fachbereich Biologie der Georg-August-Universität Göttingen.

Herrn Prof. Dr. G. Hunsmann danke ich für die Arbeitsmöglichkeit in der Abteilung für Virologie und Immunologie des Deutschen Primatenzentrums.

Mein besonderer Dank gilt Dr. Dirk Motzkus für die kompetente Betreuung meiner Arbeit und die vielen Diskussionen, aus denen ich unendlich viel gelernt habe. Ich hätte keinen besseren Mentor finden können!

Ebenso möchte ich mich ganz herzlich bei Dr. Reiner Hitt, Jana Heikens und Lennart Opitz aus dem Transkriptomanalyselabor der Universität Göttingen für die gute Zusammenarbeit bei der Entwicklung und Durchführung der miRNA-MicroArrays bedanken und bei Dr. Walther Schulz-Schäffer aus der Abteilung Neuropathologie des Universitätsklinikums Göttingen für die immunohistologischen Arbeiten und die Probenentnahme aus dem Hirngewebe.

Den Mitarbeitern der Abteilung für Virologie und Immunologie des Deutschen Primatenzentrums möchte ich für die angenehme Atmosphäre danken. Dabei waren besonders die sowohl entspannenden als auch kreativen Kaffeepausen eine wichtige mentale Stütze, besonders während des Schreibens.

Mein letzter und größter Dank gilt meinem Mann Matthias und meiner Familie. Ohne Euren Rückhalt und eure Unterstützung wäre ich nie so weit gekommen. Danke für alles. 


\section{LEBENSLAUF}

$\begin{array}{ll}\text { Name } & \text { Judith Montag } \\ \text { Anschrift } & \text { In der Roten Erde 4 } \\ & \text { D-37075 Göttingen } \\ \text { geboren am } & 18.01 .1980 \\ \text { Geburtsort } & \text { Geseke } \\ \text { Staatsangehörigkeit } & \text { deutsch }\end{array}$

Schulbildung

1986 bis 1990

kath. Grundschule St. Johannes Baptist, Delbrück

1990 bis $1999 \quad$ Gymnasium Nepomucenum Rietberg

Abschluss: Abitur

Hochschulstudium

Diplomarbeit

Doktorarbeit
10/1999 bis 07/2003 Studium der Biologie an der Georg-AugustUniversität zu Göttingen

10/2003 bis 07/2004 angefertigt am Deutschen Primatenzentrum in Göttingen

Thema: Selektion rekombinanter anti-Prion Protein Antikörper mittels PhageDisplay

Abschluss: Diplom-Biologin

09/2004 bis 03/2007 angefertigt am Deutschen Primatenzentrum in Göttingen

Thema: Übertragung von BSE auf nichthumane Primaten als Modell für die variante Creutzfeldt-Jakob Erkrankung (vCJD) im Menschen 